\title{
Viability of Pushrod Dilatometry Techniques for High Temperature In- Pile Measurements
}

J. E. Daw

J. L. Rempe

D. L. Knudson

K. G. Condie

J. C. Crepeau

March 2008

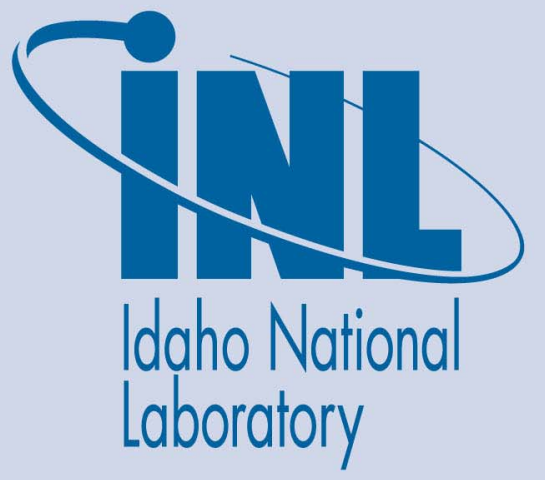

The INL is a U.S. Department of Energy National Laboratory operated by Battelle Energy Alliance 
INL/EXT-07-13120

\title{
Viability of Pushrod Dilatometry Techniques for High Temperature In-Pile Measurements
}

\author{
J. E. Daw \\ J. L. Rempe \\ D. L. Knudson \\ K. G. Condie \\ J. C. Crepeau \\ March 2008 \\ Idaho National Laboratory \\ Idaho Falls, Idaho 83415 \\ Prepared for the \\ U.S. Department of Energy \\ Office of Nuclear Energy \\ Under DOE Idaho Operations Office \\ Contract DE-AC07-05ID14517
}


The INL is a U.S. Department of Energy National Laboratory operated by Battelle Energy Alliance 


\section{CONTENTS}

CONTENTS

iii

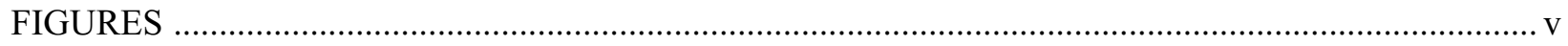

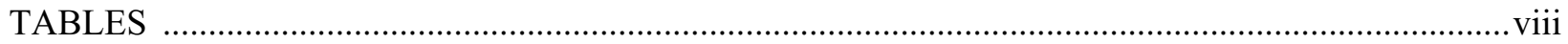

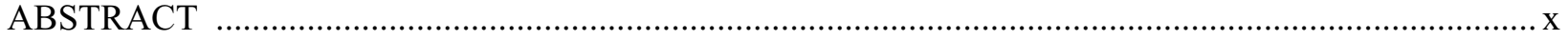

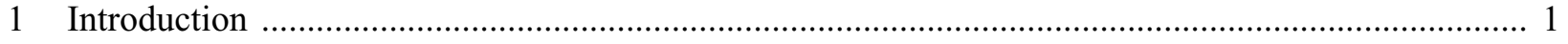

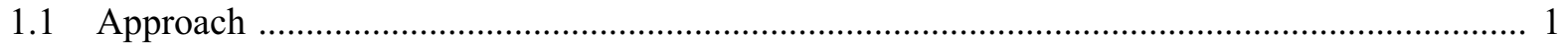

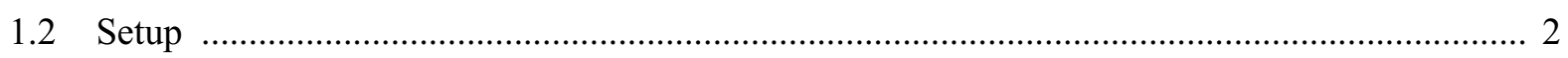

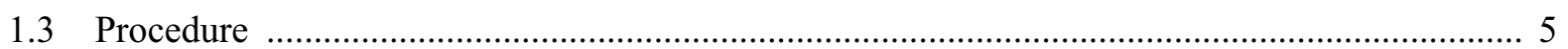

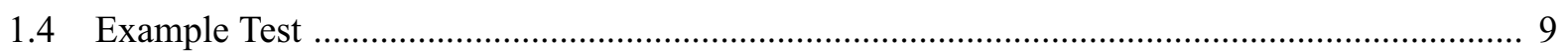

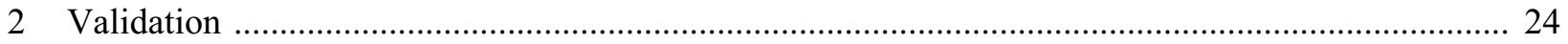

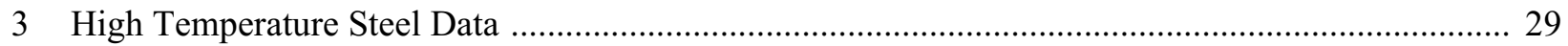

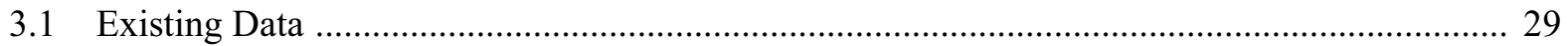

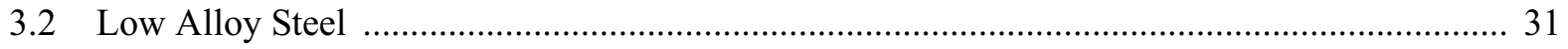

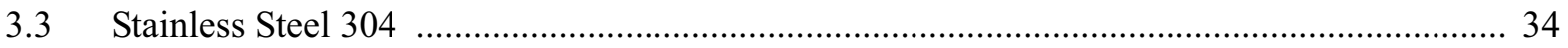

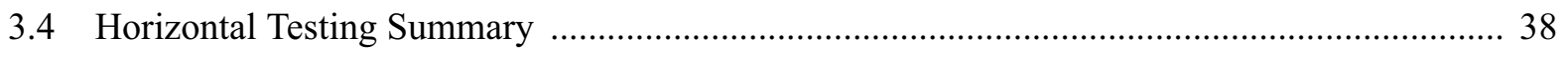

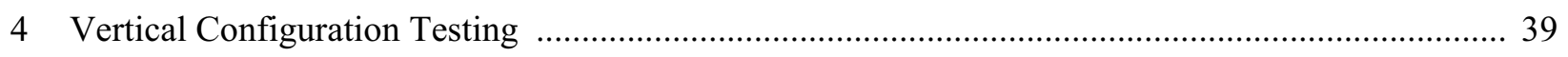

4.1 Vertical Configuration Trial ….................................................................................... 39

4.2 Low Alloy Steel (SA533B1) Vertical Test ............................................................................. 42

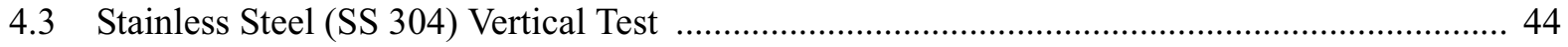

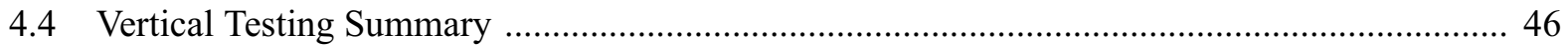

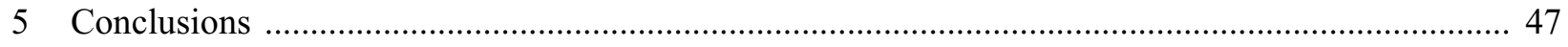

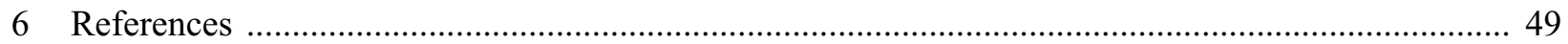

INL/EXT-07-13120 $\quad$ iii 


\section{FIGURES}

1. Schematic of dilatometer in horizontal configuration. .............................................................. 2

2. Dilatometer measurement system in horizontal configuration. ............................................. 3

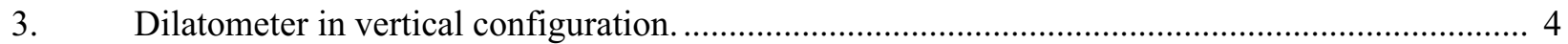

4. Close up of sample holder at point of insertion into furnace. ................................................. 5

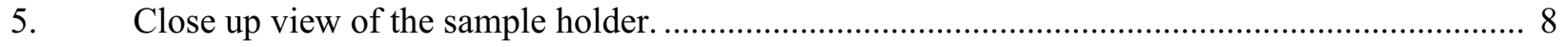

6. Close up view of sample holder adjustment screws................................................................ 8

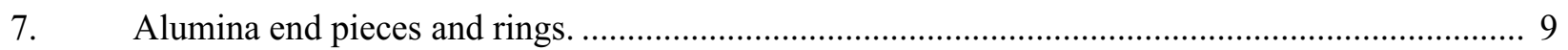

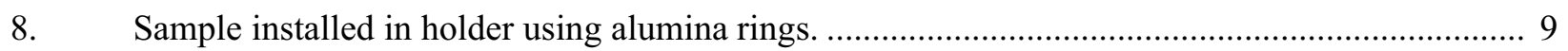

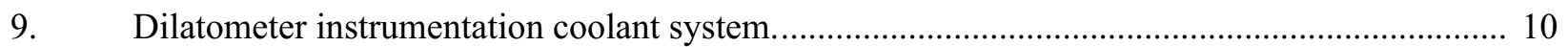

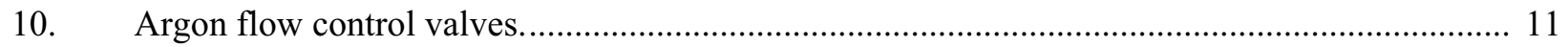

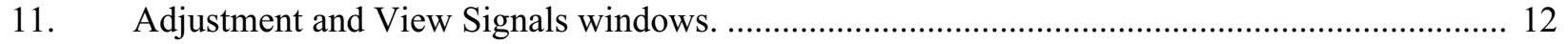

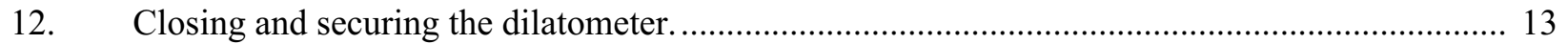

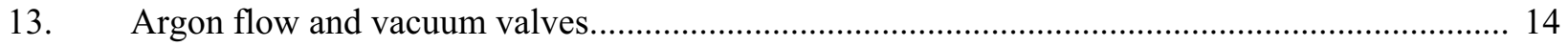

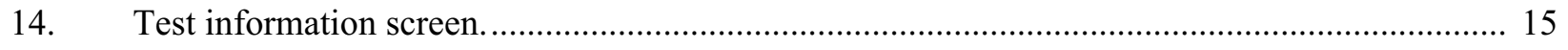

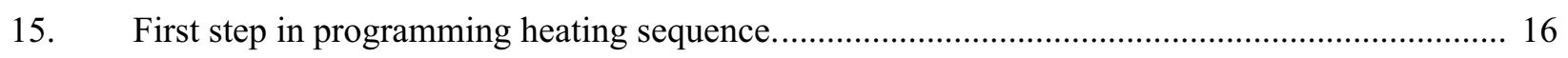

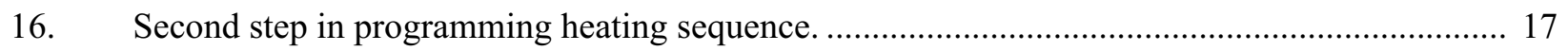

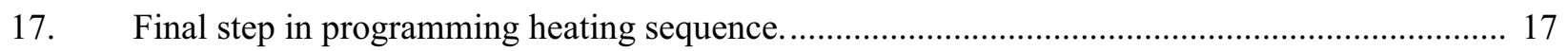

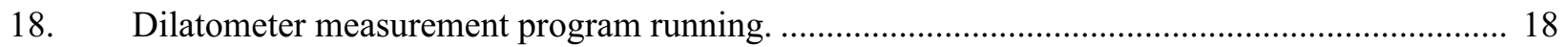

19. Open correction file window used to select correction file corresponding to

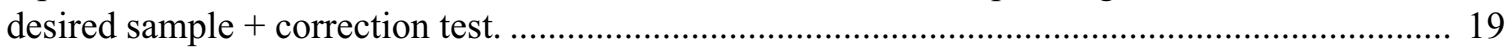

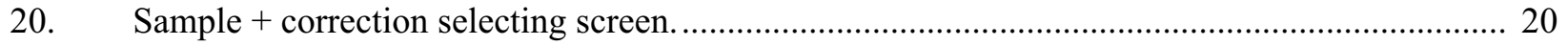

21. Settings drop down menu in Proteus used for changing plot parameters. ................................. 21

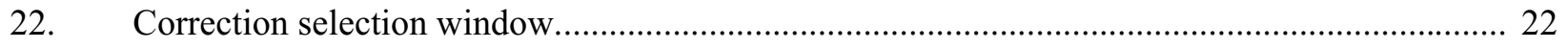

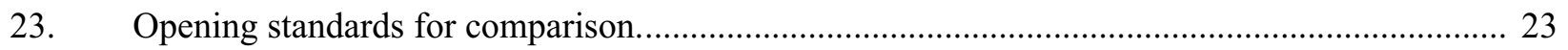

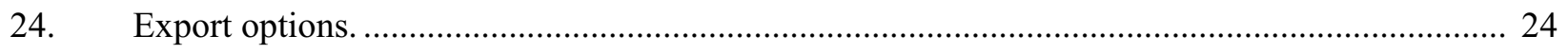

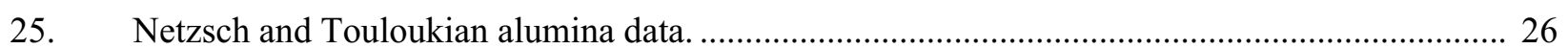

26. Netzsch and Touloukian quartz data.............................................................................. 26

27. HTTL and Netzsch data for alumina thermal expansion. .................................................... 27

28. HTTL and Netzsch data for quartz glass thermal expansion. ................................................ 28

29. HTTL and Netzsch data for sapphire thermal expansion...................................................... 28

30. Touloukian and MATPRO thermal elongation data for 304 stainless steel............................... 30

31. MATPRO data for thermal elongation of low alloy steel...................................................... 30

32. HTTL data for thermal expansion of low alloy steel sample SA-A. ........................................ 31

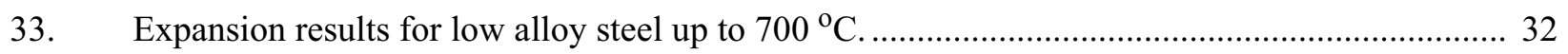

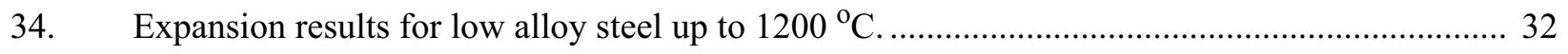




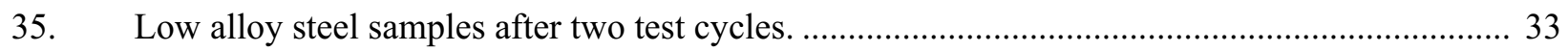

36. Comparison of new low alloy steel (SA 533 B1) data with values in MATPRO...................... 34

37. HTTL data for thermal expansion of stainless steel sample SS-A............................................ 35

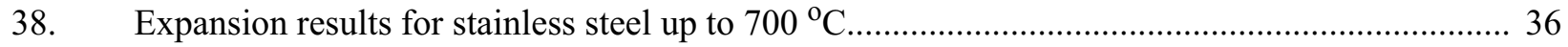

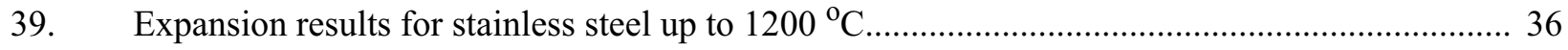

40. Comparison of new stainless steel (SS304) data with values in Touloukian and MATPRO....... 37

41. Stainless steel samples after two test cycles. ...................................................................... 37

42. Comparison of correction data for horizontal and vertical configurations. ................................ 41

43. Comparison of corrected expansion data for horizontal and vertical configurations .................. 42

44. Data acquired for low alloy steel sample SA-V1 using vertical configuration........................... 43

45. Data acquired for low alloy steel sample SA-V2 using vertical configuration.......................... 43

46. Comparison of vertical low alloy steel data with data obtained using horizontal configuration. . 44

47. Data acquired for stainless steel sample SS-V1 using vertical configuration............................ 45

48. Data acquired for stainless steel sample SS-V2 using vertical configuration........................... 45

49. Comparison of vertical stainless steel data with data obtained using horizontal configuration. .. 46 


\section{TABLES}

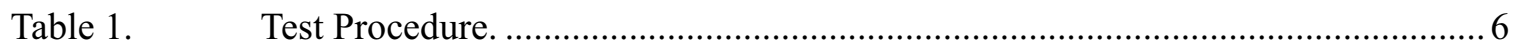

Table 2. Samples tested and tests performed in reference configuration. ..........................25

Table 3. Comparison of expansion data between HTTL and references............................38

Table 4. $\quad$ Percent differences between INL test data and values found in literature............38

Table 5. Tests performed in experimental (vertical) configuration. ................................... 39

Table 6. Comparison of expansion data for horizontal and vertical configurations...........46

Table 7. Percent differences between horizontal and vertical test data............................. 47 


\begin{abstract}
To evaluate the performance of new fuel, cladding, and structural materials for use in advanced and existing nuclear reactors, robust instrumentation is needed. Changes in material deformation are typically evaluated out-of-pile, where properties of materials are measured after samples were irradiated for a specified length of time. To address this problem, a series of tests were performed to examine the viability of using pushrod dilatometer techniques for in-pile instrumentation to measure deformation. The tests were performed in three phases. First, familiarity was gained in the use and accuracy of this system by testing samples with well defined thermal elongation characteristics. Second, high temperature data for steels, specifically SA533 Grade B, Class 1 (SA533B1) Low Alloy Steel and Stainless Steel 304 (SS304), found in Light Water Reactor (LWR) vessels, were aquired. Finally, data were obtained from a short pushrod in a horizontal geometry to data obtained from a longer pushrod in a vertical geometry, the configuration likely to be used for in-situ measurements. Results of testing show that previously accepted data for the structural steels tested, SA533B1 and SS304, are inaccurate at high temperatures (above $500{ }^{\circ} \mathrm{C}$ ) due to extrpolation of high temperature data. This is especially true for SA533B1, as previous data do not account for the phase transformation of the material between $730{ }^{\circ} \mathrm{C}$ and $830{ }^{\circ} \mathrm{C}$. Also, comparison of results for horizontal and vertical configurations show a maximum percent difference of $2.02 \%$ for high temperature data.
\end{abstract}




\section{Introduction}

To resolve principal technical and scientific obstacles related to the long-term future use of nuclear energy, new reactor designs must offer enhanced safety and overcome issues involving proliferation risks, economics, and nuclear waste disposal. To meet these goals, new materials are being considered for fuel, cladding, and structures in advanced and existing nuclear reactors. However, there are insufficient data to characterize the performance of these new materials in high temperature, oxidizing, and radiation conditions. To evaluate candidate material performance, robust instrumentation is needed that can survive these conditions. Typical in-pile instrumentation, such as thermocouples, either degrades at temperatures above $1100{ }^{\circ} \mathrm{C}$ or degrades due to transmutation. Changes in material thermal conductivity and deformation are typically evaluated out-of-pile, where properties of materials are measured after samples were irradiated for a specified length of time. The labor and time to remove, examine, and return irradiated samples for each measurement makes this approach very expensive. Furthermore, processes involved in sample handling can adversely affect conditions to be measured. To address this critical need, INL developed designs for high temperature in-pile measurements of temperature, thermal conductivity, and deformation. Results from efforts to evaluate the designs for measuring temperature and thermal conductivity may be found in References 1 and 2 . This report documents INL efforts to explore the viability of using pushrod dilatometer techniques for in-pile instrumentation to measure deformation. Specifically, this report documents results obtained using the Netzsch DIL 402 ES dilatometer system installed at INL's High Temperature Test Laboratory (HTTL) to complete three objectives. The first objective is to gain familiarity with the use and accuracy of this system. Second, results are reported from INL efforts to use this system to obtain high temperature data for steels, specifically SA533 Grade B, Class 1 (SA533B1) Low Alloy Steel and Stainless Steel 304 (SS304), found in Light Water Reactor (LWR) vessels. As discussed in this report, a literature review reveals that high temperature properties are extrapolated with little, if any, data above $700{ }^{\circ} \mathrm{C}$ for these materials. Finally, results are reported from INL efforts to explore the viability of using a pushrod dilatometer for in-pile deformation measurements. Specifically, data are compared that were obtained from a short pushrod in a horizontal geometry to data obtained from a longer pushrod in a vertical geometry.

\subsection{Approach}

Dilatometry is a method by which the thermal expansion of a material may be measured. There are many types of dilatometers. Dilatometers may use a pushrod, capacitor, or optical system to sense expansion and may be configured in horizontal, vertical, or in-between configurations. A schematic of the type of pushrod dilatometer used at the HTTL can be seen in Figure 1. 


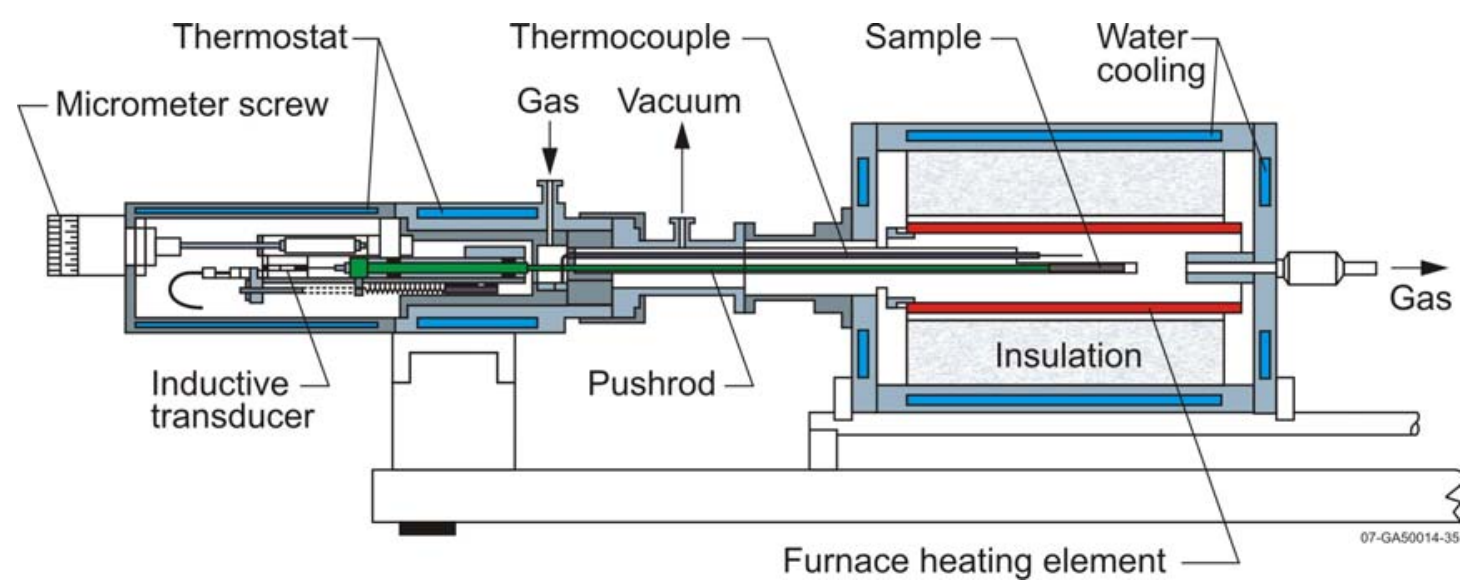

Figure 1. Schematic of dilatometer in horizontal configuration.

Dilatometers utilize a Linear Differential Variable Transformer (LVDT) to convert a pushrod displacement to a voltage. This voltage is recorded and converted to a recordable displacement signal by software. By carefully controlling and recording, via thermocouple, the temperature of a sample at the free end of the pushrod, the thermal elongation characteristics of a sample may be determined. When changes in length are driven by changes in temperature, it must be recognized that dilatometer components can also be affected. For that reason, two test runs are required for each experimental sample. The first run is performed using a material with known thermal expansion characteristics. This first "correction" run allows determination of changes in length of the dilatometer components (sample holder and pushrod) by subtracting changes of the known material from the total. The second run is performed with the experimental sample. Changes in length of the experimental sample can be determined by subtracting changes in length of the system components from the total changes in length.

Horizontal and vertical dilatometers each have advantages and disadvantages due to orientation. Horizontal dilatometers minimize thermal expansion of components because convection effects are minimized, whereas component expansion in vertical dilatometers may be much greater as heat is carried by convection along the length of the sample holder and pushrod. A disadvantage of horizontal dilatometers is friction. Typically, the sample is placed in contact with the sample holder, and it must expand along the surface. This is not a problem with vertical dilatometers. The sample is set on a fixed plate, and the pushrod is lowered to contact the sample.

\subsection{Setup}

Figure 2 shows the Netzsch DIL 402 ES dilatometer measurement system installed at INL's High Temperature Test Laboratory (HTTL) in its horizontal configuration. The system consists of the dilatometer (which contains the LVDT, the sample holder, and the furnace), the Thermal Analysis System Controller (TASC) 414/4 (which links the dilatometer hardware to the measurement software), the furnace power source, the coolant system (which keeps the LVDT at 
a constant temperature of $25^{\circ} \mathrm{C}$ ), the vacuum pump (for evacuating oxidizing gases), and the CPU (for recording and processing data). The Netzsch DIL 402 system is supplied with two separate software packages. First is the DIL 402E Measurement package. This program allows data logging of LVDT and thermocouple data as well as temperature control programming. Second is the Proteus Analysis package which allows data correction, analysis, and comparison.

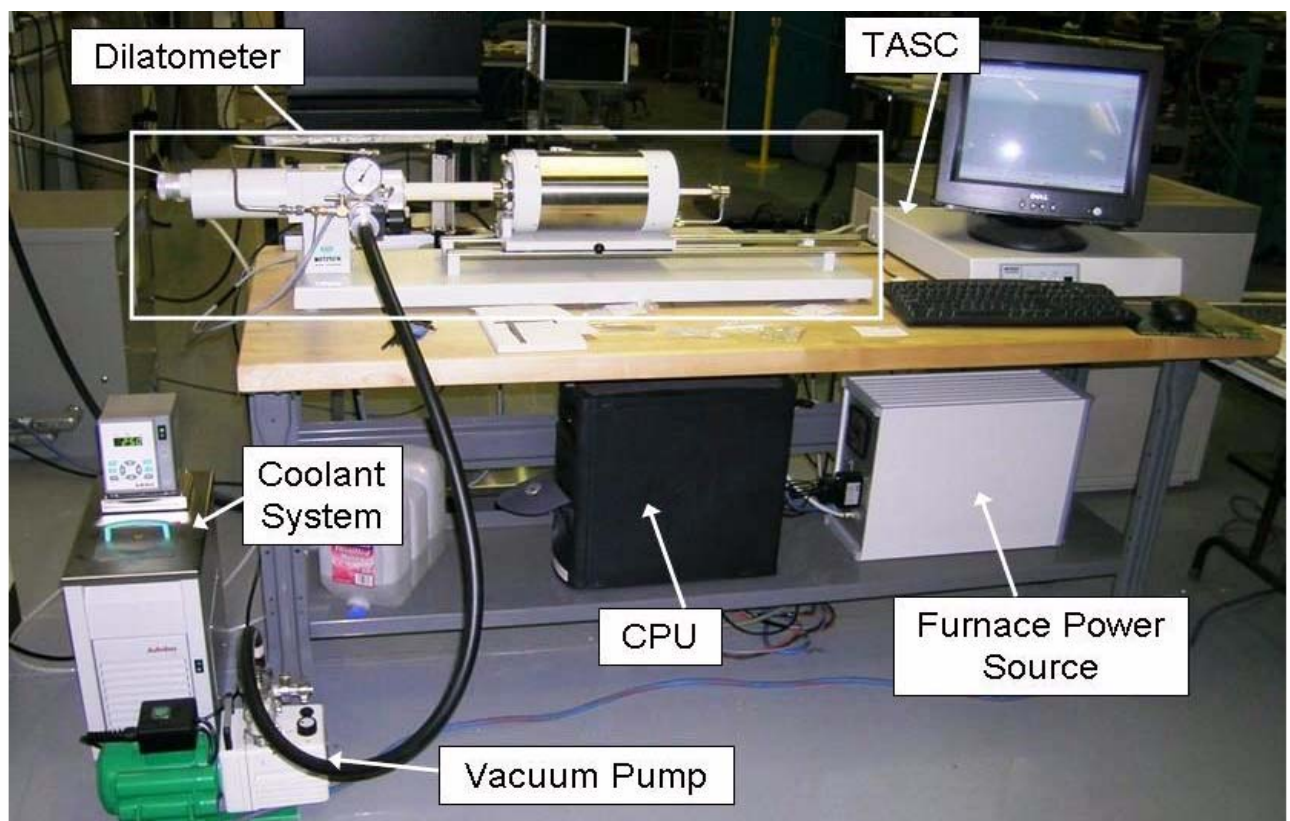

Figure 2. Dilatometer measurement system in horizontal configuration.

Figure 3 shows the dilatometer installed in a vertical configuration. Note the elongated pushrod/sample holder. In addition to the new orientation, this is the primary change in the dilatometer. Figure 4 shows a close up of the sample holder at the point of insertion into the furnace. Due to the elongation of the sample holder, the dilatometer is no longer vacuum sealable. Instead, argon gas flows through the furnace, entering through a tube at the bottom of the furnace and exiting through the open insertion point above the sample position (the flow direction is reversed when compared to the horizontal setup.) Buoyant forces maintain the inert atmosphere in the vicinity of the sample. 


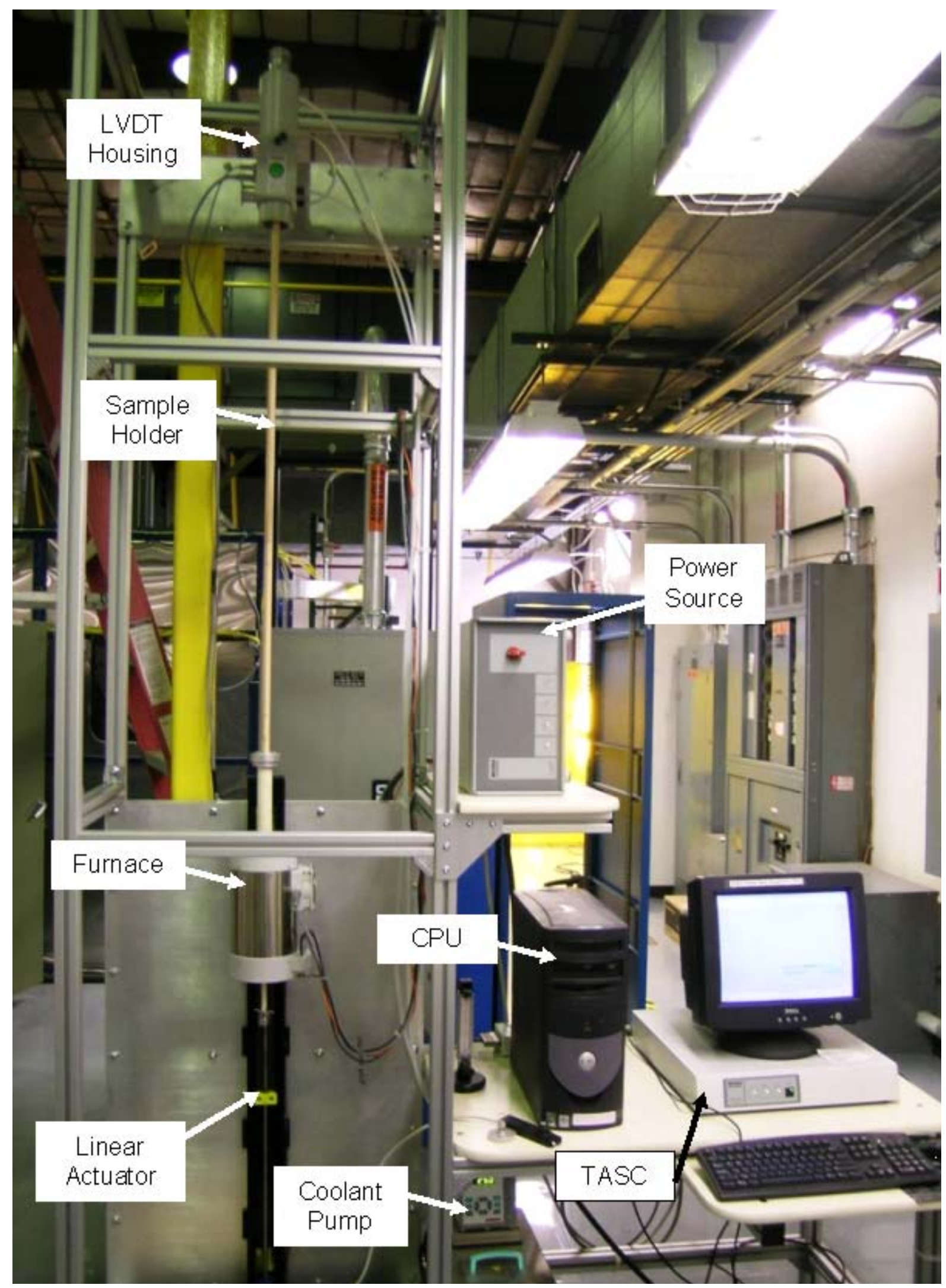

Figure 3. Dilatometer in vertical configuration. 


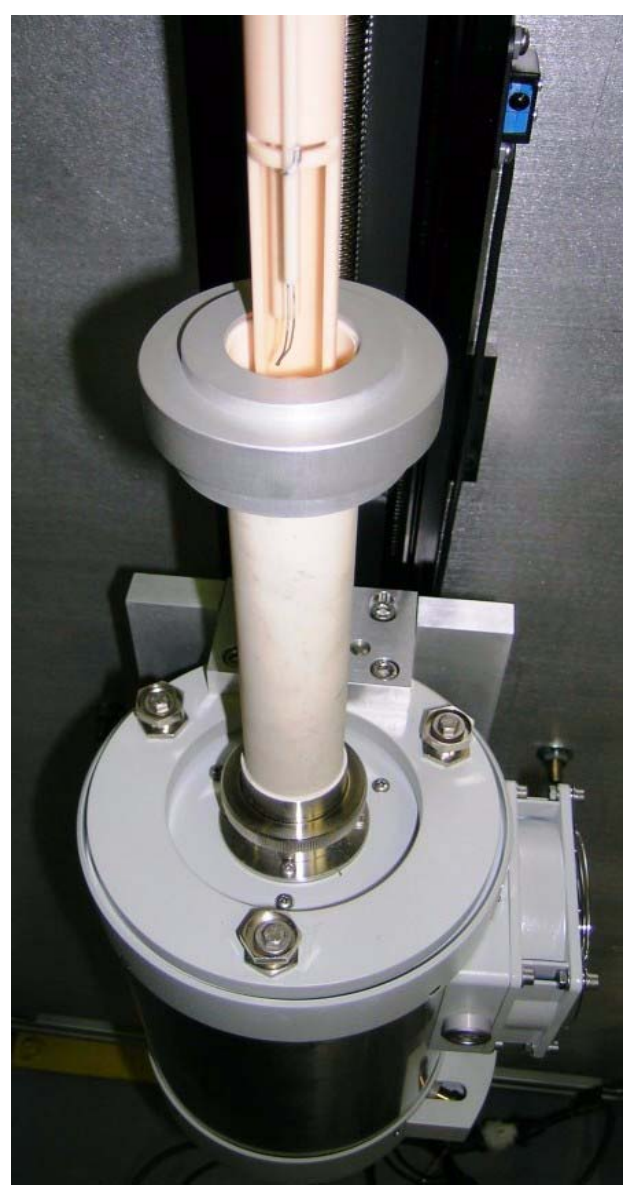

Figure 4. Close up of sample holder at point of insertion into furnace.

\subsection{Procedure}

Table 1 details the test procedure used. The test procedure makes reference to the sample holder (shown in Figure 5) and the sample holder adjustment system (shown in Figure 6). 
Table 1. Test Procedure.

\begin{tabular}{|c|c|c|c|c|c|}
\hline & Step & Action & Process & Purpose & Comments \\
\hline \multirow{6}{*}{$\begin{array}{l}\text { Prepare } \\
\text { System }\end{array}$} & 1 & $\begin{array}{l}\text { Start Coolant } \\
\text { System }\end{array}$ & $\begin{array}{c}\text { Set } 2 \text { Toggle Switches and } \\
1 \text { Touch Pad Key to On } \\
\text { Position }\end{array}$ & $\begin{array}{c}\text { Start Coolant Flow } \\
\text { to LVDT }\end{array}$ & $\begin{array}{l}\text { Coolant Should Be Allowed to Run } \\
\text { for } 2 \text { to } 6 \text { Hours Prior to Testing }\end{array}$ \\
\hline & 2 & $\begin{array}{l}\text { Start Argon } \\
\text { Flow }\end{array}$ & $\begin{array}{c}\text { Open Tank Valve and } \\
\text { Adjust Flow Meter to Max } \\
(190 \mathrm{ml} / \mathrm{min} .)\end{array}$ & $\begin{array}{c}\text { Purge Sample } \\
\text { Holder of Oxidizing } \\
\text { Gases }\end{array}$ & $\begin{array}{l}\text { Flow Should Continue for Up to } 1 \\
\text { Hour After Sample Installation Before } \\
\text { Testing }\end{array}$ \\
\hline & 3 & Start CPU & $\begin{array}{l}\text { Press On/Off Switch on } \\
\text { Computer and Log In }\end{array}$ & $\begin{array}{l}\text { Allows Data } \\
\text { Logging and } \\
\text { Processing }\end{array}$ & \\
\hline & 4 & Start TASC & $\begin{array}{c}\text { Set Toggle Switch on Back } \\
\text { of TASC to On Position }\end{array}$ & $\begin{array}{l}\text { Link Dilatometer } \\
\text { System to CPU }\end{array}$ & \\
\hline & 5 & $\begin{array}{l}\text { Start Furnace } \\
\text { Power Source }\end{array}$ & Set Knob to On Position & $\begin{array}{l}\text { Start Power to } \\
\text { Furnace }\end{array}$ & \\
\hline & 6 & $\begin{array}{c}\text { Open DIL } 402 \\
\text { Program }\end{array}$ & Double Click on Icon & $\begin{array}{l}\text { Start Measurement } \\
\text { Program }\end{array}$ & \\
\hline \multirow{9}{*}{$\begin{array}{l}\text { Prepare } \\
\text { Sample }\end{array}$} & 7 & Clean Sample & $\begin{array}{c}\text { Using Proper PPE, } \\
\text { Thoroughly Clean Sample } \\
\text { With Acetone }\end{array}$ & $\begin{array}{c}\text { Eliminate Impurities } \\
\text { Which Could React } \\
\text { With Sample }\end{array}$ & $\begin{array}{l}\text { The Sample Should Be Handled With } \\
\text { Gloves or Tweezers from This Point } \\
\text { On }\end{array}$ \\
\hline & 8 & $\begin{array}{l}\text { Measure } \\
\text { Sample }\end{array}$ & $\begin{array}{l}\text { Measure Sample with } \\
\text { Micrometer }\end{array}$ & $\begin{array}{l}\text { Get Base Length } \\
\text { Measurement }\end{array}$ & $\begin{array}{l}\text { Accurate Base Length Measurement is } \\
\text { Necessary for Program }\end{array}$ \\
\hline & 9 & $\begin{array}{l}\text { Secure } \\
\text { Sample }\end{array}$ & $\begin{array}{l}\text { Place Sample In Holder } \\
\text { Parallel With Pushrod, } \\
\text { Replace Back Plate }\end{array}$ & $\begin{array}{c}\text { Allow Measurement } \\
\text { of Sample } \\
\text { Elongation }\end{array}$ & $\begin{array}{l}\text { Place End Pieces and Rings if } \\
\text { Necessary }\end{array}$ \\
\hline & 10 & $\begin{array}{l}\text { Adjust } \\
\text { Sample } \\
\text { Holder }\end{array}$ & $\begin{array}{l}\text { Using Screws, Adjust } \\
\text { Holder to Make Pushrod } \\
\text { Parallel With Sample }\end{array}$ & $\begin{array}{l}\text { Align Pushrod and } \\
\text { Sample }\end{array}$ & $\begin{array}{l}\text { Pushrod Should Be as Close to In- } \\
\text { Line With Sample as Possible }\end{array}$ \\
\hline & 11 & \begin{tabular}{|c|} 
Adjust \\
Thermocouple
\end{tabular} & $\begin{array}{l}\text { Using Forceps, Gently } \\
\text { Bend Wires So That T.C. } \\
\text { Junction is Near Sample }\end{array}$ & $\begin{array}{l}\text { Accurately Measure } \\
\text { Sample Temperature }\end{array}$ & $\begin{array}{c}\text { unction Should Be Near Sample } \\
\text { Without Touching, Make Sure Wires } \\
\text { Are Not Touching }\end{array}$ \\
\hline & 12 & Close Furnace & $\begin{array}{c}\text { Slide Furnace Over Sample } \\
\text { Holder, Secure Threaded } \\
\text { Collar }\end{array}$ & $\begin{array}{l}\text { Isolate Sample } \\
\text { Environment }\end{array}$ & \\
\hline & 13 & $\begin{array}{l}\text { Start Vacuum } \\
\text { Pump }\end{array}$ & $\begin{array}{l}\text { Set Toggle Switch to On } \\
\text { Position }\end{array}$ & $\begin{array}{c}\text { Allow for Oxygen } \\
\text { Removal }\end{array}$ & \\
\hline & 14 & Purge Furnace & $\begin{array}{c}\text { Alternate Opening Vacuum } \\
\text { and Argon Valves }\end{array}$ & $\begin{array}{c}\text { Flush Oxygen From } \\
\text { System }\end{array}$ & $\begin{array}{c}\text { Let Argon Flow for } 1 \text { Hour to Purge } \\
\text { System of Oxygen }\end{array}$ \\
\hline & 15 & $\begin{array}{l}\text { Adjust } \\
\text { Pushrod }\end{array}$ & \begin{tabular}{|c|} 
Open Adjustment and \\
View Signals Windows, \\
Adjust Pushrod Using Dial
\end{tabular} & $\begin{array}{c}\text { Set Initial } \\
\text { Elongation to Zero }\end{array}$ & $\begin{array}{c}\text { Adjust Pushrod as Close to Zero } \\
\text { Measurement as Possible (Between } 0 \\
\text { and }-0.5 \mu \mathrm{m}\end{array}$ \\
\hline
\end{tabular}


Table 1. Test Procedure.

\begin{tabular}{|c|c|c|c|c|c|}
\hline \multirow{9}{*}{$\begin{array}{c}\text { Prepare } \\
\text { Test }\end{array}$} & 16 & \begin{tabular}{|c|} 
Start New \\
Measurement \\
File \\
\end{tabular} & \begin{tabular}{|l} 
Select New or Open File \\
\end{tabular} & $\begin{array}{l}\text { Start File for Data } \\
\text { Logging }\end{array}$ & $\begin{array}{l}\text { New File for Correction Run or Open } \\
\text { File for Sample+Correction }\end{array}$ \\
\hline & 17 & $\begin{array}{c}\text { Select Type of } \\
\text { Test }\end{array}$ & $\begin{array}{l}\text { Select "Correction" or } \\
\text { "Sample + Correction" }\end{array}$ & $\begin{array}{l}\text { Determine Type of } \\
\text { Test }\end{array}$ & $\begin{array}{c}\text { If "Sample + Correction" Skip Steps } \\
16 \text { Through } 19\end{array}$ \\
\hline & 18 & $\begin{array}{l}\text { Enter Test } \\
\text { Information }\end{array}$ & $\begin{array}{l}\text { Enter Information as } \\
\text { Required by Program }\end{array}$ & $\begin{array}{l}\text { Record Sample } \\
\text { Identification }\end{array}$ & $\begin{array}{l}\text { Enter Necessary Information and } \\
\text { Comments About Sample and User }\end{array}$ \\
\hline & 19 & $\begin{array}{l}\text { Select } \\
\text { Calibration } \\
\text { File }\end{array}$ & \begin{tabular}{|c|} 
Select Temperature \\
Calibration File From List
\end{tabular} & & Tcalzero is the Standard File Used \\
\hline & 20 & $\begin{array}{c}\text { Select Sample } \\
\text { Holder }\end{array}$ & \begin{tabular}{|c|} 
Select Sample Holder \\
Material From List of File
\end{tabular} & $\begin{array}{l}\text { Correct for Sample } \\
\text { Holder Expansion }\end{array}$ & $\begin{array}{l}\text { HTTL Dilatometer Uses an Alumina } \\
\text { Sample Holder }\end{array}$ \\
\hline & 21 & \begin{tabular}{|l} 
Select \\
Correction \\
Standard
\end{tabular} & $\begin{array}{l}\text { Select Standard Used for } \\
\text { Correction From List }\end{array}$ & $\begin{array}{l}\text { Baseline Sample } \\
\text { Correction }\end{array}$ & $\begin{array}{l}\text { Alumina Used in Horizontal Tests, } \\
\text { Sapphire Used in Vertical Tests }\end{array}$ \\
\hline & 22 & $\begin{array}{c}\text { Set Heating } \\
\text { Program }\end{array}$ & \begin{tabular}{|c|} 
Set Initial Temperature, \\
Final Temperature, Heating \\
Rate and Final \\
Temperature Reset
\end{tabular} & $\begin{array}{c}\text { Programs } \\
\text { Temperature Steps }\end{array}$ & $\begin{array}{l}\text { Click Add to Add a Step or to } \\
\text { Continue }\end{array}$ \\
\hline & 23 & $\begin{array}{l}\text { Select File } \\
\text { Name }\end{array}$ & $\begin{array}{c}\text { Enter Name of } \\
\text { Measurement File }\end{array}$ & $\begin{array}{c}\text { Identify } \\
\text { Measurement }\end{array}$ & \\
\hline & 24 & Start Program & $\begin{array}{l}\text { When Start Option Is } \\
\text { Available, Select Start }\end{array}$ & Begin Test & $\begin{array}{c}\text { Note: Dilatometer is Very Sensitive to } \\
\text { Vibration }\end{array}$ \\
\hline \multirow{5}{*}{$\begin{array}{c}\text { Analyze } \\
\text { Data }\end{array}$} & 25 & $\begin{array}{c}\text { Open Proteus } \\
\text { Program }\end{array}$ & Double Click on Icon & Start Program & \\
\hline & 26 & \begin{tabular}{|c|} 
Open \\
Measurement \\
File
\end{tabular} & $\begin{array}{l}\text { Select Open, Choose File } \\
\text { to Analyze }\end{array}$ & & \\
\hline & 27 & \begin{tabular}{|c|} 
Set Plot \\
Parameters \\
\end{tabular} & $\begin{array}{c}\text { Using Toolbar, Set Desired } \\
\text { Plot Characteristics }\end{array}$ & & $\begin{array}{c}\text { Select Temperature as X-Axis, Set } \\
\text { Elongation Units to \% }\end{array}$ \\
\hline & 28 & $\begin{array}{c}\text { Select } \\
\text { Correction }\end{array}$ & $\begin{array}{l}\text { Right Click on Data Plot, } \\
\text { Select Correction, Choose } \\
\text { Proper Correction Type }\end{array}$ & $\begin{array}{l}\text { Correct for Sample } \\
\text { Holder Expansion }\end{array}$ & $\begin{array}{c}\text { Select Sample Holder for Correction } \\
\text { Files, Calibration for Sample + } \\
\text { Correction Files }\end{array}$ \\
\hline & 29 & Export Data & $\begin{array}{c}\text { Under Extras, Select } \\
\text { Export Data, Select Full } \\
\text { Range and Single Point, } \\
\text { Click Export } \\
\end{array}$ & $\begin{array}{l}\text { Allows Data to Be } \\
\text { Transferred to Excel }\end{array}$ & $\begin{array}{l}\text { Creates CSV File, Need to Save as } \\
\text { XLS File to Use All Excel Features }\end{array}$ \\
\hline \multirow{3}{*}{$\begin{array}{l}\text { Shut } \\
\text { Down }\end{array}$} & 30 & $\begin{array}{c}\text { Close } \\
\text { Software }\end{array}$ & Close Program Windows & & \\
\hline & 31 & $\begin{array}{l}\text { Remove } \\
\text { Sample }\end{array}$ & $\begin{array}{c}\text { Reverse Steps } 8 \text { Through } \\
12\end{array}$ & & Only After System Has Cooled! \\
\hline & 32 & $\begin{array}{c}\text { Shut Down } \\
\text { System }\end{array}$ & Reverse Steps 1 Through 5 & & \\
\hline
\end{tabular}




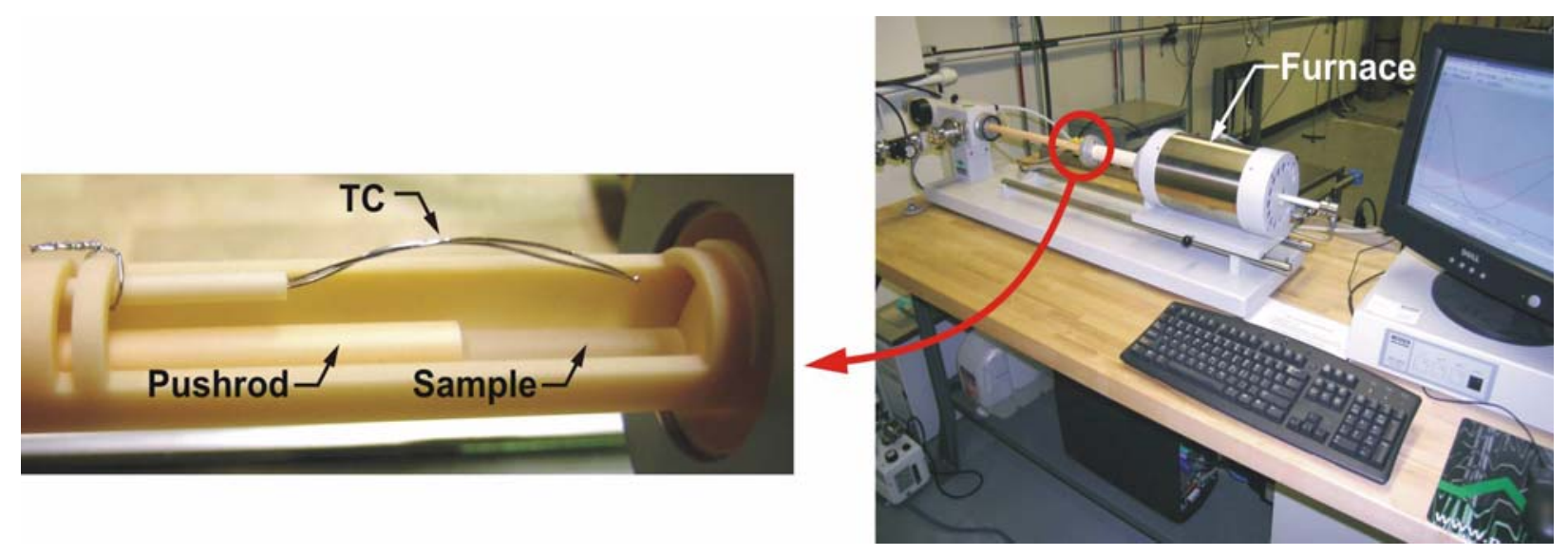

Figure 5. Close up view of the sample holder.

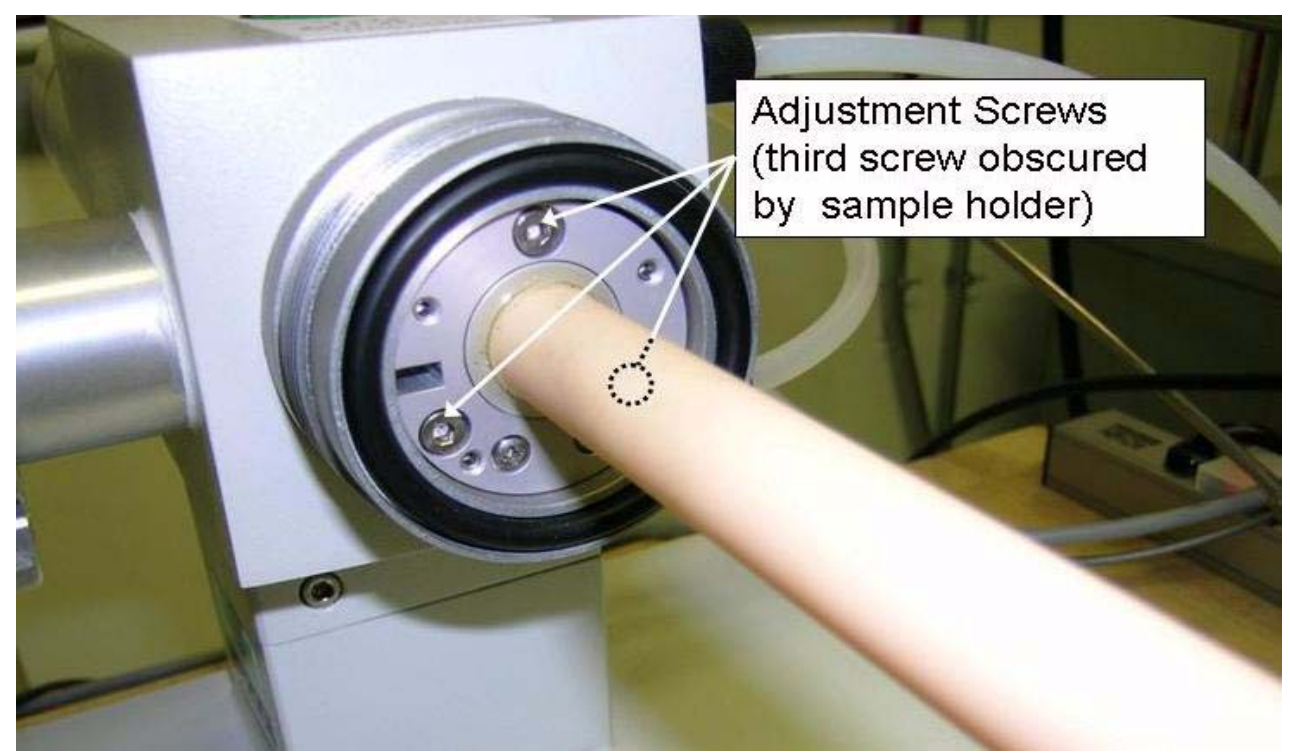

Figure 6. Close up view of sample holder adjustment screws.

To minimize oxidation of samples at high temperatures, the system was purged with a constant flow of ultra high purity argon for selected tests. Even with argon flow, there may be oxygen present due to impurities in the argon and from incomplete vacuum purging. Stainless steel tubing was used for horizontal testing, but a small Tyvex section was required. The vertical configuration required flexible tubing (Tyvex) for furnace mobility. Oxides produced may have a tendency to diffuse into the dilatometer components which are in contact with the sample. To stem diffusion of oxides into the dilatometer components, the alumina rings and end pieces shown in Figure 7 were used. These end pieces are disposable circular wafers placed between the sample and the dilatometer components. The rings separate the sample from the sample holder and allow the pushrod to be aligned parallel to the sample, as shown in Figure 8. 


\section{Alumina End Pieces}

\section{Alumina Rings}

Figure 7. Alumina end pieces and rings.

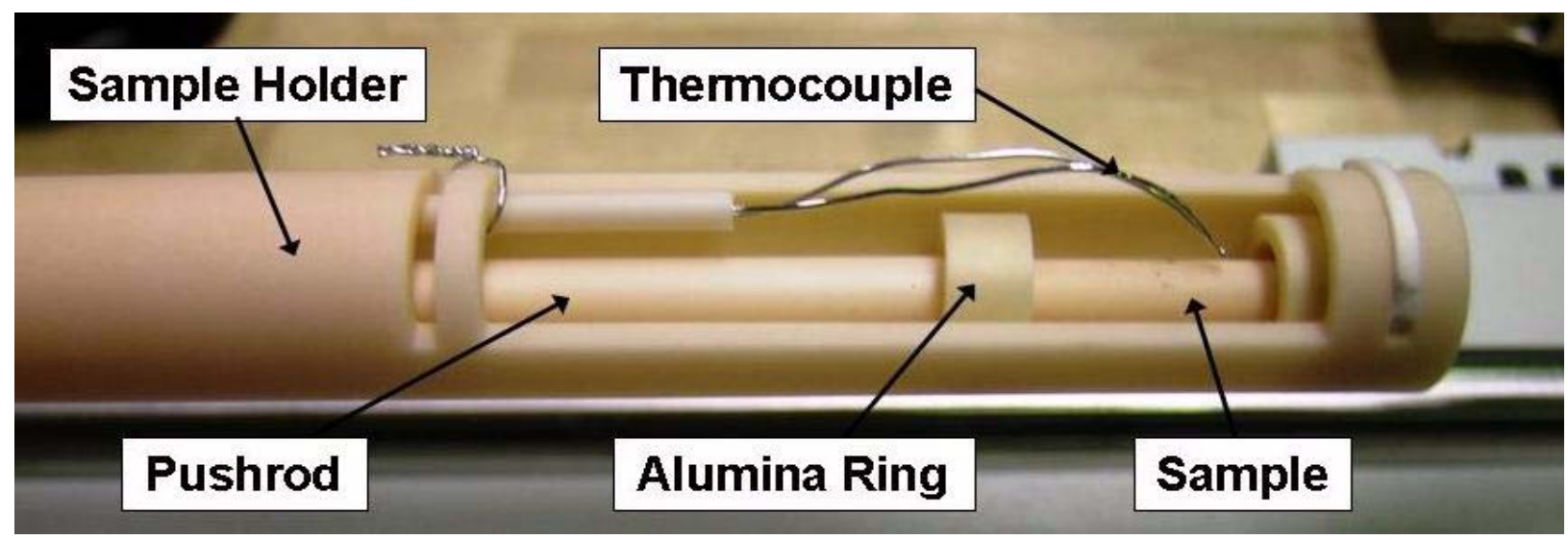

Figure 8. Sample installed in holder using alumina rings.

To ensure that the dilatometer is working properly for runs in which test data are collected, test runs were performed using an alumina standard prior to each test with steel. These alumina tests were compared to standard data. These tests, if valid, were used to compensate for expansion of the dilatometer components, a built in capability of the Netzsch system.

\subsection{Example Test}

This section details an example test for the purpose of clarifying the testing process. The section will follow the procedure outlined in Table 1.

Step 1: Start the coolant system by setting the two toggle switches to the on position and pressing the I/O touch pad key. These switches are shown in Figure 9. The display screen will 
read $25.0^{\circ} \mathrm{C}$ when the system is running. This coolant system keeps the LVDT at a constant temperature and should be allowed to run for up to six hours prior to testing.

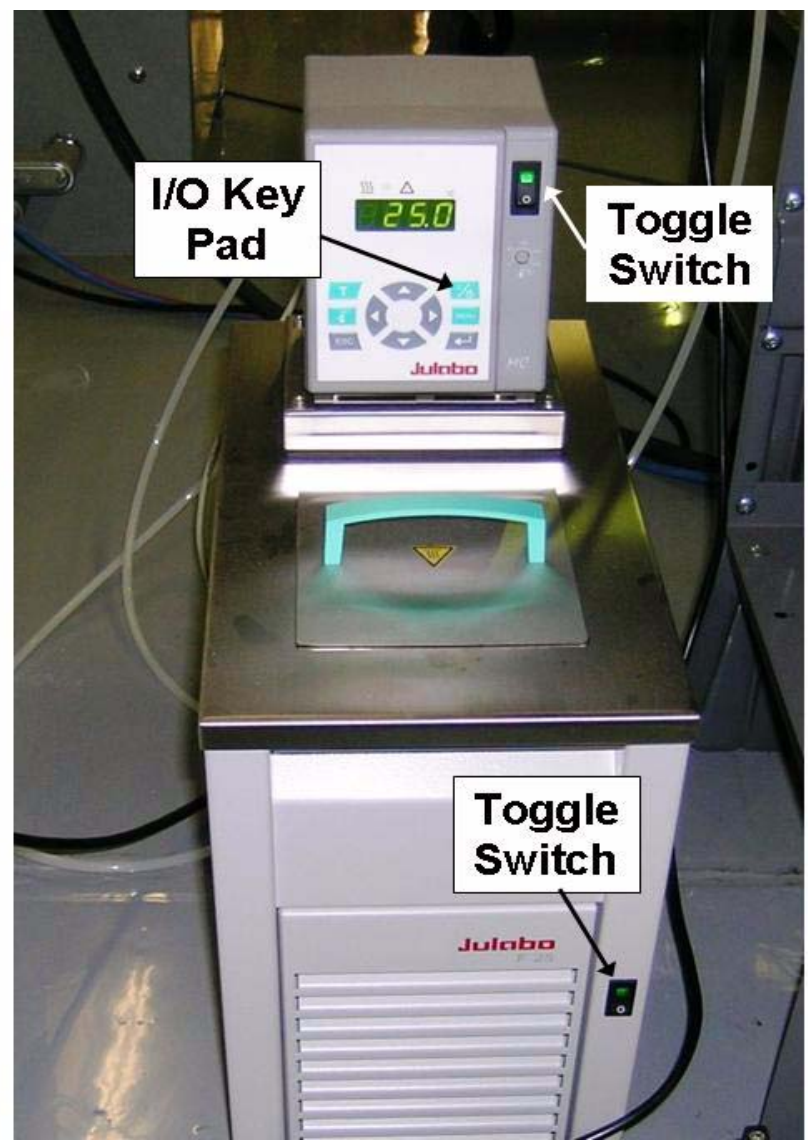

Figure 9. Dilatometer instrumentation coolant system.

Step 2: Start the argon flow by opening the tank valves and setting the flowmeter to the maximum flow position. This is a flow rate of 190 milliliters per minute. The flow meter is rated for nitrogen flow but, according to the manufacturer, correcting for the density of argon is not required. The argon flow controls are shown in Figure 10.

Step 3: Start the CPU by pressing the button on the front of the CPU casing. Also the monitor should be turned on at this time. Once logged on, the CPU allows data logging and processing.

Step 4: Start the TASC by setting the toggle switch on the back of the unit to the on position. The TASC links the CPU to the dilatometer measurement systems and allows for monitoring the sample elongation as well as monitoring and controlling the furnace temperature.

Step 5: Start the furnace power source by turning the knob on the front of the unit to the on position. This unit supplies power to the furnace. 

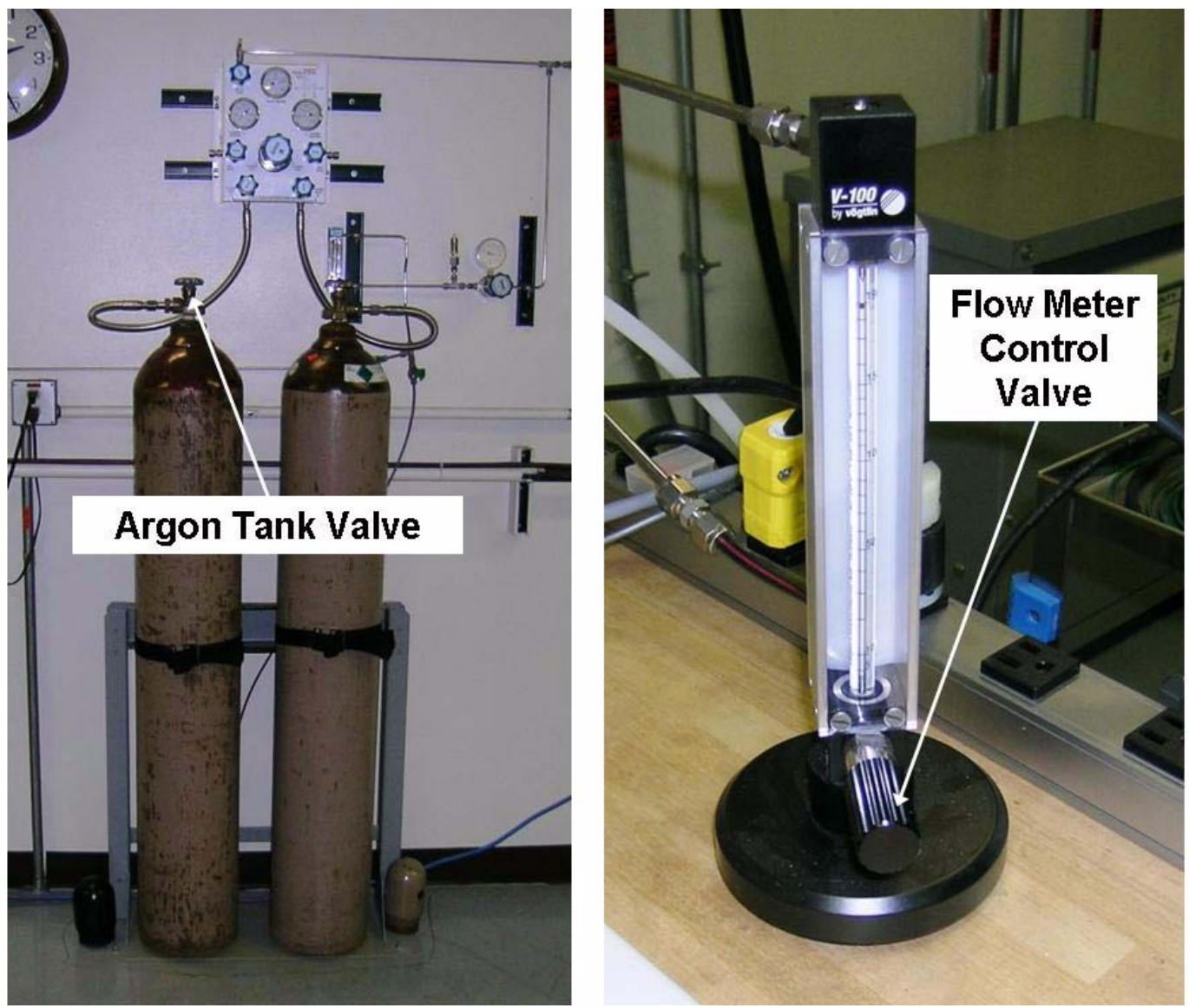

Figure 10. Argon flow control valves.

Step 6: Open the DIL 402 program by double clicking on the proper icon.

Step 7: Clean the sample with acetone or isopropyl alcohol. This will remove any contaminants that might react with the sample at high temperatures. After this step, the sample should be handled with gloves or tweezers.

Step 8: Measure the room temperature length of the sample using a micrometer. This measurement is entered into the computer and used as the initial (unelongated) sample length.

Step 9: Secure the sample in the sample holder as seen in Figure 8. The sample must be as close to parallel to the pushrod as possible. Alumina rings and end pieces should also be installed at this point if required. Adjust the pushrod by slowly turning the micrometer dial on the end of the dilatometer. The adjustment and view signals windows must be open at this time. Open the windows using the tools submenu on the tool bar. The adjustment and view signals windows are shown in Figure 11.

Step 10: Adjust the sample holder position using the set screws pictured in Figure 6. 

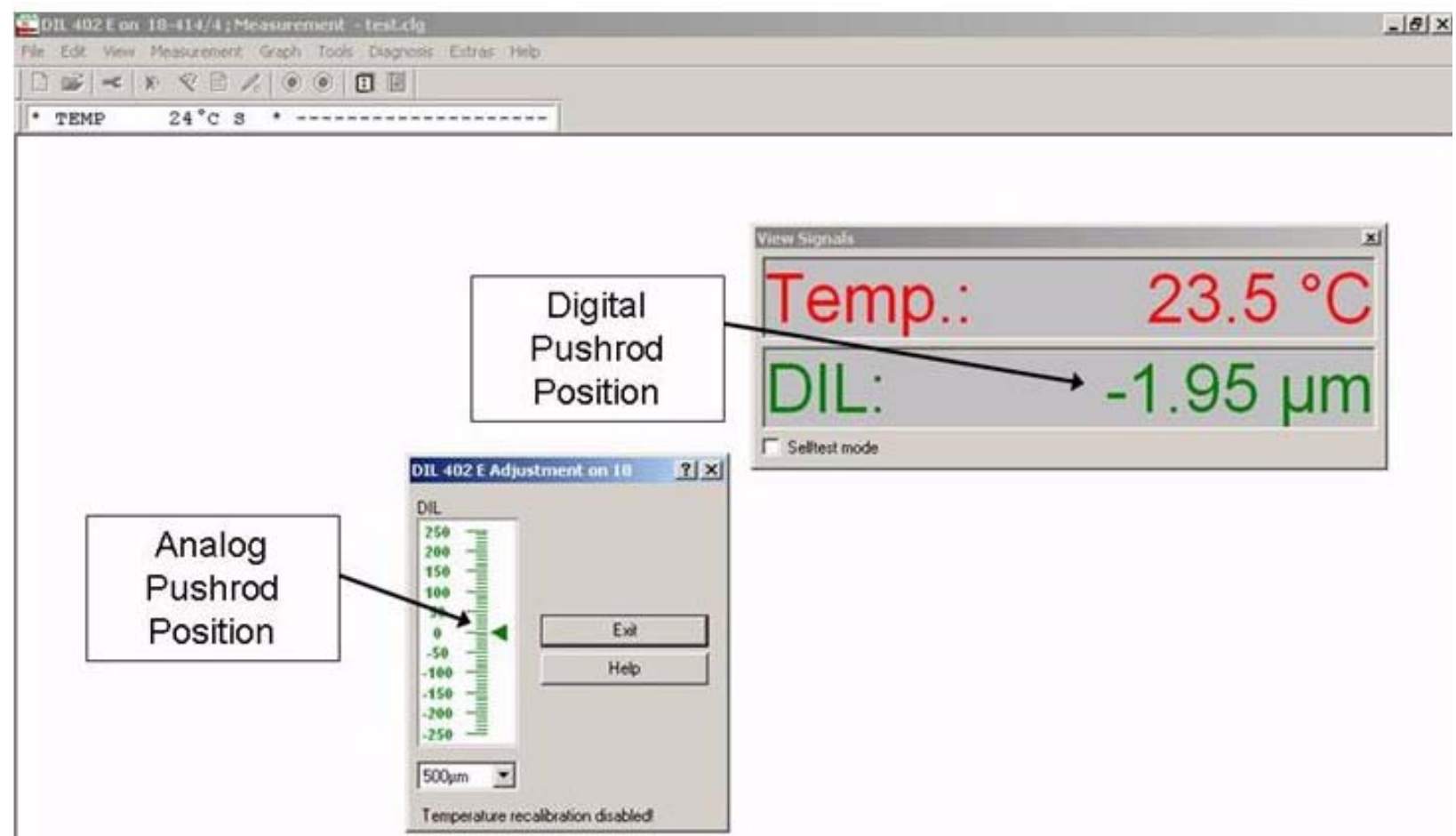

Ready to start ot $20.0^{\circ} \mathrm{C}$...

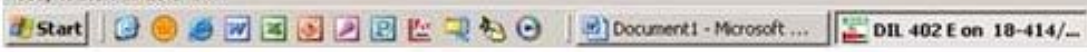

Figure 11. Adjustment and View Signals windows.

Step 11: Gently adjust the thermocouple so that the junction is as close as possible to the sample without touching it. Care must be taken during this step as the thermocouple wires may become brittle after heating. Also, the wires must not be touching each other, except at the junction, or the signal will not be accurate.

Step 12: Close the system by sliding the furnace section over the sample holder as shown in Figure 12. Secure the system by turning the threaded locking collar clockwise until it is tight. Note: the vacuum pump cannot be used with the vertical setup, so after the furnace is positioned over the sample holder steps 13 and 14 may be replaced by letting the argon flow for a longer period of time (30 minutes) before starting the heating program.

Step 13: If necessary, start the vacuum pump by setting the toggle switch on top of the unit to the on position. 


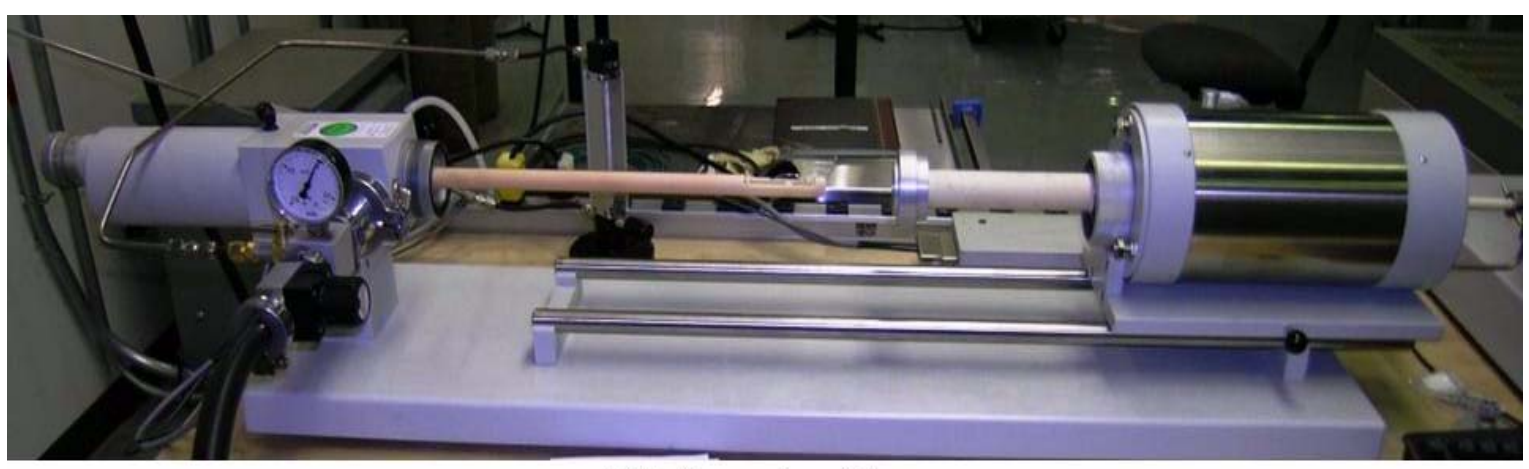

Dilatometer Open

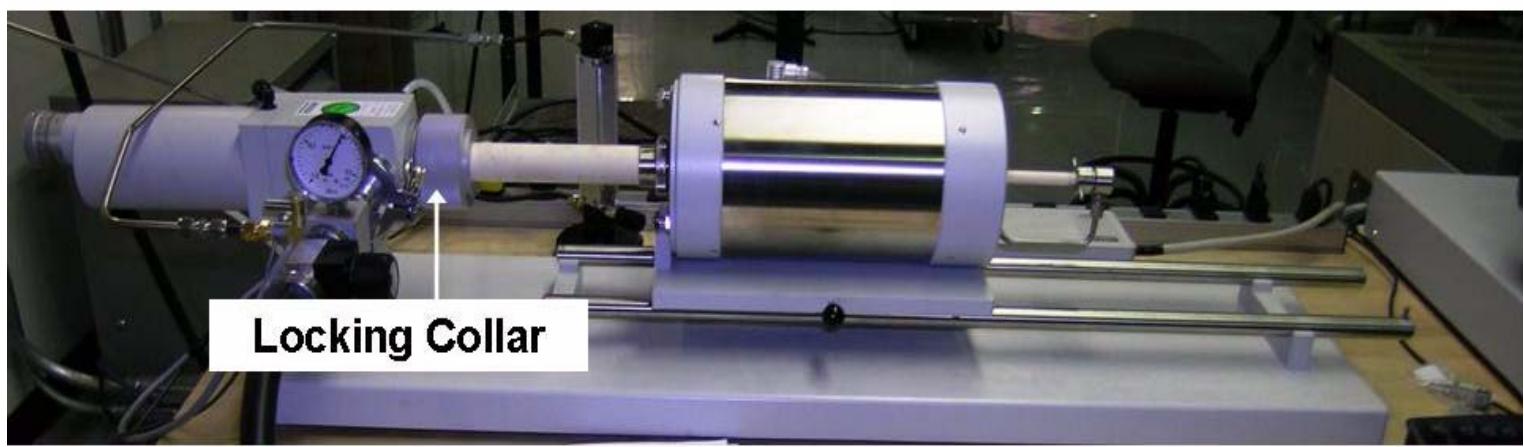

Dilatometer Closed

Figure 12. Closing and securing the dilatometer.

Step 14: Purge the furnace of oxygen by alternating the argon flow and vacuum valves, shown in Figure 13. With the flow exit blocked, close the argon flow valve and open the vacuum valve. Next, close the vacuum valve and open the argon flow valve. Repeat this several times. With the vacuum valve closed and the argon flow valve open, open the flow exit. Turn off the vacuum pump.

Step 15: Adjust the pushrod again as closing the furnace may have changed its position. The final position of the pushrod should yield a DIL of between 0 and -0.5 on the view signals window.

Note that for a calibration (correction) test steps 16 through 24 are somewhat different than for an experimental (sample + correction) test. Steps for a calibration test will be denoted as steps 16 a through $24 \mathrm{a}$, while steps for an experimental test will be denoted as $16 \mathrm{~b}$ through $24 \mathrm{~b}$.

Step 16a: Start a new measurement file by clicking the new file icon on the DIL 402 start page.

Steps 17a and 18a: Enter the type of test you want to perform by clicking on the proper measurement type. At this point only "correction" and "sample" will be available, as seen in Figure 14. Correction is the proper type to use with a standard (calibration) sample, such as those supplied by Netzsch. The correction test will allow the program software to remove the thermal 


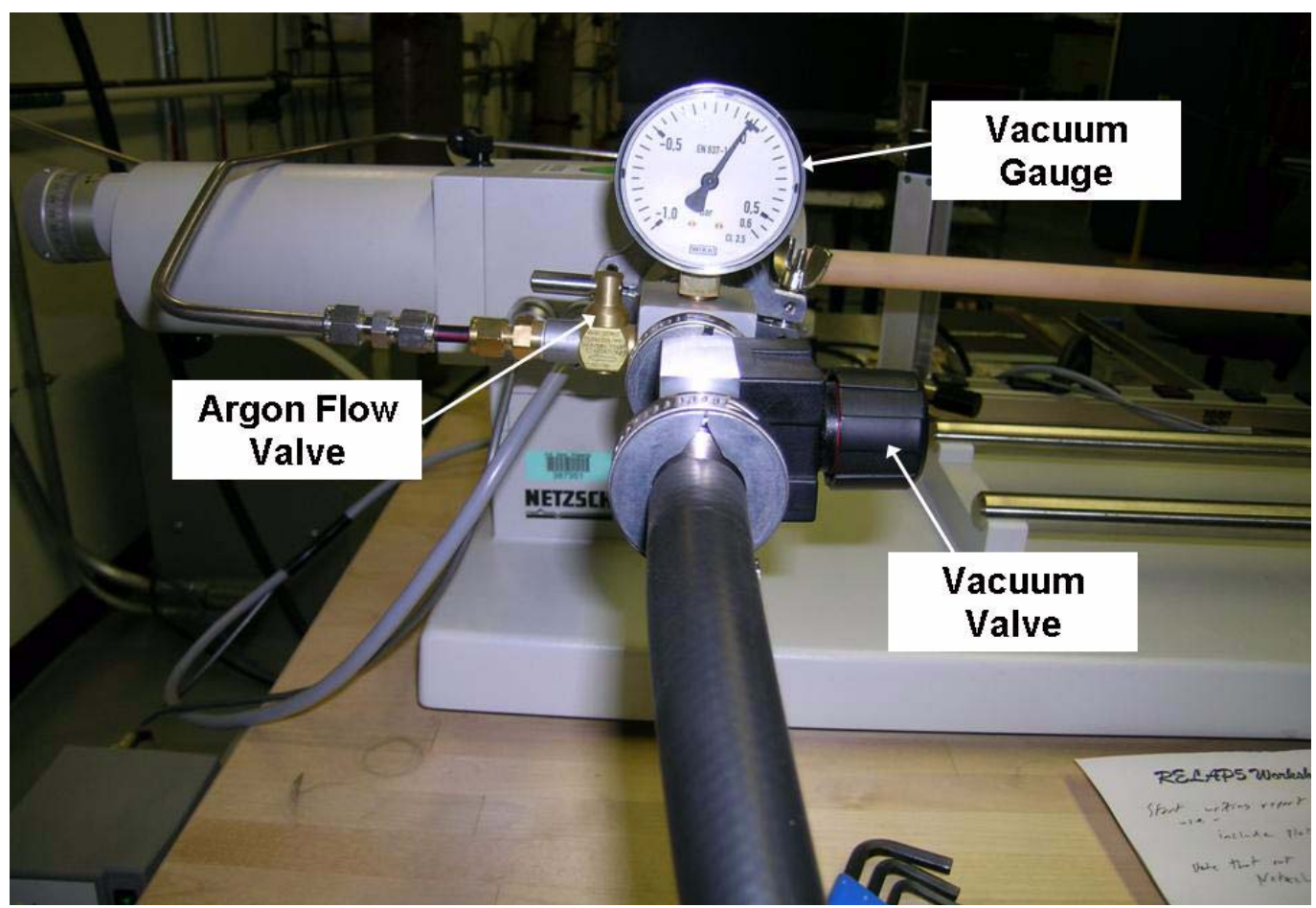

Figure 13. Argon flow and vacuum valves.

elongation effects of the system from the test when an experimental sample is tested. At this point, information about the test conditions and sample must be entered. Note, sample identification information and length must be entered.

Step 19a: After steps 17a and 18a are complete, click continue. The next screen will allow selection of the proper calibration file. At this point, the only option is "Tcalzero." Select this file and click open.

Step 20a: Select the proper sample holder material. There are several options. The sample holder used in the HTTL dilatometer is made from alumina $\left(\mathrm{Al}_{2} \mathrm{O}_{3}\right)$. Select this material and click open.

Step 21a: Select the correction standard that is to be used and click open. Netzsch has supplied the HTTL with standards constructed from alumina, sapphire, and fused quartz glass. 


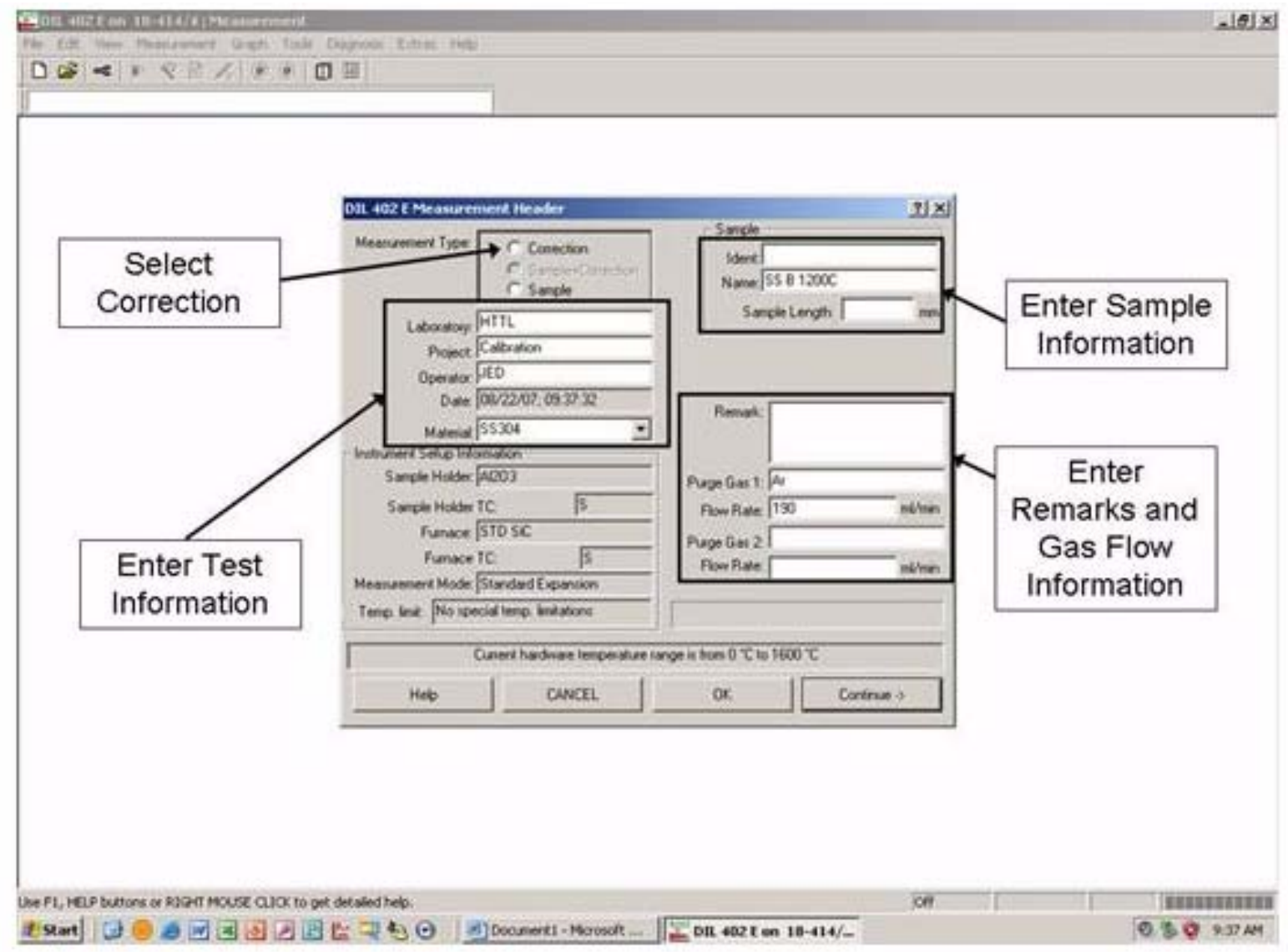

Figure 14. Test information screen.

Step 22a: Program the heating sequence. This step requires several sub-steps. The first screen, shown in Figure 15, allows the initial temperature to be set, this should be the ambient room temperature. Also, on the same screen, select STC and choose which gas, if any, will be used. STC is sample temperature control, this setting causes the furnace to heat the sample holder to about $30^{\circ} \mathrm{C}$ above the programmed temperature. This is to ensure that the sample will heat at the desired rate. If STC is not selected, the sample temperature will lag behind the program temperature by an undesirable amount $\left(30^{\circ} \mathrm{C}\right.$ to $\left.50{ }^{\circ} \mathrm{C}\right)$. 


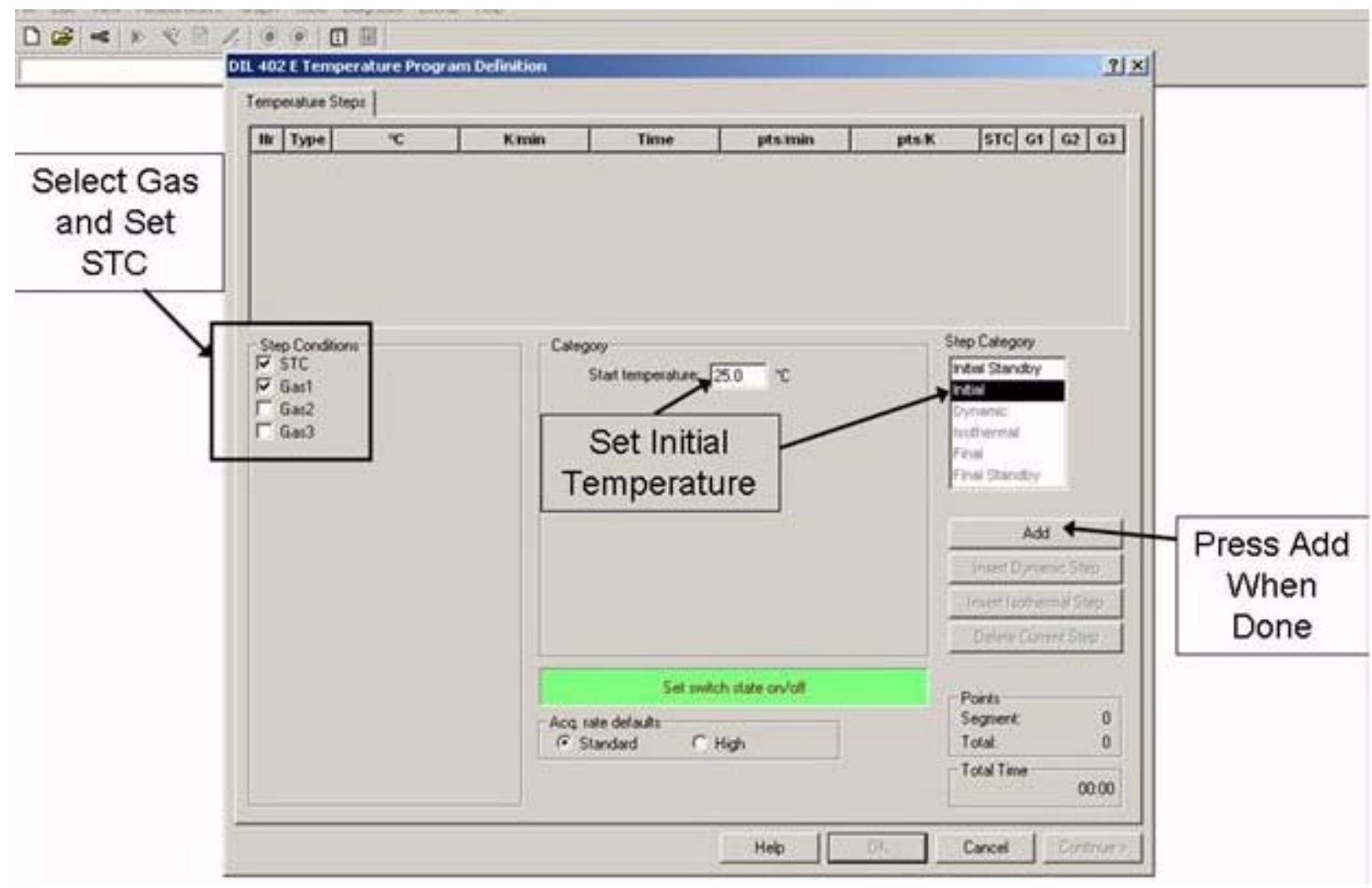

Figure 15. First step in programming heating sequence.

When the first program step is complete, click add to add a second step. On the next screen (see Figure 16), select Dynamic. This setting allows for temperature changes. Enter the desired final temperature, and click add. Note, STC and gas do not have to be selected for each step.

On the next screen, shown in Figure 17, select Final. This allows an emergency reset temperature to be added. If this temperature is reached, the furnace will automatically shut down. The emergency reset temperature should be $10^{\circ} \mathrm{C}$ to $30^{\circ} \mathrm{C}$ above the final program temperature. More complicated programs can be used; but for a simple thermal elongation test, this is all that is required.

Step 23a: Choose a location and file name and click save. The file will be saved with a .clg suffix. This indicates that it is a correction file. The .clg file contains all the information entered about the test in the previous steps, including sample information, calibration file, sample and holder material, and temperature program. 


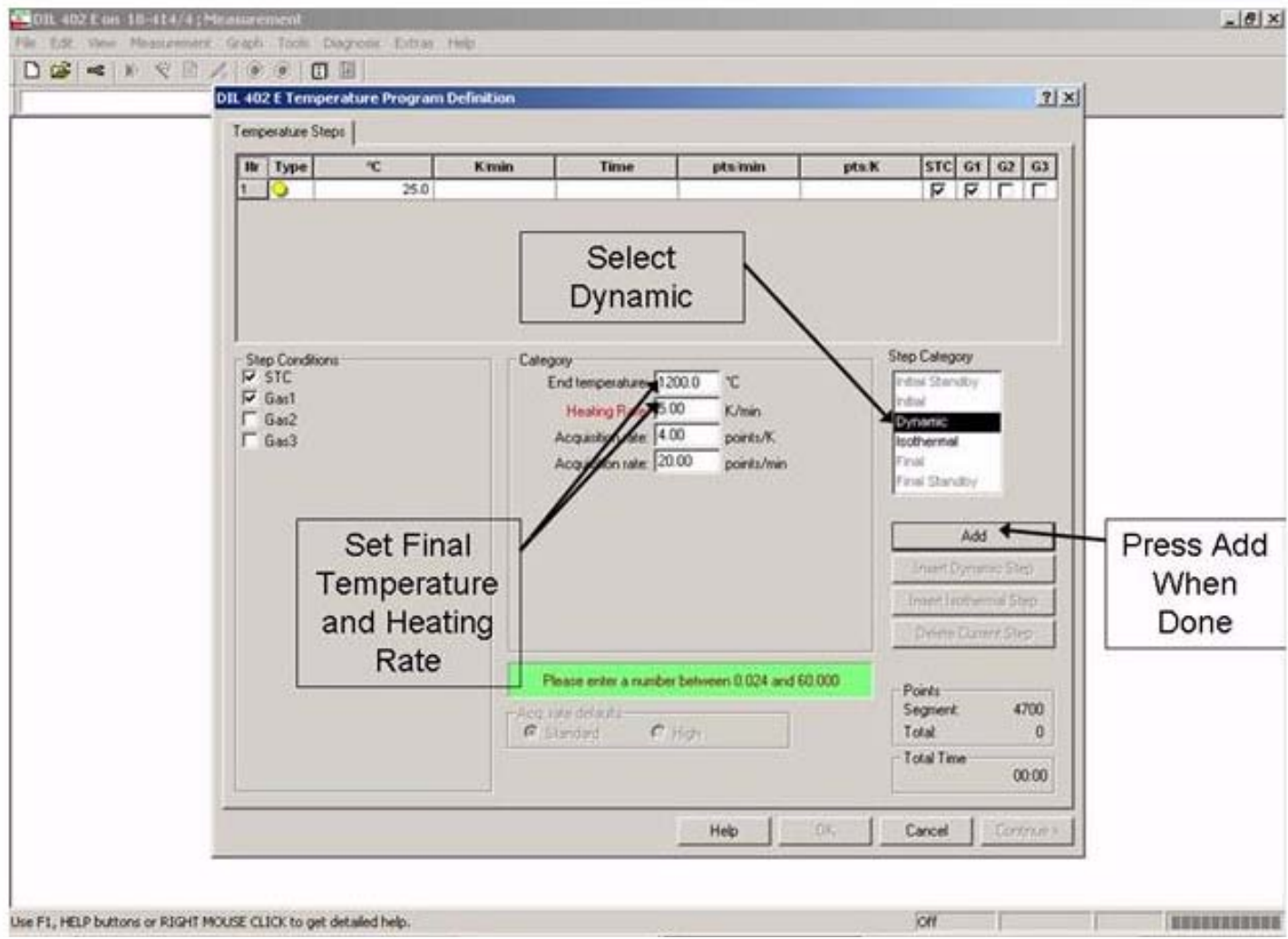

Figure 16. Second step in programming heating sequence.

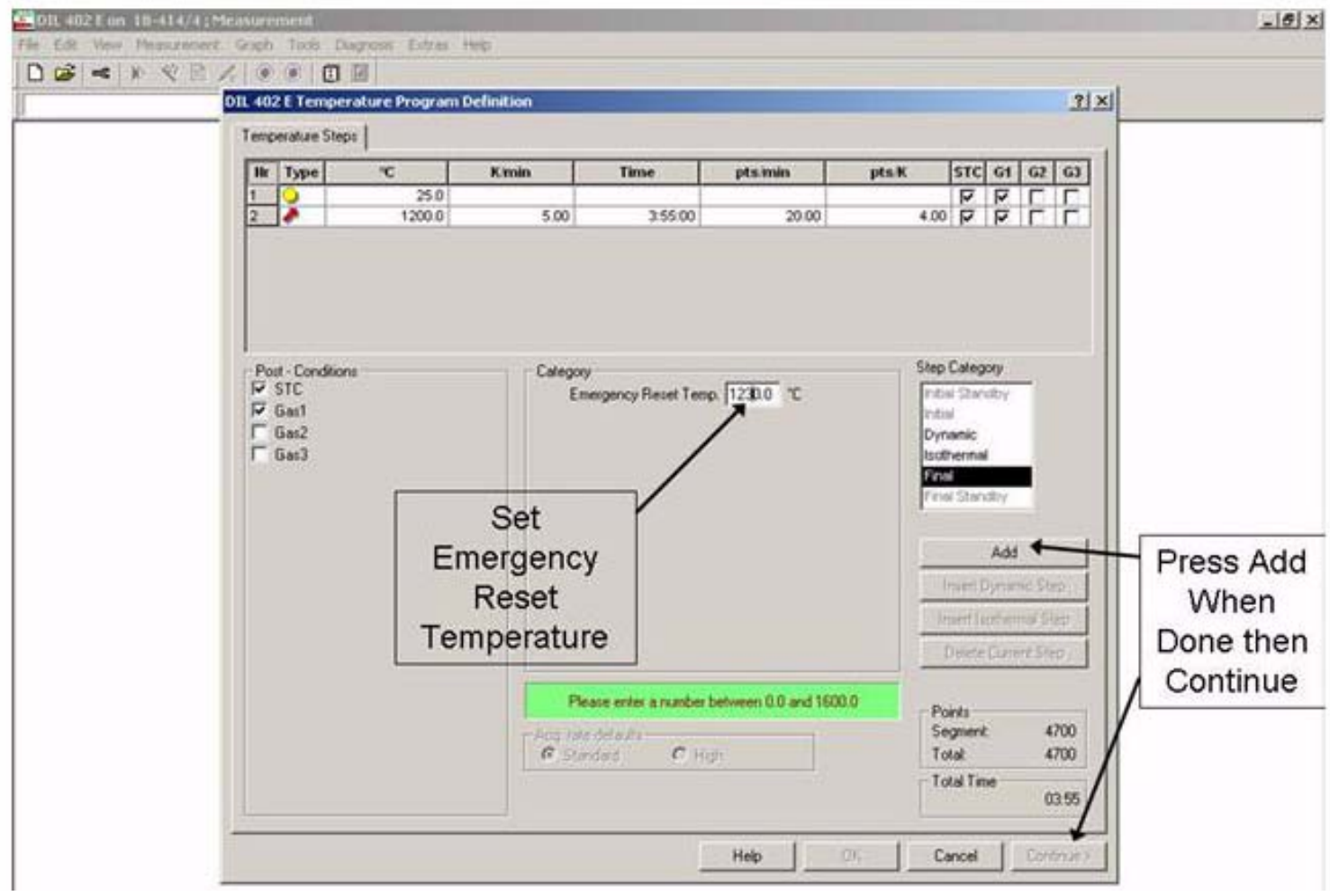

Figure 17. Final step in programming heating sequence. 
Step 24a: The next screen will show the adjustment window. Make any necessary final adjustments to the pushrod position. When the program is ready, the start button will become active. Click this button when ready. When the program is running, the screen will look like the one shown in Figure 18.

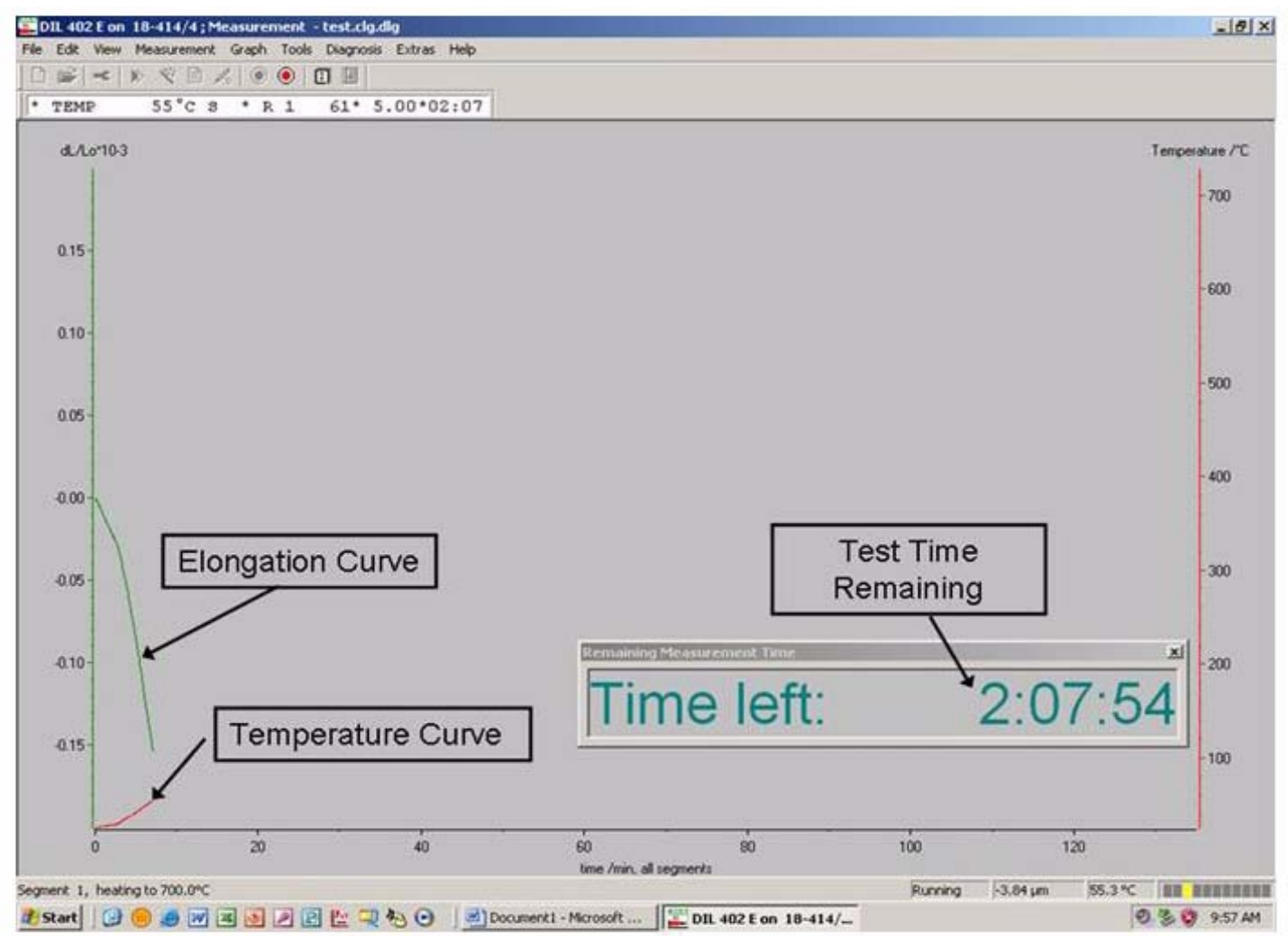

Figure 18. Dilatometer measurement program running.

Step 16b: Open a previously run correction measurement file by clicking the open file icon on the DIL 402 start page. Choose a correction test with temperature limits matching or exceeding those desired for the sample + correction test. Note that information about the correction test is displayed at the bottom of the open file window, as seen in Figure 19. It may be necessary to scroll through the information, and the sub-folders displayed (particularly temperature steps), to view all the test information. 


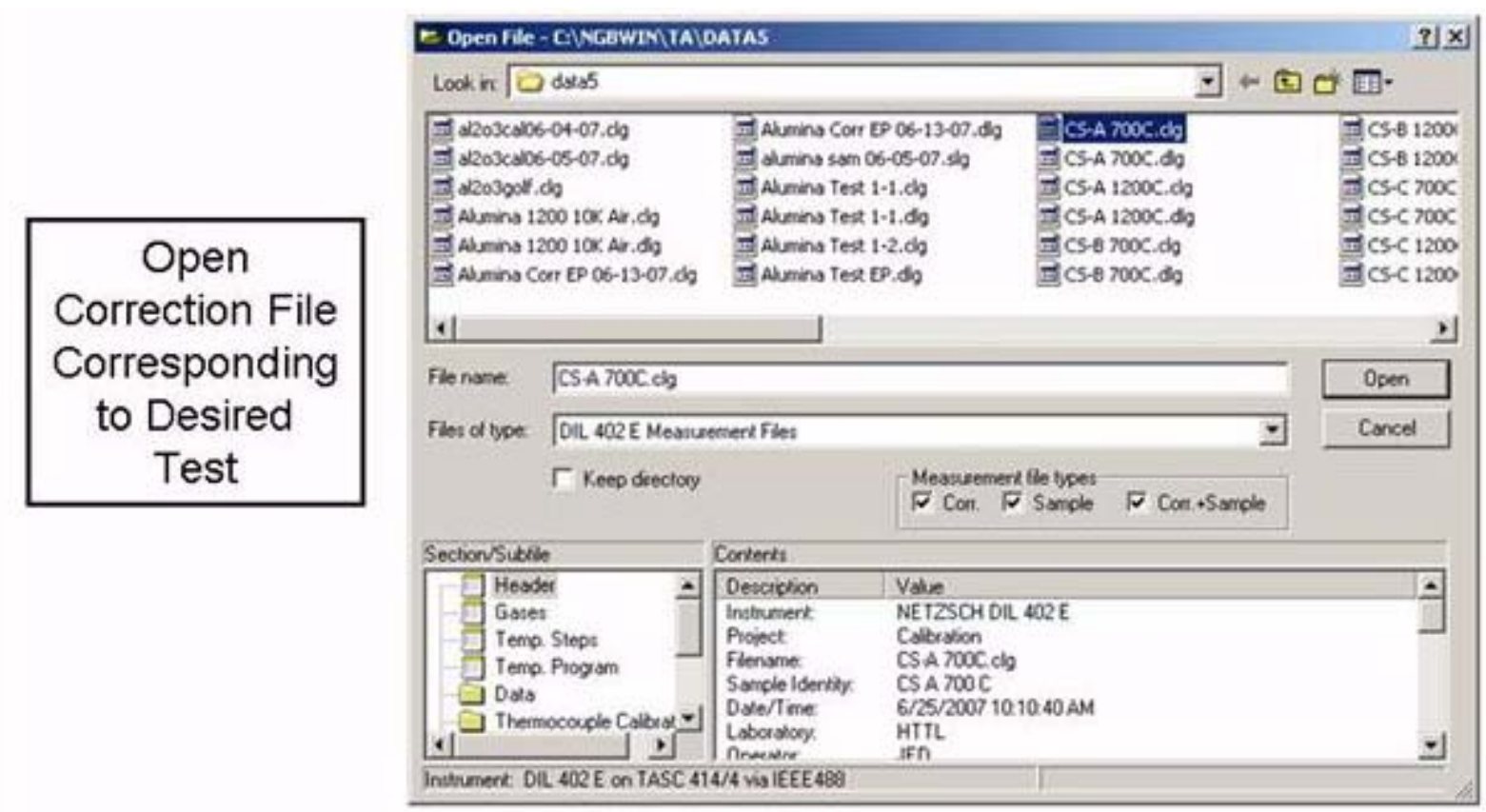

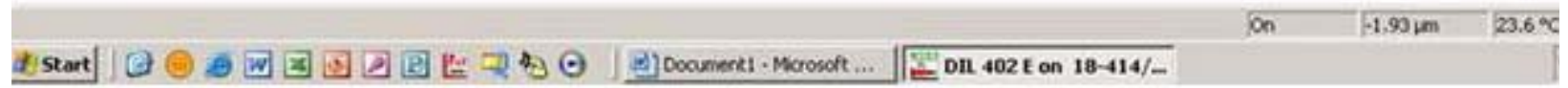

Figure 19. Open correction file window used to select correction file corresponding to desired sample + correction test.

Steps $17 \mathrm{~b}$ and 18b: Enter the type of test you want to perform by clicking on the proper measurement type. At this point "correction", "sample", and "sample + correction" will be available, as seen in Figure 20. "Sample + correction" is the proper type to use with an experimental sample, for which elongation information is not available. The sample + correction test will record raw elongation data about the sample as well as the sample holder, alumina end pieces, pushrod, etc. The previously recorded correction data will allow the software to remove the effects of the elongation of the dilatometer components so that the elongation of the sample may be isolated. At this point, information about the test conditions and sample must be entered. Note, sample identification information and length must be entered. The next screen will be the same screen that was used to enter information about the correction test. Select sample + correction and change any information that is different from the correction test, such as sample material, sample length, etc. 


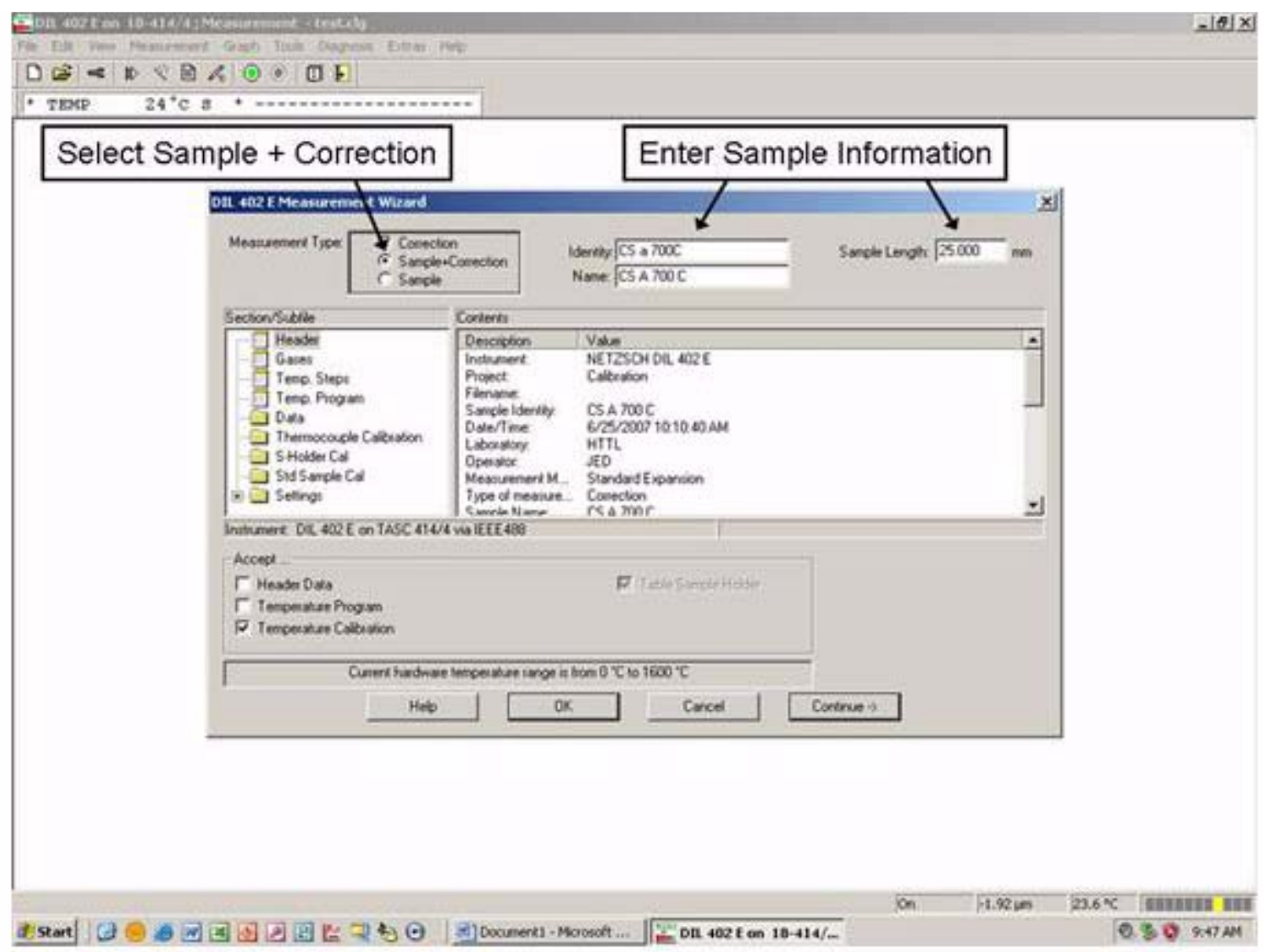

Figure 20. Sample + correction selecting screen.

Step 19b: This step is not necessary for a sample + correction test, and will be skipped by the program, because the calibration file used must be the same as that used for a correction test.

Step 20b: This step is not necessary for a sample + correction test, and will be skipped by the program, because the sample holder file used must be the same as that used for a correction test.

Step 21b: This step is not necessary for a sample + correction test, and will be skipped by the program, because the calibration standard file used must be the same as that used for a correction test.

Step 22b: The heating sequence program screen will appear. Changes cannot be made to the program. Verify that the program is correct and click continue.

Step 23b: Choose a location and file name and click save. The file will be saved with a .dlg suffix. This indicates that it is a sample + correction data file. The .dlg file contains all the information from the correction file as well as the information and data from the sample + correction test. 
Step 24b: The next screen will show the adjustment window. Make any necessary final adjustments to the pushrod position. When the program is ready, the start button will become active. Click this button when ready. When the program is running, the screen will look like the one shown in Figure 18.

Steps 25 through 29 are used with the Proteus analysis program and are used to analyze, compare, and export test data.

Step 25: Open the Proteus analysis program by clicking on the proper icon on the CPU desktop.

Step 26: Click open on the toolbar, and select the file for analysis.

Step 27: Set the plot parameters as desired using the settings drop down menu, as shown in Figure 21. Settings include $\mathrm{x}$-axis, which changes between a two curve plot of temperature and elongation as a function of time and a one curve plot with elongation as a function of temperature, and units, which allow the units of elongation to be changed.

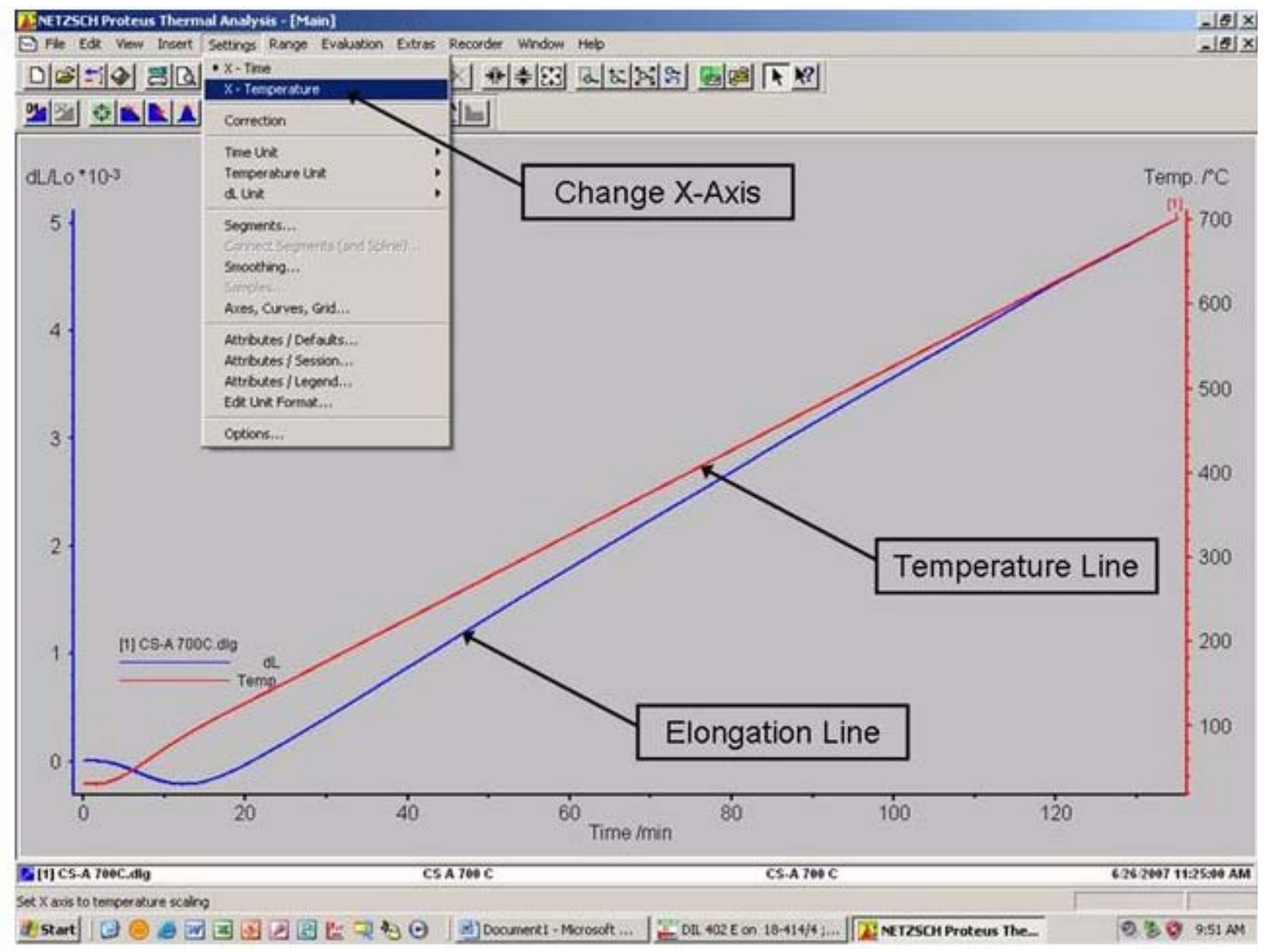

Figure 21. Settings drop down menu in Proteus used for changing plot parameters. 
Step 28: Right click on the elongation curve. Select correction on the menu that appears. A pop up screen (Figure 22) appears that contains correction types. Select sample holder for .clg (correction) files, this will correct for the sample holder expansion and allow the data to be compared to standards that may be opened using the file drop down menu by clicking import standards, and DIL, as seen in Figure 23. Select calibration for .dlg (sample + correction) files, this corrects for dilatometer component elongation and yields the true elongation characteristics of the sample material.

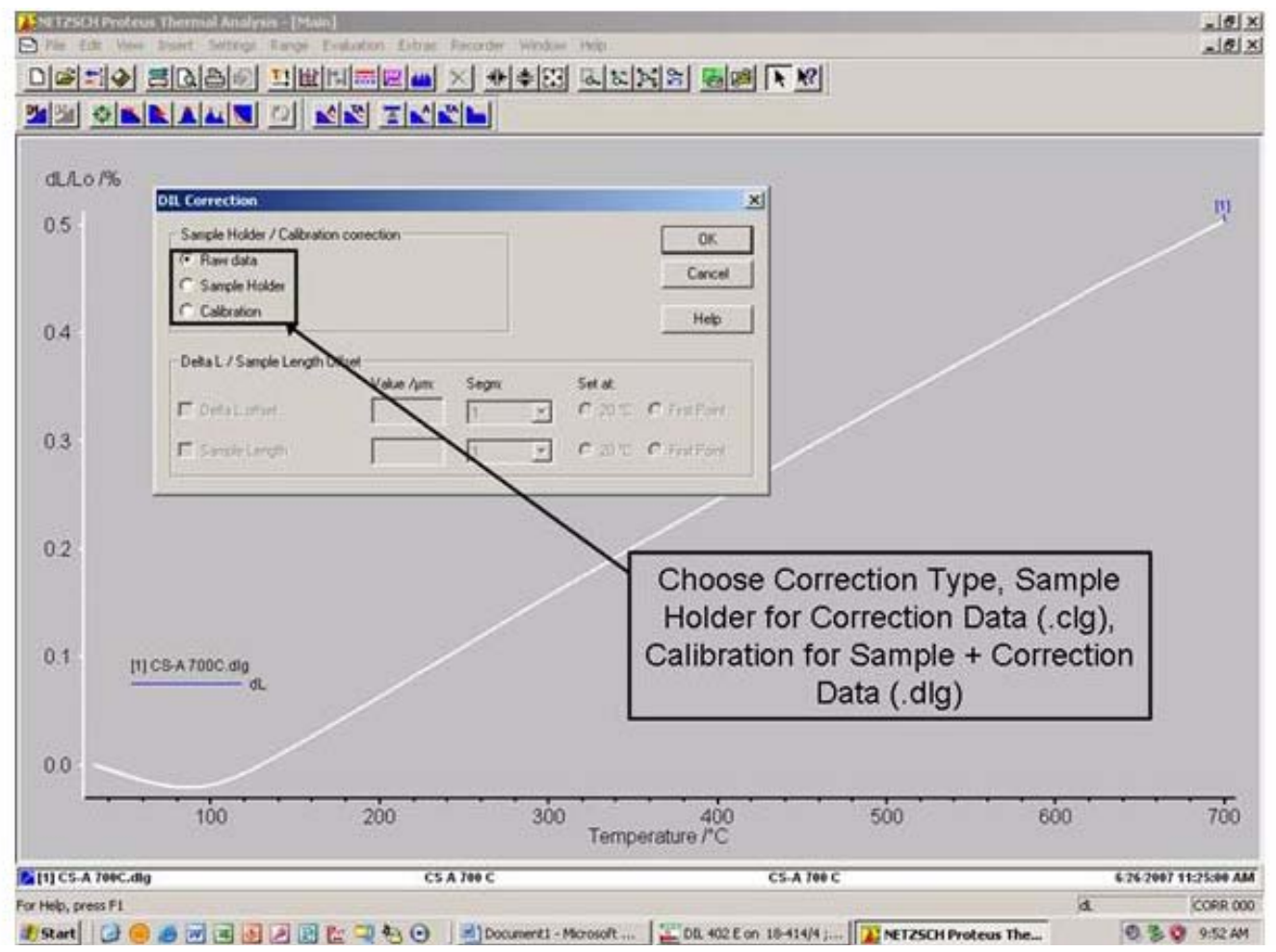

Figure 22. Correction selection window. 


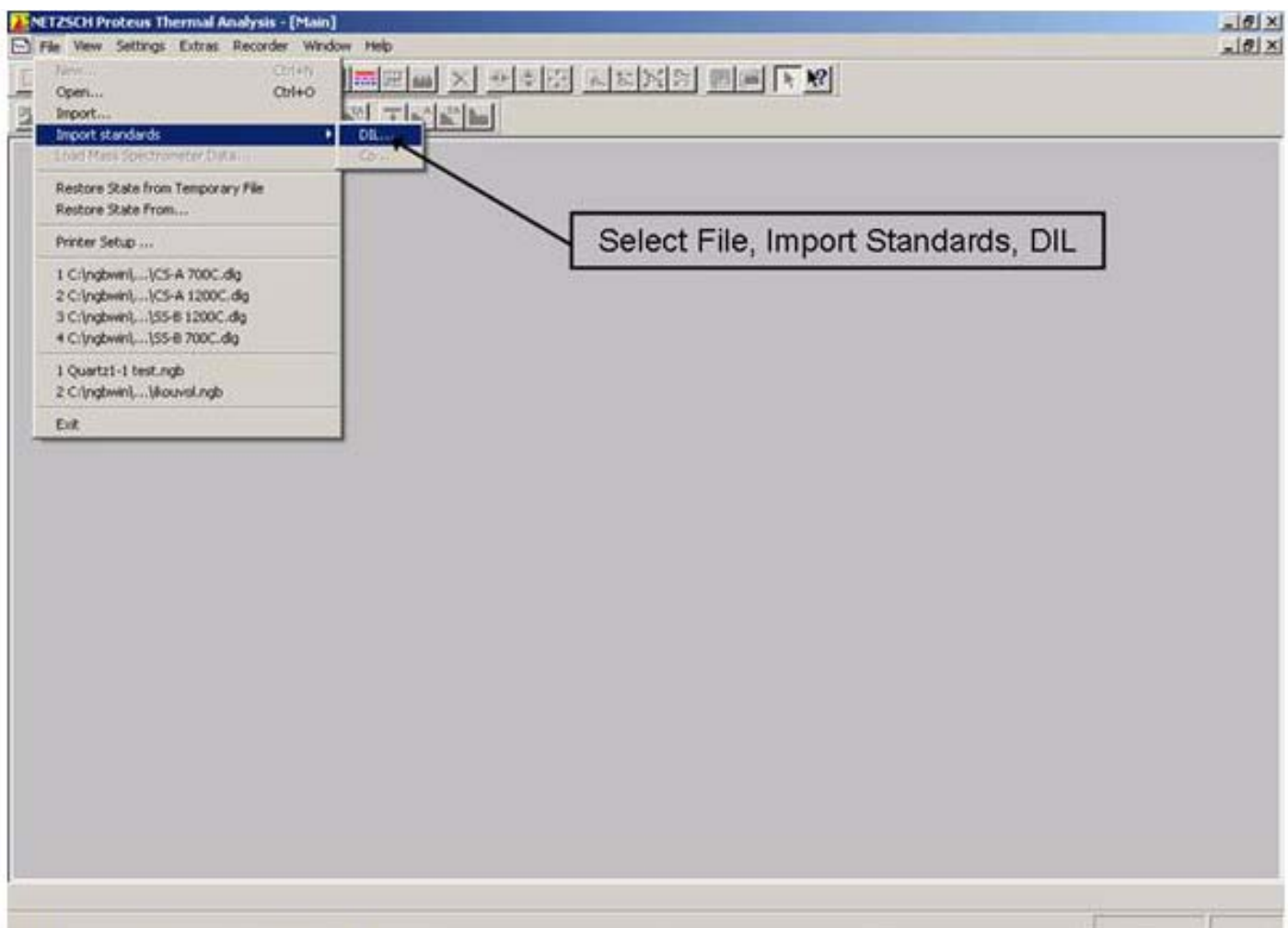

Figure 23. Opening standards for comparison.

Step 29: Export data using the extras drop down menu, and clicking export data. The screen will change (see Figure 24) to show export options such as data range, export parameters, and files. Select full range, all files, and set export parameters to a comma separated CSV file in ASCII format. This file type will be usable in Excel for data processing. Note, only temperature and time information for the curve that is highlighted will be exported. To export this information for other curves, each curve must be exported separately. When ready to export, click export. Next select file name and location. The file may now be opened and processed using Excel.

Steps 30 through 32 simply detail the shut down process used after a test has been run.

Step 30: Close all program windows.

Step 31: Remove the sample by reversing steps 8 through 12 . Only remove the sample after it has cooled sufficiently.

Step 32: Shut down the system by completing steps 1 through 5 in reverse order. 


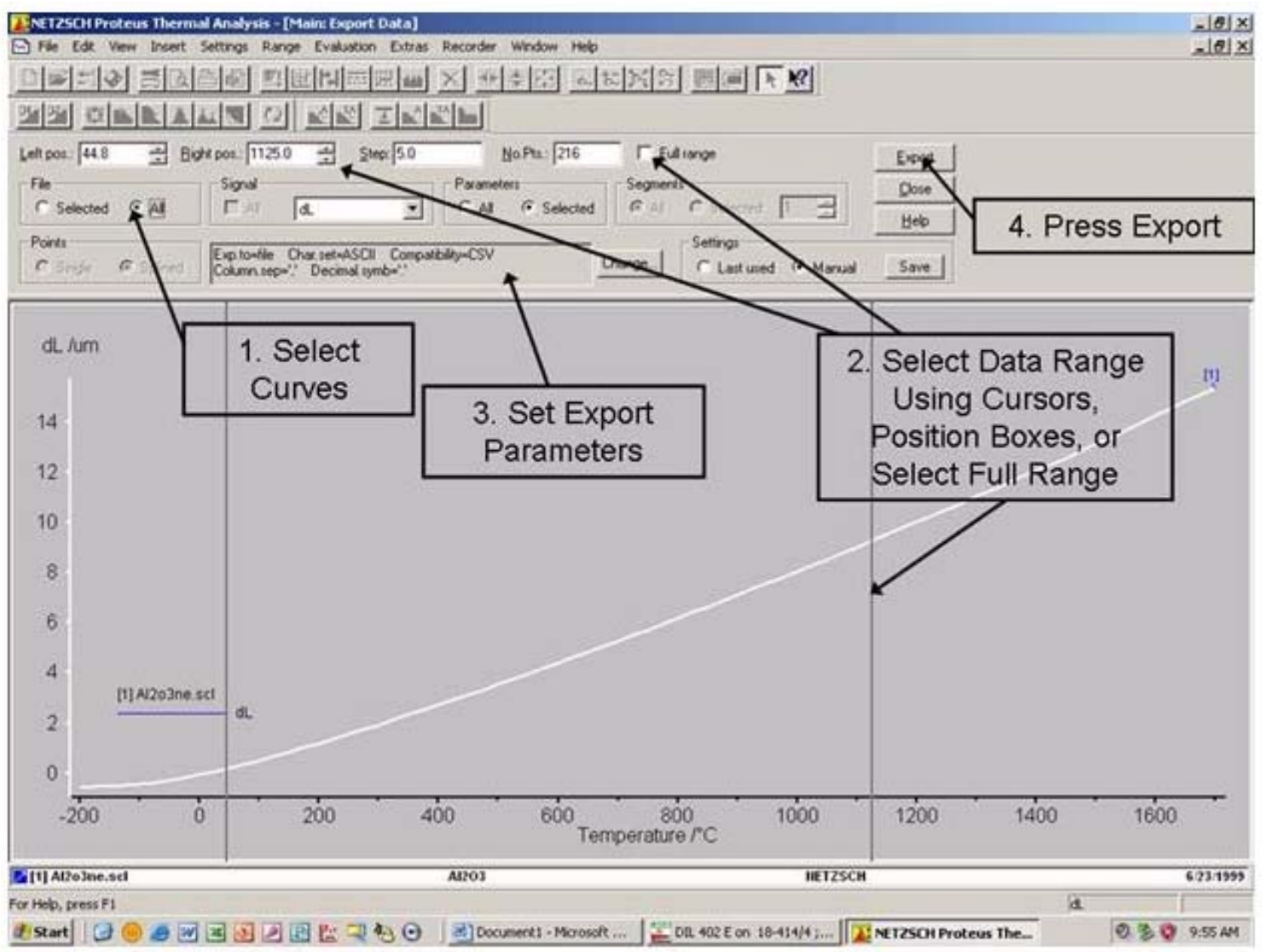

Figure 24. Export options.

\section{Validation}

All tests performed in the horizontal configuration are listed in Table 2 Alumina, quartz, and sapphire tests were used to demonstrate the validity of the measurement technique. This was accomplished by comparing results to values provided by Netzsch ${ }^{3}$ and Touloukian. ${ }^{4}$

The reference data provided by Netzsch includes expansion data for fused quartz glass, polycrystalline alumina, and sapphire (single crystal alumina.) As shown in Figures 25 and 26, the Netzch data closely matches data from Touloukian. ${ }^{4}$ Figure 25 shows the Netzsch data for alumina (aluminum oxide) plotted with Touloukian data for the same material. Figure 26 shows similar plots for quartz. The Netzsh and Touloukian data show close agreement. 
Table 2. Samples tested and tests performed in reference configuration.

\begin{tabular}{|c|c|c|c|c|c|c|c|c|}
\hline Sample & Designator & Test & $\begin{array}{l}\text { Calibration } \\
\text { Standard }\end{array}$ & Test Material & $\begin{array}{l}\text { Sample Base } \\
\text { Length }(\mathrm{mm})\end{array}$ & $\begin{array}{l}\text { End } \\
\text { Pieces }\end{array}$ & $\begin{array}{l}\text { Starting } \\
\text { Temp }\end{array}$ & Ending Temp \\
\hline \multirow{4}{*}{$\begin{array}{l}\text { Netzch } \\
\text { Alumina }\end{array}$} & Alumina Corr & Correction & Alumina & Alumina & 25 & No & $25^{\circ} \mathrm{C}$ & $1100^{\circ} \mathrm{C}$ \\
\hline & Alumina Test & Sample + Correction & Alumina & Alumina & 25 & No & $25^{\circ} \mathrm{C}$ & $1100^{\circ} \mathrm{C}$ \\
\hline & Alumina Corr EP & Correction & Alumina & Alumina & 25.21 & Yes & $29^{\circ} \mathrm{C}$ & $1100^{\circ} \mathrm{C}$ \\
\hline & Alumina Test EP & Sample + Correction & Alumina & Alumina & 25.21 & Yes & $29^{\circ} \mathrm{C}$ & $1100^{\circ} \mathrm{C}$ \\
\hline \multirow{4}{*}{$\begin{array}{l}\text { Netzch } \\
\text { Quartz }\end{array}$} & Quartz Corr & Correction & Quartz & Quartz & 25 & No & $23^{\circ} \mathrm{C}$ & $1000^{\circ} \mathrm{C}$ \\
\hline & Quartz Test & Sample + Correction & Quartz & Quartz & 25 & No & $23^{\circ} \mathrm{C}$ & $1000^{\circ} \mathrm{C}$ \\
\hline & Quartz Corr EP & Correction & Quartz & Quartz & 25.007 & Yes & $25^{\circ} \mathrm{C}$ & $1000^{\circ} \mathrm{C}$ \\
\hline & Quartz Test EP & Sample + Correction & Quartz & Quartz & 25.007 & Yes & $25^{\circ} \mathrm{C}$ & $1000^{\circ} \mathrm{C}$ \\
\hline \multirow{4}{*}{$\begin{array}{l}\text { Netzch } \\
\text { Sapphire }\end{array}$} & Sapphire Corr & Correction & Sapphire & Sapphire & 20.002 & No & $24.3^{\circ} \mathrm{C}$ & $1100^{\circ} \mathrm{C}$ \\
\hline & Sapphire Test & Sample + Correction & Sapphire & Sapphire & 20.002 & No & $24.3^{\circ} \mathrm{C}$ & $1100^{\circ} \mathrm{C}$ \\
\hline & Sapphire Corr EP & Correction & Sapphire & Sapphire & 20.002 & Yes & $24^{\circ} \mathrm{C}$ & $1100^{\circ} \mathrm{C}$ \\
\hline & Sapphire Test EP & Sample + Correction & Sapphire & Sapphire & 20.002 & Yes & $24^{\circ} \mathrm{C}$ & $1100^{\circ} \mathrm{C}$ \\
\hline \multirow{4}{*}{ CSA } & CS A 700 Corr & Correction & Alumina & Alumina & 25.004 & Yes & $25^{\circ} \mathrm{C}$ & $700^{\circ} \mathrm{C}$ \\
\hline & CS A 700 Test & Sample + Correction & Alumina & Carbon Steel & 25.42 & Yes & $25^{\circ} \mathrm{C}$ & $700^{\circ} \mathrm{C}$ \\
\hline & CS A 1200 Corr & Correction & Alumina & Alumina & 25.004 & Yes & $24.4^{\circ} \mathrm{C}$ & $1200^{\circ} \mathrm{C}$ \\
\hline & CS A 1200 Test & Sample + Correction & Alumina & Carbon Steel & 25.004 & Yes & $24.4^{\circ} \mathrm{C}$ & $1200^{\circ} \mathrm{C}$ \\
\hline \multirow{4}{*}{ CS B } & CS B 700 Corr & Correction & Alumina & Alumina & 25.01 & Yes & $25^{\circ} \mathrm{C}$ & $700^{\circ} \mathrm{C}$ \\
\hline & CS B 700 Test & Sample + Correction & Alumina & Carbon Steel & 25.423 & Yes & $25^{\circ} \mathrm{C}$ & $700^{\circ} \mathrm{C}$ \\
\hline & CS B 1200 Corr & Correction & Alumina & Alumina & 25.001 & Yes & $40^{\circ} \mathrm{C}$ & $1200^{\circ} \mathrm{C}$ \\
\hline & CS B 1200 Test & Sample + Correction & Alumina & Carbon Steel & 25.415 & Yes & $40^{\circ} \mathrm{C}$ & $1200^{\circ} \mathrm{C}$ \\
\hline \multirow{4}{*}{ CS C } & CS C 700 Corr & Correction & Alumina & Alumina & 25.005 & Yes & $25^{\circ} \mathrm{C}$ & $700^{\circ} \mathrm{C}$ \\
\hline & CS C 700 Test & Sample + Correction & Alumina & Carbon Steel & 25.396 & Yes & $25^{\circ} \mathrm{C}$ & $700^{\circ} \mathrm{C}$ \\
\hline & CS C 1200 Corr & Correction & Alumina & Alumina & 25.005 & Yes & $25^{\circ} \mathrm{C}$ & $1200^{\circ} \mathrm{C}$ \\
\hline & CS C 1200 Test & Sample + Correction & Alumina & Carbon Steel & 25.398 & Yes & $25^{\circ} \mathrm{C}$ & $1200^{\circ} \mathrm{C}$ \\
\hline \multirow{4}{*}{ SS A } & SS A 700 Corr & Correction & Alumina & Alumina & 25.008 & Yes & $29^{\circ} \mathrm{C}$ & $700^{\circ} \mathrm{C}$ \\
\hline & SS A 700 Test & Sample + Correction & Alumina & Stainless Steel & 25.416 & Yes & $29^{\circ} \mathrm{C}$ & $700^{\circ} \mathrm{C}$ \\
\hline & SS A 1200 Corr & Correction & Alumina & Alumina & 25.004 & Yes & $30^{\circ} \mathrm{C}$ & $1200^{\circ} \mathrm{C}$ \\
\hline & SS A 1200 Test & Sample + Correction & Alumina & Stainless Steel & 25.41 & Yes & $30^{\circ} \mathrm{C}$ & $1200^{\circ} \mathrm{C}$ \\
\hline \multirow{4}{*}{ SS B } & SS B 700 Corr & Correction & Alumina & Alumina & 25 & Yes & $27^{\circ} \mathrm{C}$ & $700^{\circ} \mathrm{C}$ \\
\hline & SS B 700 Test & Sample + Correction & Alumina & Stainless Steel & 25.439 & Yes & $27^{\circ} \mathrm{C}$ & $700^{\circ} \mathrm{C}$ \\
\hline & SS B 1200 Corr & Correction & Alumina & Alumina & 25.001 & Yes & $25^{\circ} \mathrm{C}$ & $1200^{\circ} \mathrm{C}$ \\
\hline & SS B 1200 Test & Sample + Correction & Alumina & Stainless Steel & 25.432 & Yes & $25^{\circ} \mathrm{C}$ & $1200^{\circ} \mathrm{C}$ \\
\hline
\end{tabular}




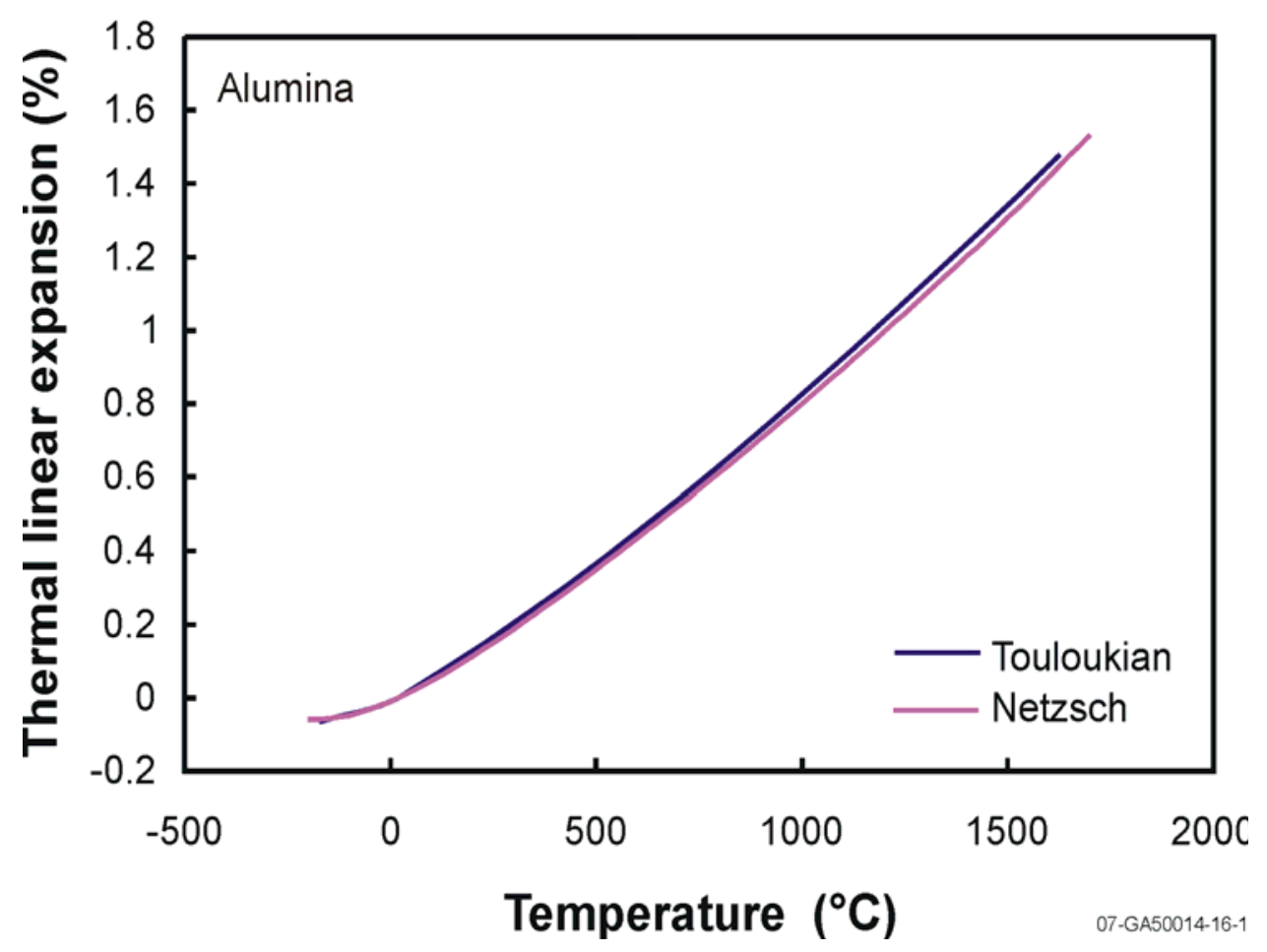

Figure 25. Netzsch and Touloukian alumina data.

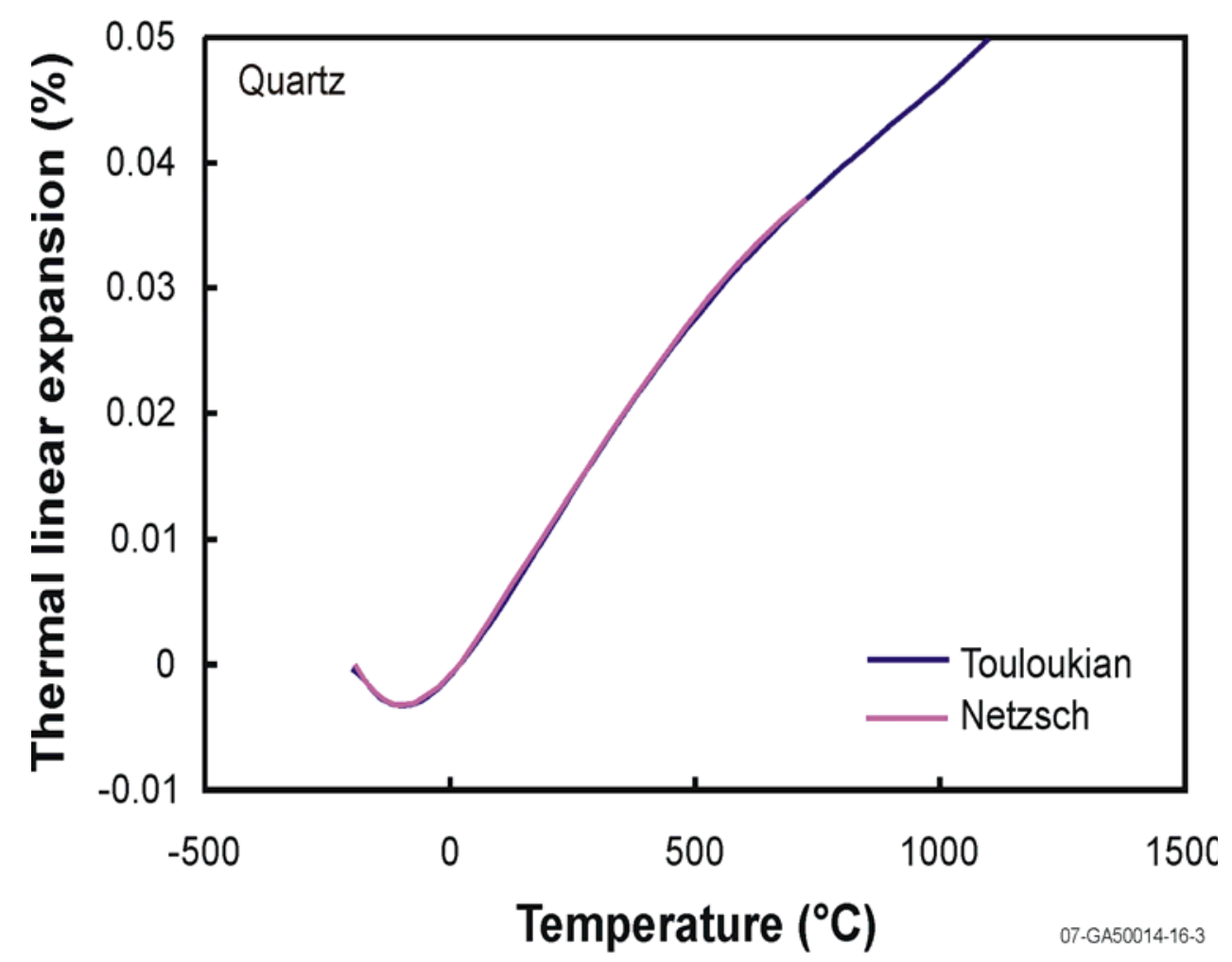

Figure 26. Netzsch and Touloukian quartz data. 
Initial results performed on test samples provided by Netzch are shown in Figures 27 through 29. Figure 27 shows the alumina test sample data collected at the HTTL plotted with the reference data provided by Netzsch. The curve labeled 'Alumina' consists of data recorded for thermal expansion of a standard sample provided by Netzsch. The curve labeled 'Alumina EP' contains data recorded for the same standard with alumina end-pieces on each end. The curve labeled 'Netzsch Alumina' is standard data provided by Netzsch. Data in all three curves match very closely. Because the Netzsch and Touloukian data also match closely, the HTTL data also matches Touloukian. The plot also shows data for the alumina sample tested with alumina end pieces in place. The consistency in the data shows that the dilatometer software accurately compensates for the presence of the end pieces. Figure 28 shows HTTL data for quartz glass with and without end pieces plotted with data from Netzsch. The quartz data also match very closely (note that the scale of elongation differences are magnified compared to other tested materials). Because the Netzsch and Touloukian data also match closely, the HTTL data also matches Touloukian. Figure 29 shows HTTL data for sapphire with and without end pieces plotted with Netzsch data. These curves indicate that the sapphire data also match closely.

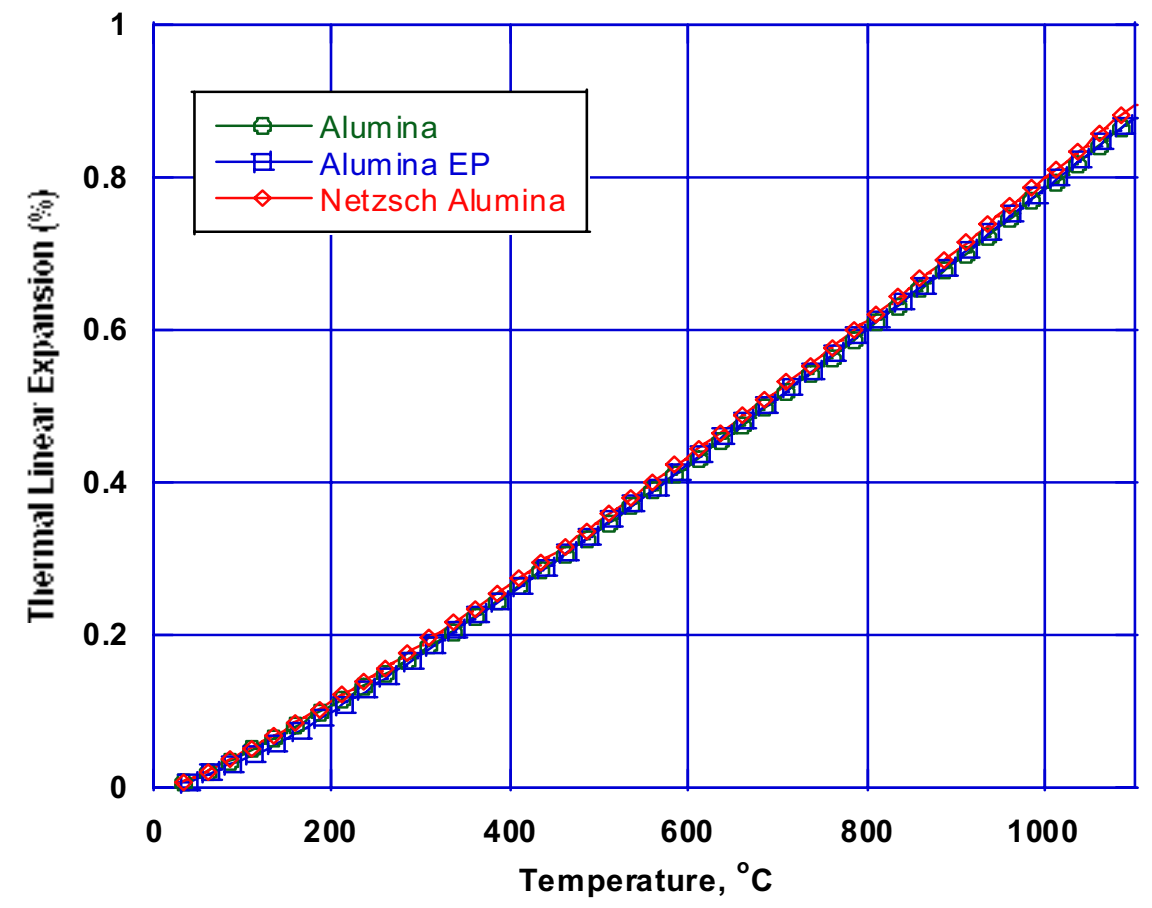

Figure 27. HTTL and Netzsch data for alumina thermal expansion. 


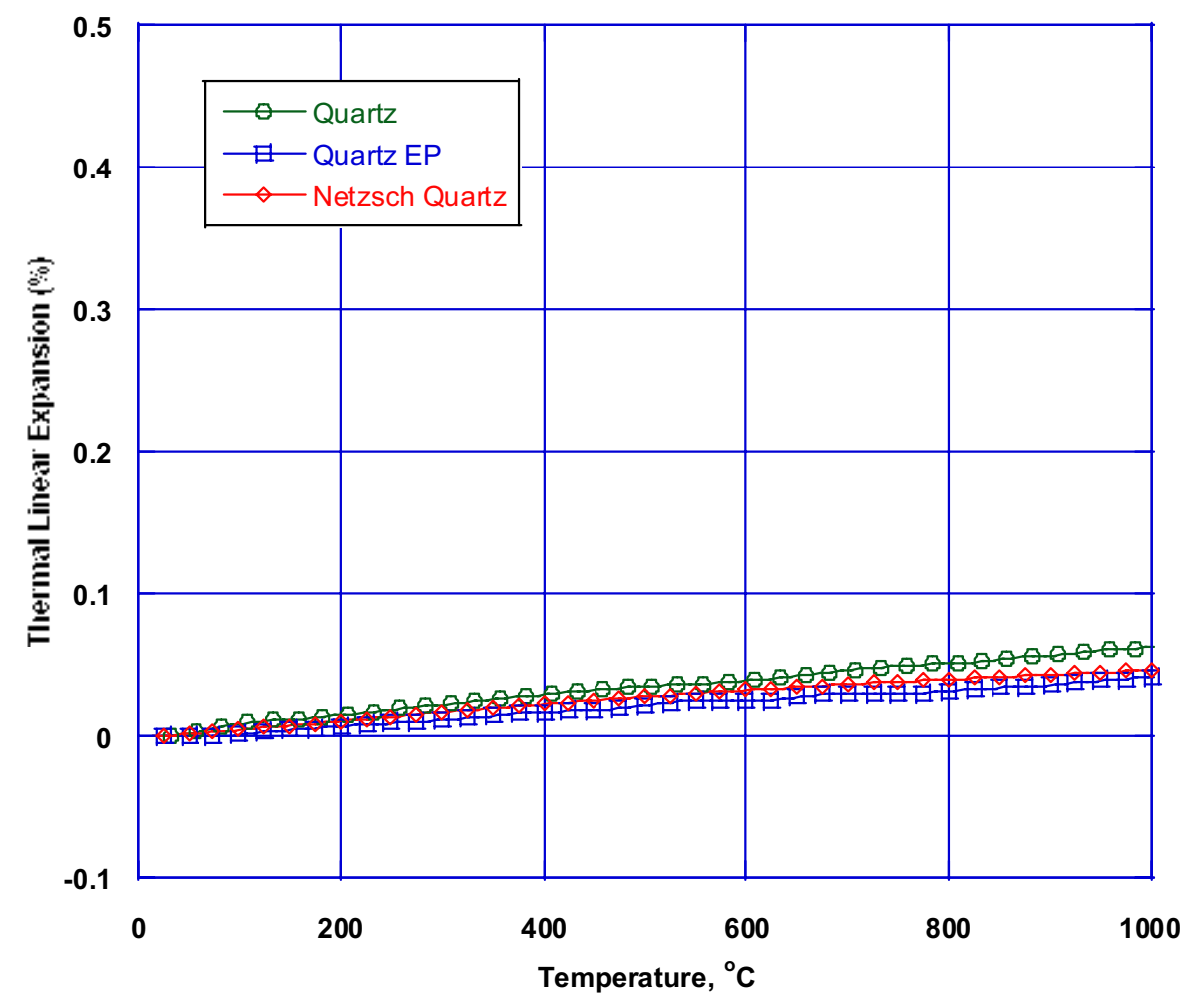

Figure 28. HTTL and Netzsch data for quartz glass thermal expansion.

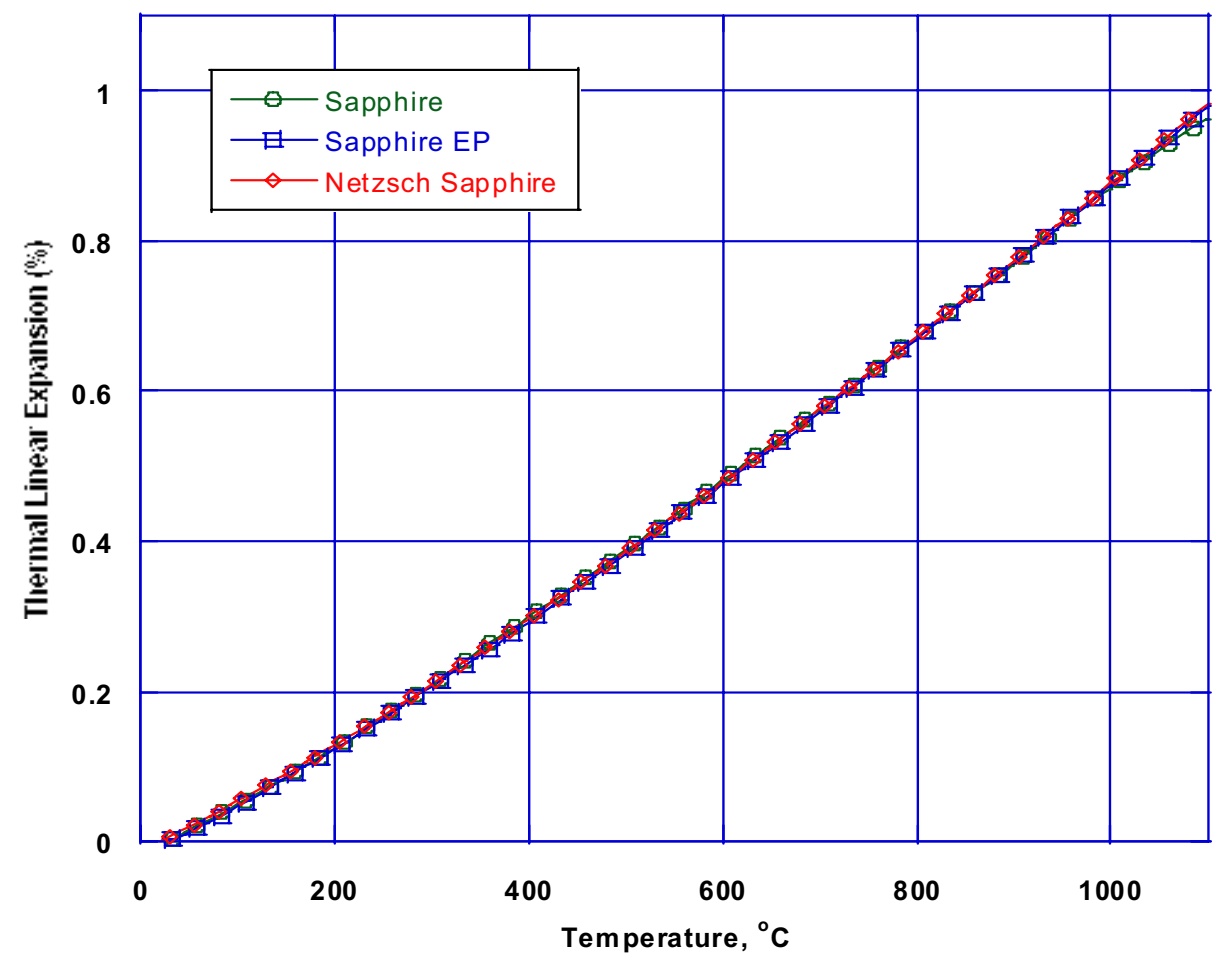

Figure 29. HTTL and Netzsch data for sapphire thermal expansion. 


\section{High Temperature Steel Data}

As discussed in Section 1, the second objective of this effort was to obtain high temperature data for steels used in Light Water Reactors (LWRs). Specifically, data were obtained for SA533 Grade B Class 1 (SA533B1) low alloy steel, which is used to fabricate most US LWR reactor vessels, and Type 304 Stainless Steel (SS304), which is used in LWR vessel piping, penetration tubes, and internal structures.

Melt relocation and vessel failure impacts the subsequent progression and associated consequences of a Light Water Reactor (LWR) accident. Hence, it is important to accurately predict the heatup and relocation of materials within the reactor vessel and heat transfer to and from the reactor vessel. However, a review of vessel and structural steel material properties used to predict such phenomena in severe accident analysis codes, such as SCDAP/RELAP5, ${ }^{5}$ MELCOR ${ }^{6}$ and MAAP, ${ }^{7}$ reveals that the required high temperature material properties are extrapolated with little, if any, data above $700{ }^{\circ} \mathrm{C}$. To reduce uncertainties in predictions relying upon this extrapolated high temperature thermal expansion coefficient data, INL recently obtained high temperature thermal diffusivity data for SA533B1 and SS304. ${ }^{8}$ This section documents INL efforts to obtain high temperature thermal expansion coefficient data for these steels using the Netzsch DIL 402 ES dilatometer measurement system.

\subsection{Existing Data}

Prior to obtaining new high temperature data, existing thermal expansion data for the SA533B1 and SS304 materials were reviewed, so that new data could be compared with data available in the literature. Figure 30 compares data from Touloukian and MATPRO ${ }^{5}$ for 304 stainless steel elongation. As seen in this figure, values differ as temperatures exceed $227^{\circ} \mathrm{C}$. Also, data are extrapolated at higher temperatures, above about $537^{\circ} \mathrm{C}$ for Touloukian and $690^{\circ} \mathrm{C}$ for MATPRO. Figure 31 contains curves based on material property data found in MATPRO for SA533B1 vessel steel. MATPRO SA533B1 data are based on information from Spanner, et al. ${ }^{9}$ As seen in Figure 31, data were only obtained below the transition temperature of $727^{\circ} \mathrm{C}$, which is the temperature where this material starts to experience a transformation (from ferritic to austenitic steel) ${ }^{10}$ 


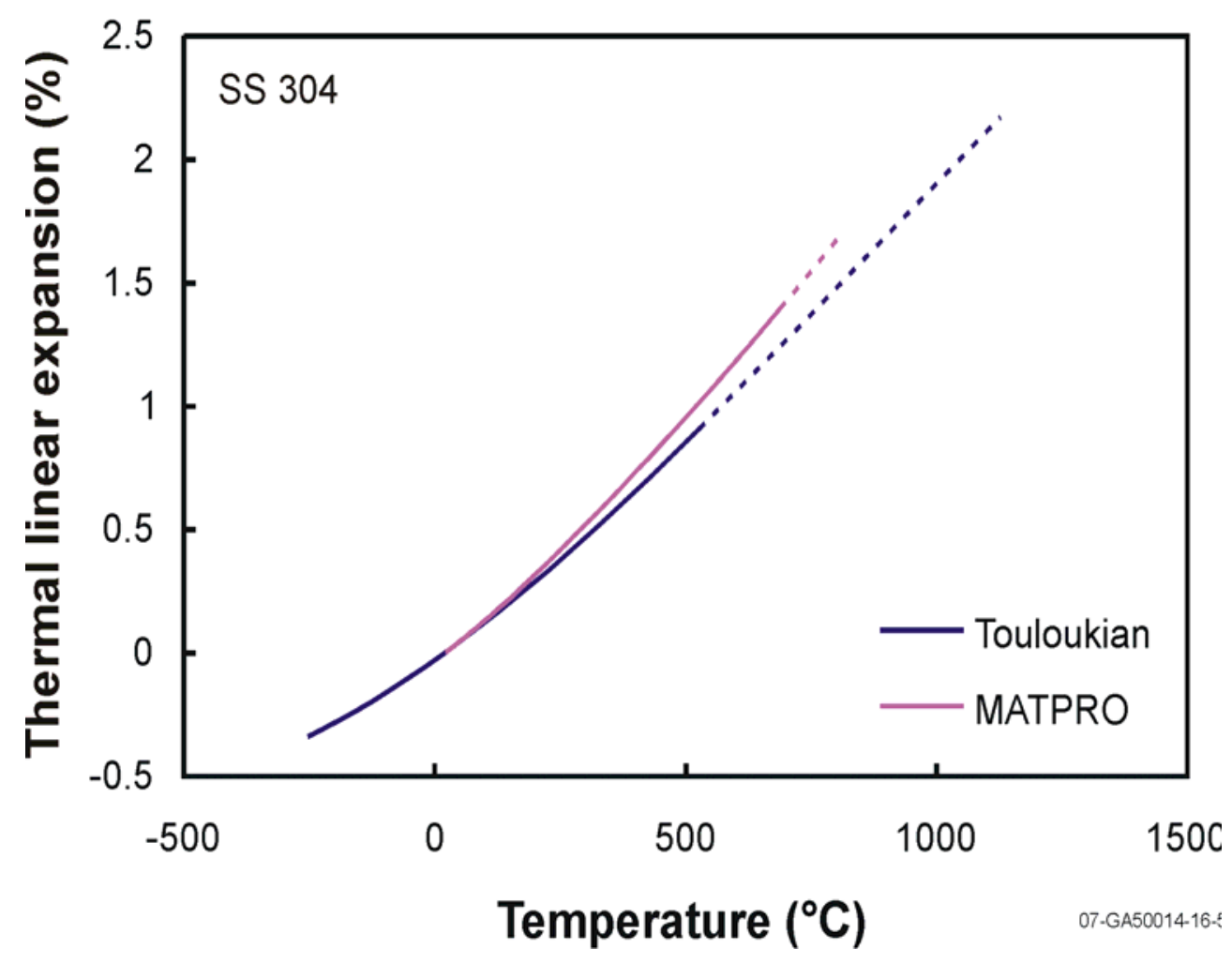

Figure 30. Touloukian and MATPRO thermal elongation data for 304 stainless steel.

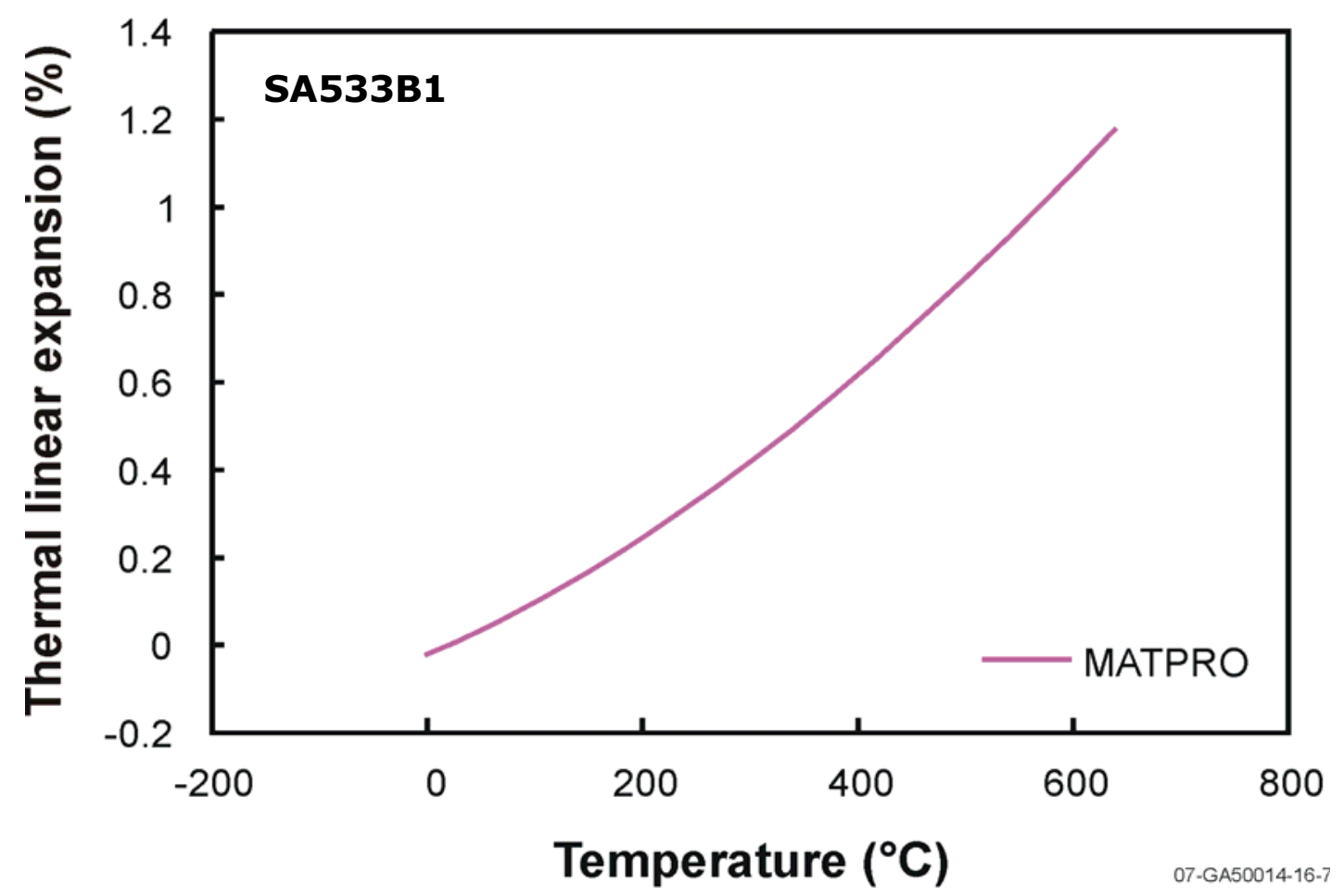

Figure 31. MATPRO data for thermal elongation of low alloy steel. 


\subsection{Low Alloy Steel}

Figure 32 shows test results for a sample of Low Alloy Steel, designated SA-A. This sample was tested in two cycles, one up to $700{ }^{\circ} \mathrm{C}$ and one up to $1200{ }^{\circ} \mathrm{C}$. Before each test cycle, the dilatometer was calibrated using the Netzsch alumina standard. The data closely match for the overlapping range. There is a significant drop through the transition phase between about $750{ }^{\circ} \mathrm{C}$ and $850^{\circ} \mathrm{C}$.

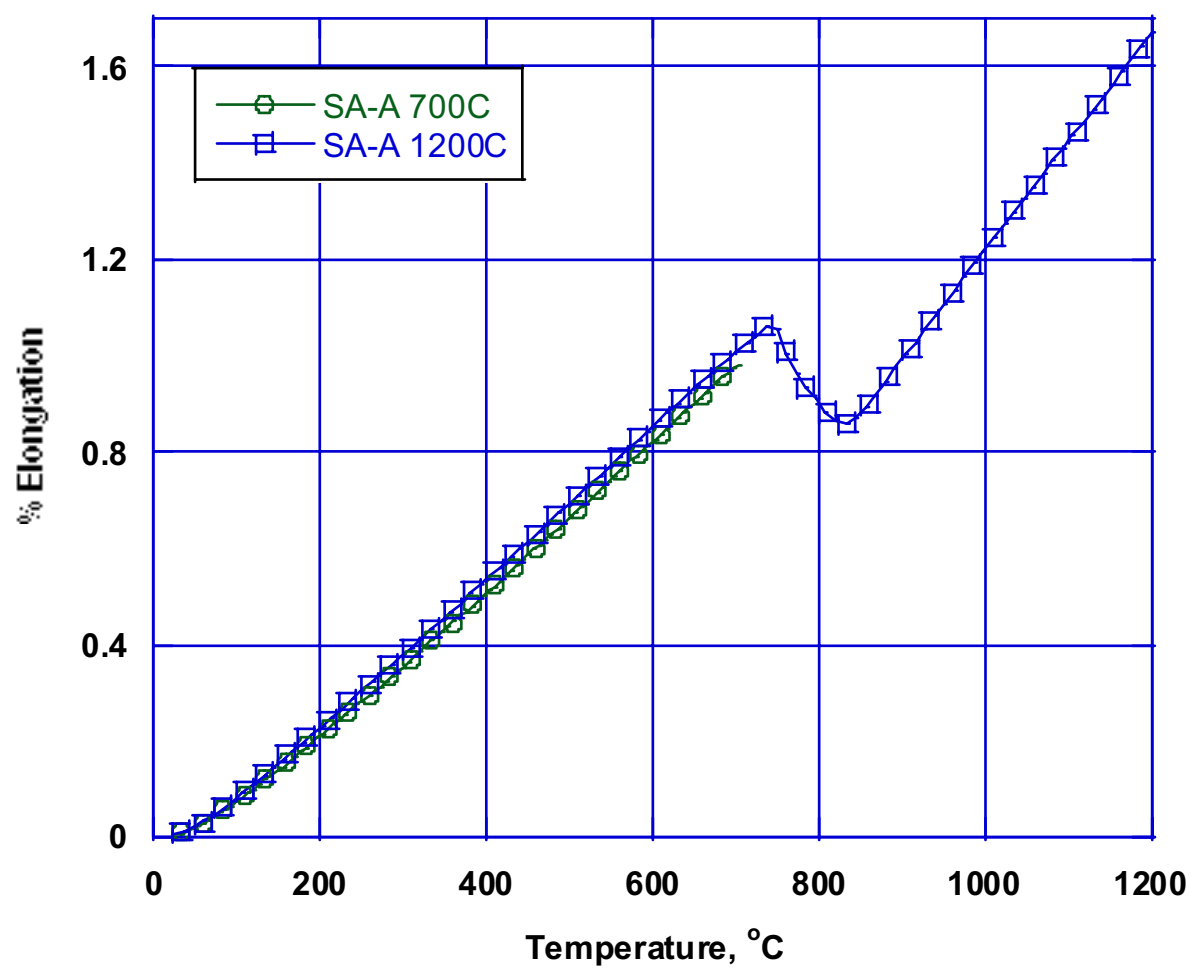

Figure 32. HTTL data for thermal expansion of low alloy steel sample SA-A.

Figure 33 shows data collected to $700{ }^{\circ} \mathrm{C}$ for three low alloy steel samples (SA-A, SA-B, and SA-C). There is some divergence at higher temperatures. Although all of the tests were conducted in argon (see Section 1.3), it is suspected that these differences may be due to different levels of oxidation or decarburization that occurred in the samples during these initial tests. Figure 34 shows data for the same samples collected to $1200^{\circ} \mathrm{C}$. Data from these samples agree well. Reduced levels of oxidation were observed on the samples after heating to $1200^{\circ} \mathrm{C}$. The oxidation seen in the samples could be due incomplete purging of the test chamber, impurity in the argon flow (possibly from leaking), or back-flow into the chamber due to low argon flow rate.After two test cycles, the outer surfaces of the three samples appeared different (Figure 35): sample SA-A became blue, sample SA-B appeared a dull gray color with some flaking; and SA-C became dull gray with no flaking. 


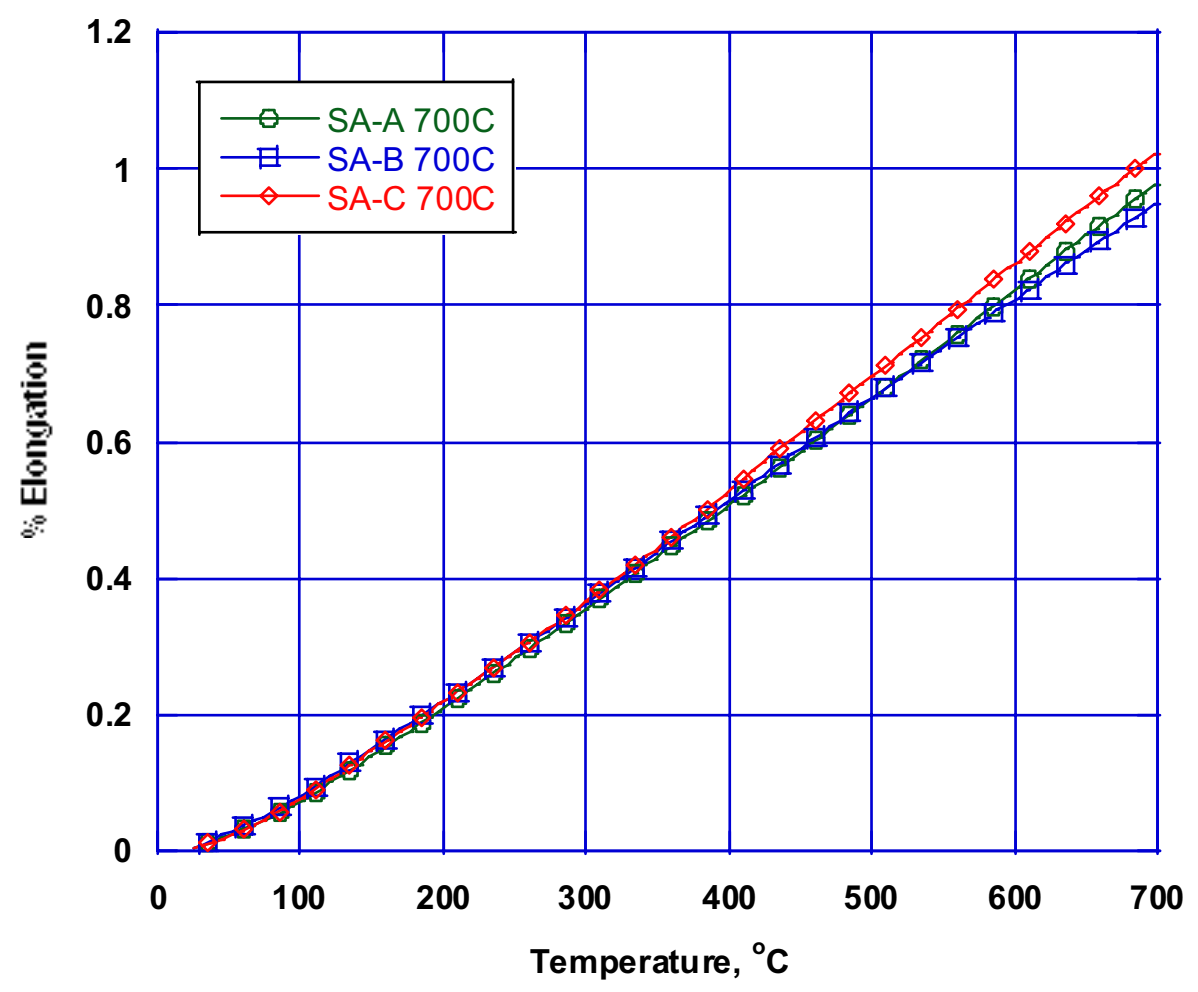

Figure 33. Expansion results for low alloy steel up to $700{ }^{\circ} \mathrm{C}$.

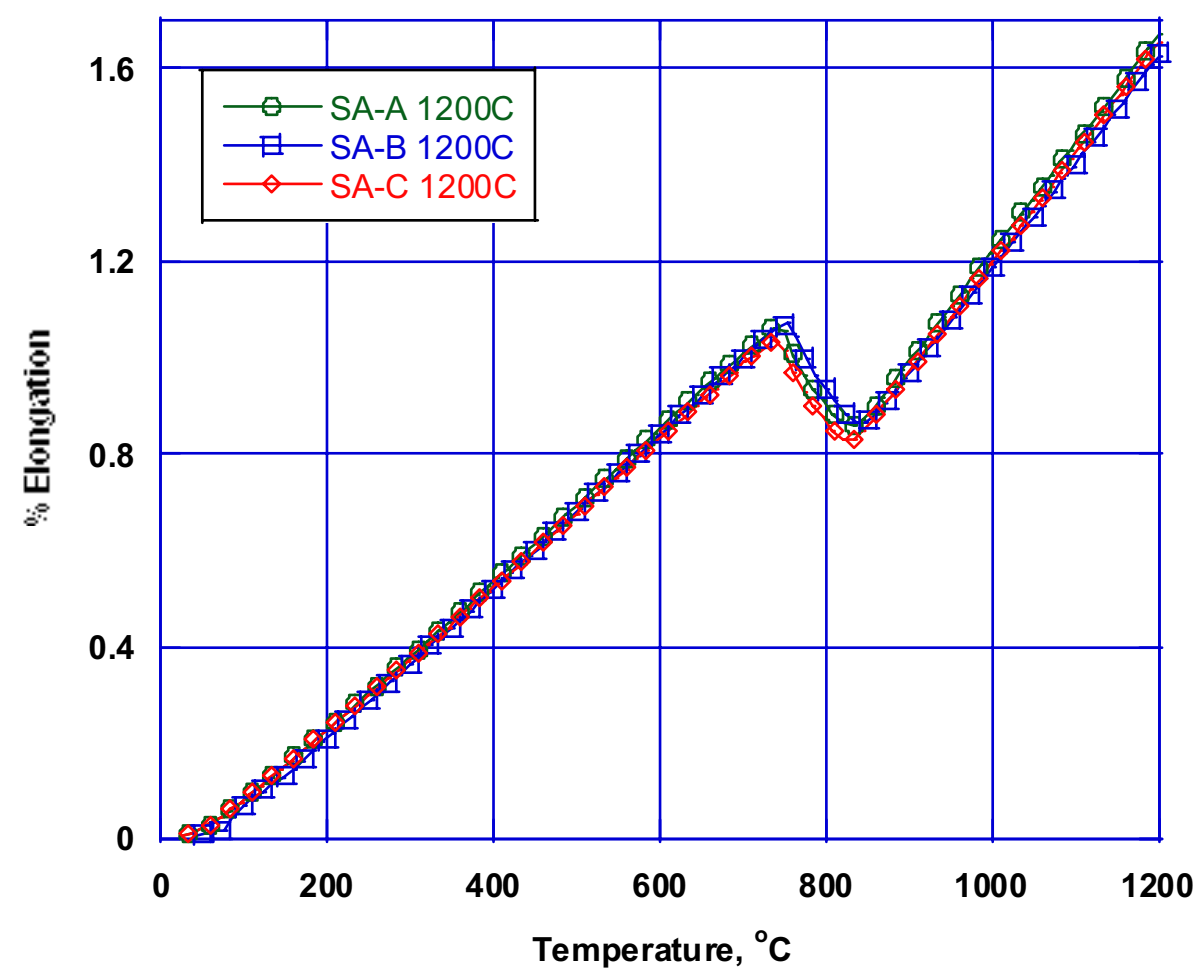

Figure 34. Expansion results for low alloy steel up to $1200^{\circ} \mathrm{C}$. 


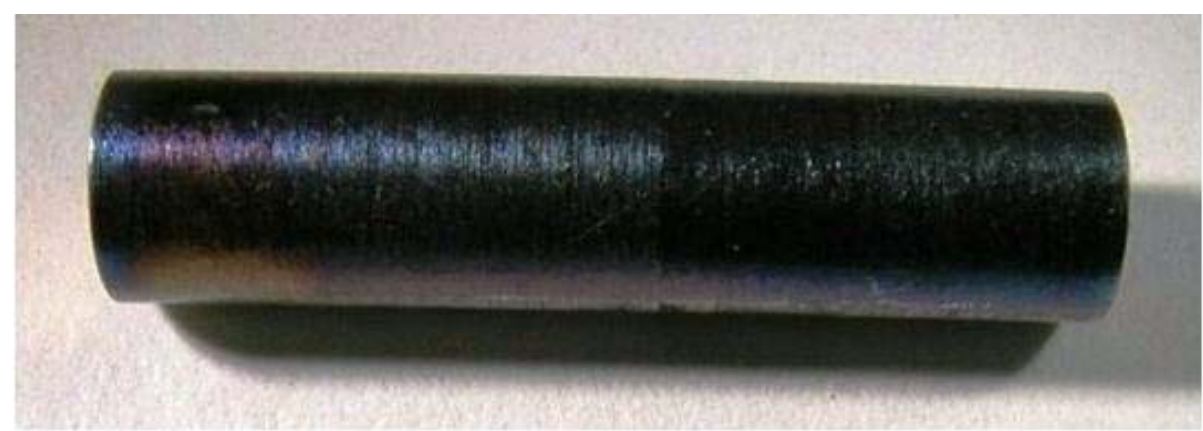

SA-A

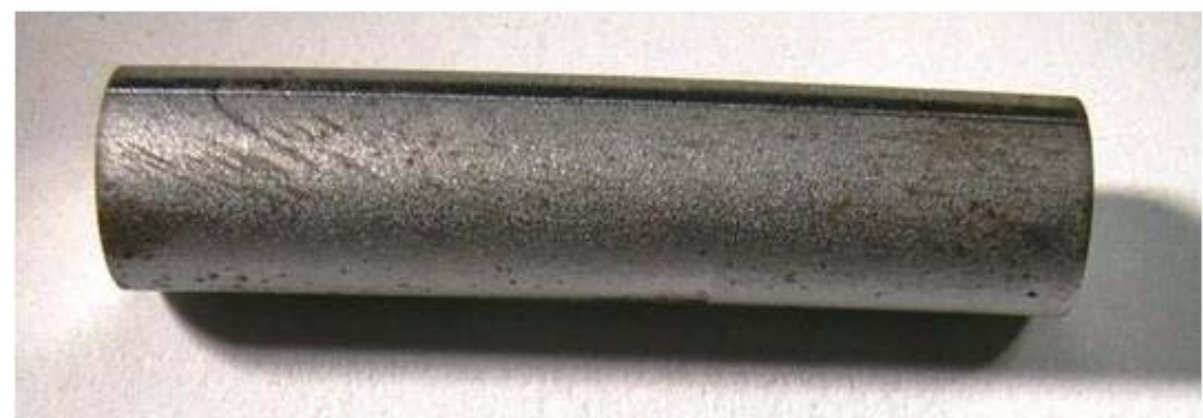

SA-B

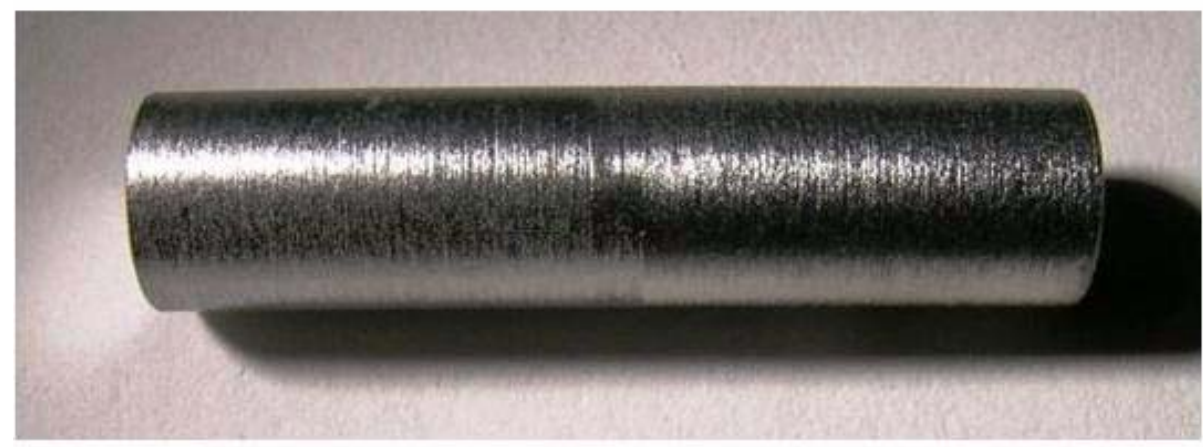

SA-C

Figure 35. Low alloy steel samples after two test cycles.

Figure 36 compares the average of the newly obtained low alloy steel data with values in MATPRO. As shown in this figure, values from the new data are lower than values reported in MATPRO. 


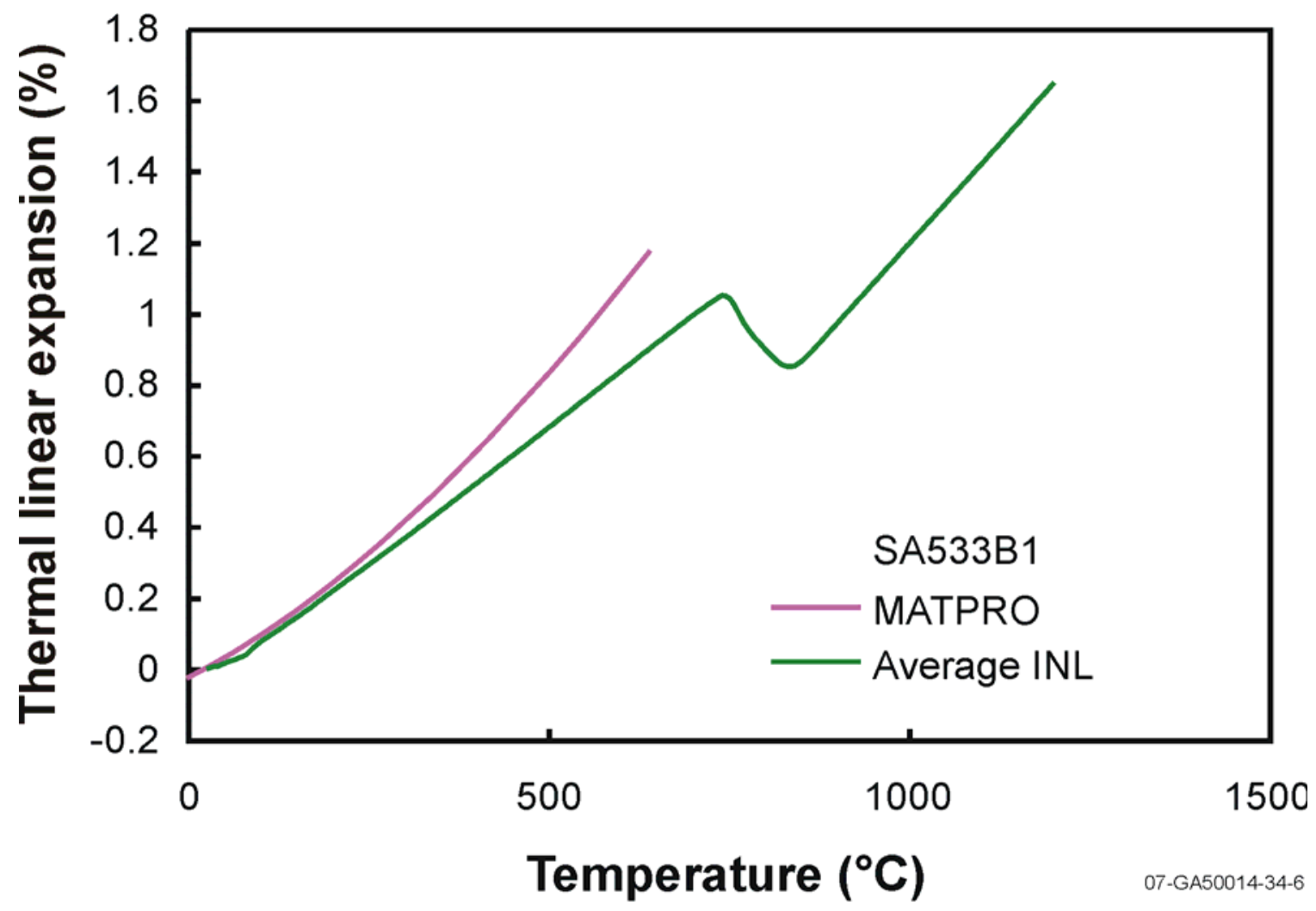

Figure 36. Comparison of new low alloy steel (SA 533 B1) data with values in MATPRO.

\subsection{Stainless Steel 304}

Figure 37 shows results for a SS304 sample (SS-A) heated to $700{ }^{\circ} \mathrm{C}$. Two features are notable about this data when compared to that of low alloy steel. First, as anticipated, there is no decrease in thermal expansion due to a transition phase. Second, the stainless steel expands to a greater degree than the low alloy steel. 


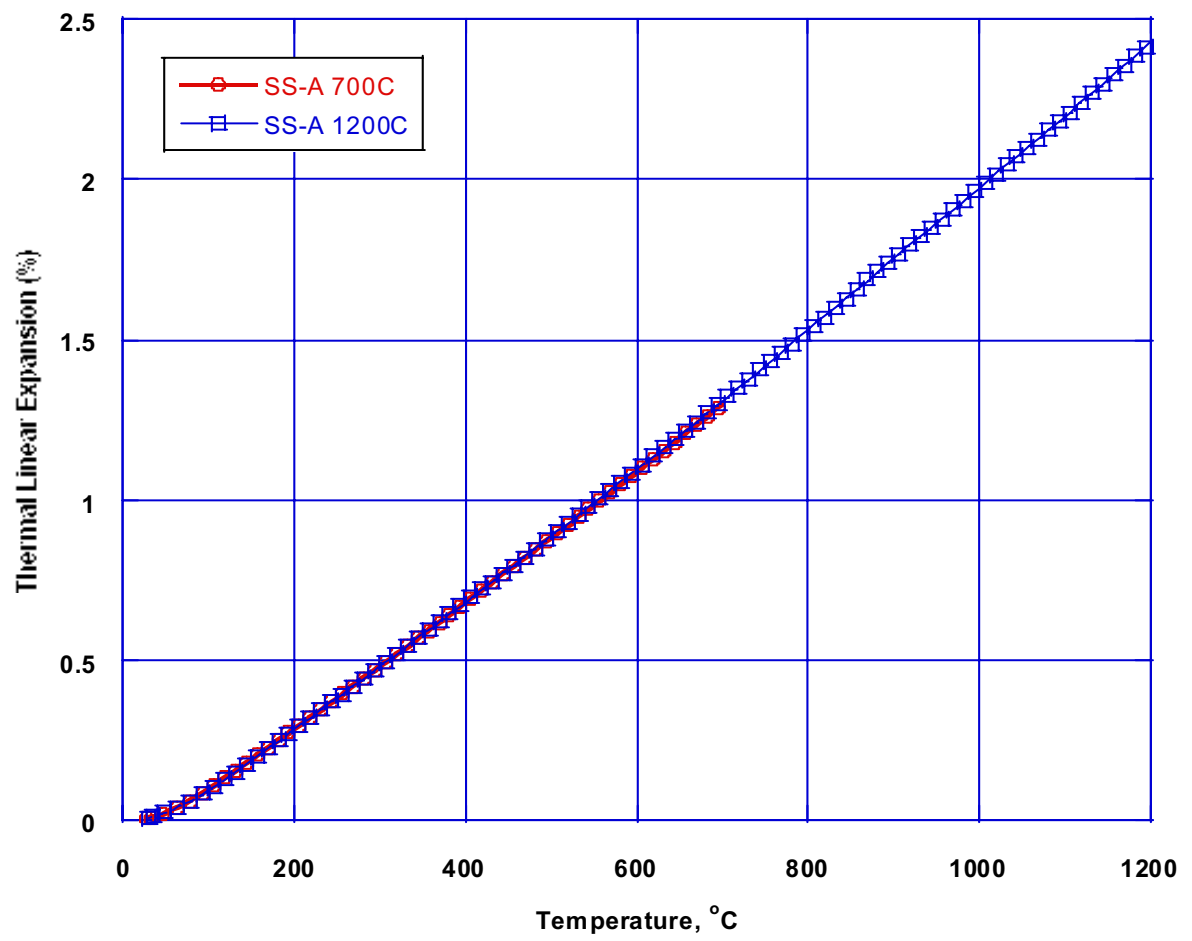

Figure 37. HTTL data for thermal expansion of stainless steel sample SS-A.

Figure 38 shows data collected to $700^{\circ} \mathrm{C}$ for two stainless steel samples (SS-A and SSB.). The data for the two samples are very consistent. No oxidation was observed on the outer surfaces of these samples after heating to $700^{\circ} \mathrm{C}$. Figure 39 shows data for the same samples collected to $1200{ }^{\circ} \mathrm{C}$. Again, both samples show consistent results. The stainless samples were notably discolored after heating to $1200{ }^{\circ} \mathrm{C}$. Sample SS-A was left with a dull green surface, while SS-B was a dull black. The stainless steel samples are shown, after two test cycles, in Figure 40. 


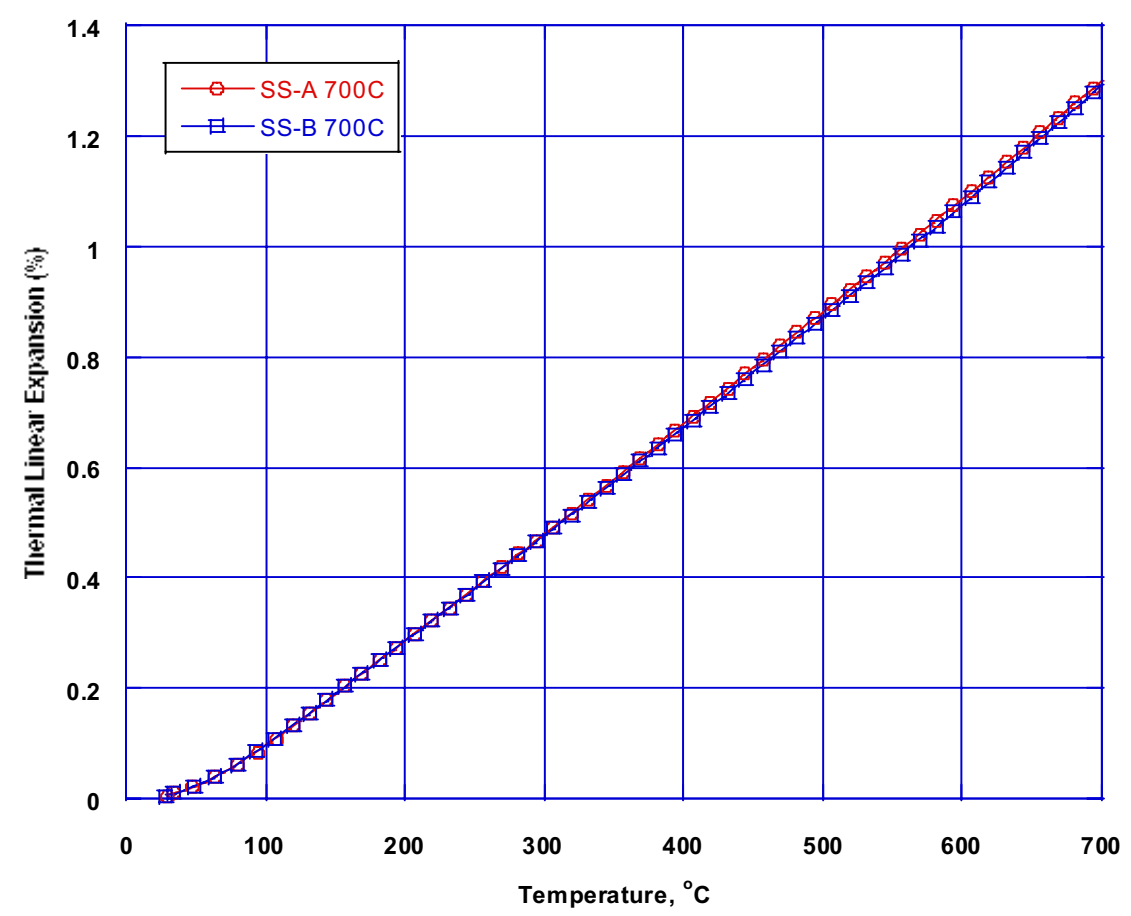

Figure 38. Expansion results for stainless steel up to $700{ }^{\circ} \mathrm{C}$.

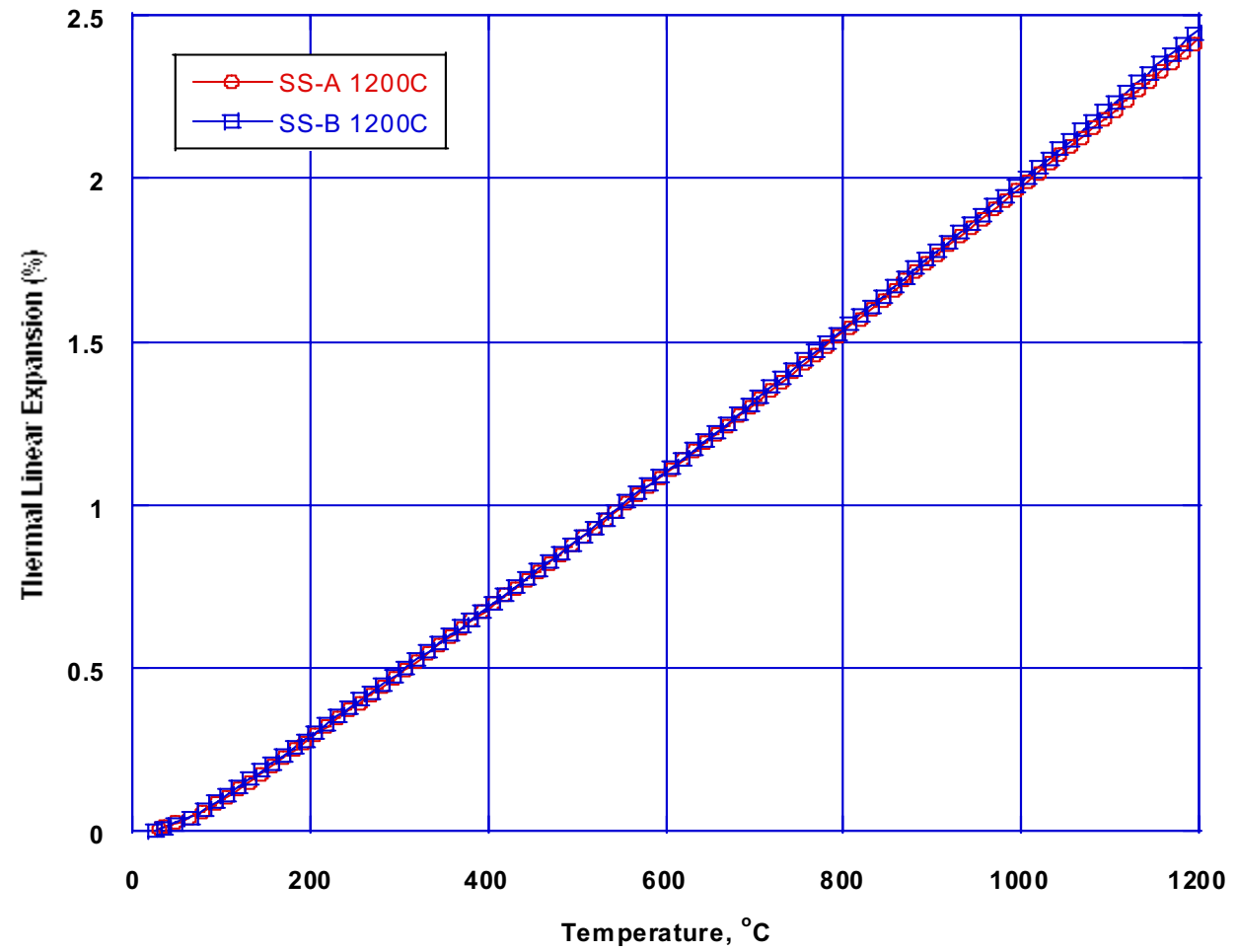

Figure 39. Expansion results for stainless steel up to $1200{ }^{\circ} \mathrm{C}$. 


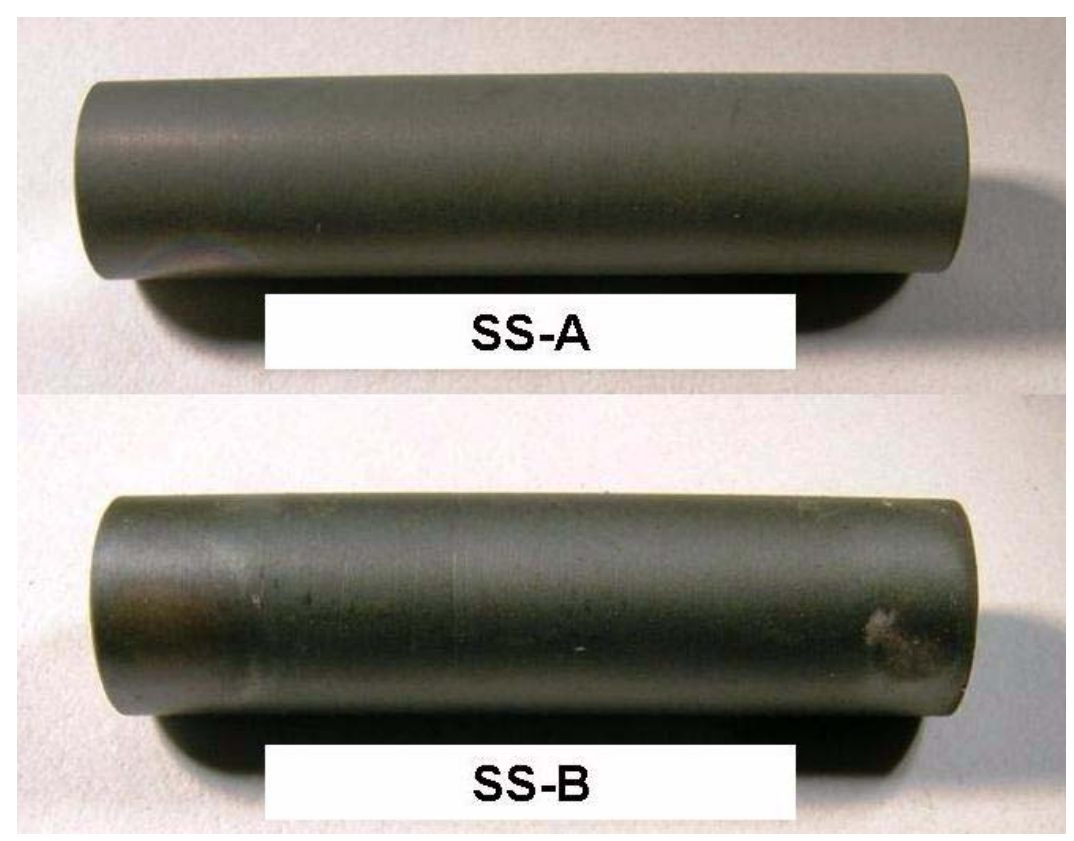

Figure 40. Stainless steel samples after two test cycles.

Figure 41 compares newly obtained stainless steel data with values found in Touloukian and MATPRO. As shown in this figure, the new data are consistent with values published in these references.

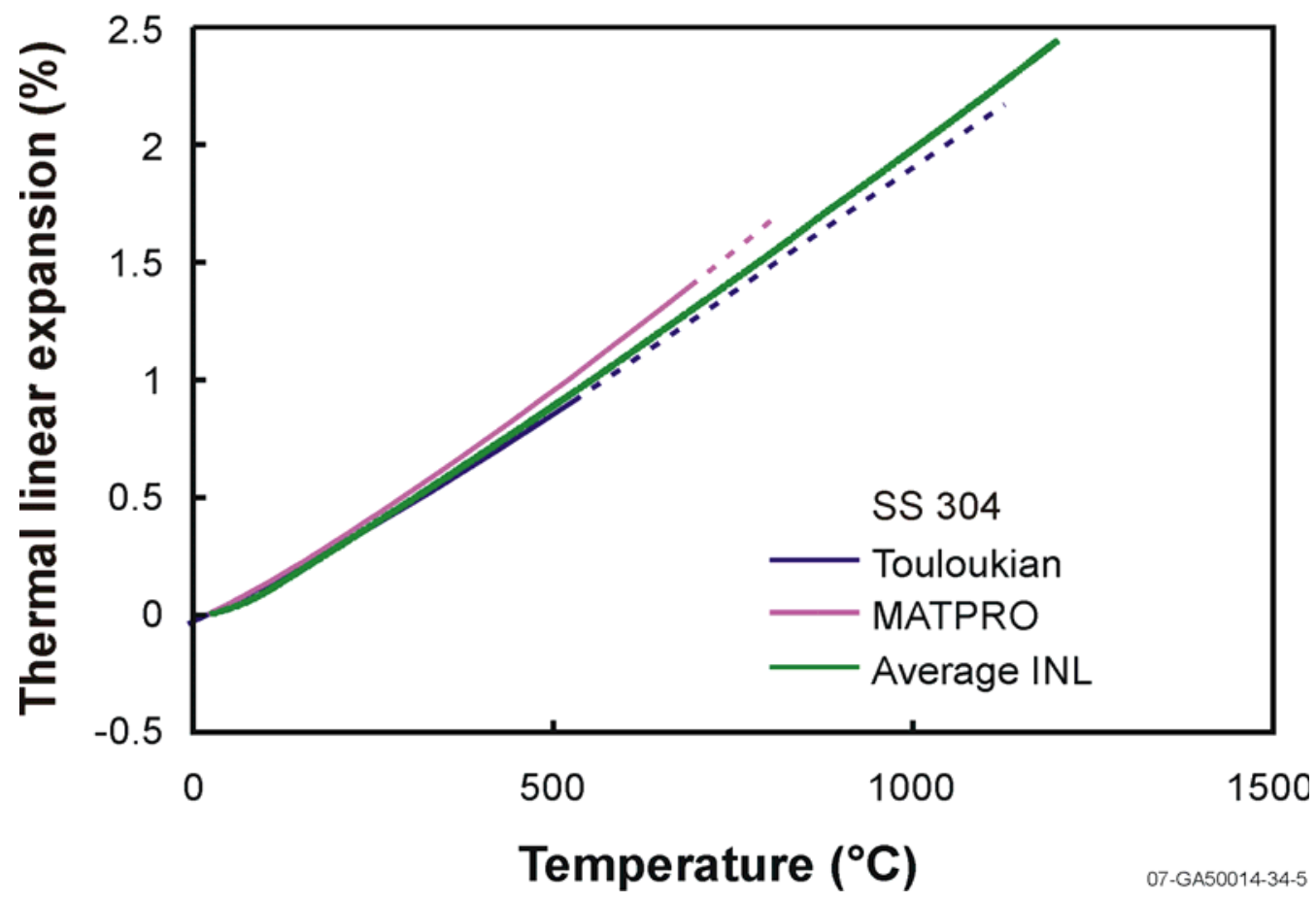

Figure 41. Comparison of new stainless steel (SS304) data with values in Touloukian and MATPRO. 


\subsection{Horizontal Testing Summary}

Pushrod dilatometry techniques were applied to obtain thermal property data up to $1200{ }^{\circ} \mathrm{C}$ for steels used in LWR vessels. Results indicate that the measured thermal expansion data behavior differs from data available in the literature, as summarized in Table 3. Data for SA

Table 3. Comparison of expansion data between HTTL and references.

\begin{tabular}{|c|c|c|c|c|c|}
\hline & \multicolumn{5}{|c|}{ \% Elongation } \\
\hline $\begin{array}{c}\text { Temperature } \\
\left({ }^{\mathbf{0}} \mathbf{C}\right)\end{array}$ & $\begin{array}{c}\text { SA 533 } \\
\text { (Average) }\end{array}$ & $\begin{array}{c}\text { MATPRO } \\
\text { Low Alloy } \\
\text { Steel }\end{array}$ & $\begin{array}{c}\text { SS 304 } \\
\text { Average) }\end{array}$ & $\begin{array}{c}\text { MATPRO } \\
\text { Stainless } \\
\text { Steel }\end{array}$ & $\begin{array}{c}\text { Touloukian } \\
\text { Stainless }\end{array}$ \\
\hline 25 & 0.003 & 0.003 & 0.003 & 0.012 & 0.012 \\
\hline 400 & 0.526 & 0.601 & 0.684 & 0.732 & 0.646 \\
\hline 600 & 0.841 & 1.079 & 1.098 & 1.171 & 1.012 \\
\hline 800 & 0.901 & NA & 1.533 & 1.677 & 1.537 \\
\hline 1000 & 1.202 & NA & 1.981 & NA & 1.896 \\
\hline 1200 & 1.652 & NA & 2.442 & NA & NA \\
\hline
\end{tabular}

533 Low Alloy Steel samples are lower than values reported by MATPRO. Thermal expansion data obtained for stainless steel closely matches Touloukian values but differed from values reported by MATPRO (it should be noted that literature values were extrapolated for temperatures above $550{ }^{\circ} \mathrm{C}$ for Touloukian and $700{ }^{\circ} \mathrm{C}$ for MATPRO). Percent differences between data recorded during INL tests and values found in the literature are shown in Table 4.

Table 4. Percent differences between INL test data and values found in literature.

\begin{tabular}{|c|c|c|c|}
\hline $\begin{array}{c}\text { Temperature, } \\
\mathbf{0} \text { C }\end{array}$ & $\begin{array}{c}\text { \% Difference } \\
\text { Between } \\
\text { INL and MATPRO } \\
\text { Data for SA 533 }\end{array}$ & $\begin{array}{c}\text { \% Difference } \\
\text { Between } \\
\text { INL and MATPRO } \\
\text { Data for SS 304 }\end{array}$ & $\begin{array}{c}\text { \% Difference } \\
\text { Between } \\
\text { INL and Touloukian } \\
\text { Data for SS 304 }\end{array}$ \\
\hline 25 & $1.18 \%$ & $73.05 \%$ & $73.05 \%$ \\
\hline 400 & $12.44 \%$ & $6.48 \%$ & $-5.86 \%$ \\
\hline 600 & $21.99 \%$ & $6.18 \%$ & $-8.51 \%$ \\
\hline 800 & N/A & $8.58 \%$ & $0.23 \%$ \\
\hline 1000 & N/A & N/A & $-4.48 \%$ \\
\hline 1200 & N/A & N/A & N/A \\
\hline
\end{tabular}


Figures 36 and 41 compare thermal expansion data obtained for these materials. As shown in Figure 36, thermal expansion data for the SA533B1 experienced a drop between $730{ }^{\circ} \mathrm{C}$ and $830^{\circ} \mathrm{C}$, which corresponds to where a phase transition occurs in this material.

\section{Vertical Configuration Testing}

For vertical testing, slight modifications must be made to the testing procedure to accommodate changes in components. Instead of sliding the furnace over the sample holder and sealing using the collar, the furnace is positioned using a linear actuator and the chamber is not sealed shut. Since the chamber is not sealed, the vacuum pump is also not used. Other than these changes, the procedure remains unchanged from the horizontal configuration.

\subsection{Vertical Configuration Trial}

Tests performed using the experimental (vertical) configuration are listed in Table 5. These tests were performed in order to exhibit the similarity in results gained from the dilatometer in both reference and experimental configurations.

Table 5. Tests performed in experimental (vertical) configuration.

\begin{tabular}{|c|c|c|c|c|c|c|c|}
\hline Sample & Designator & Test & $\begin{array}{c}\text { Calibration } \\
\text { Standard }\end{array}$ & $\begin{array}{c}\text { Test } \\
\text { Material }\end{array}$ & $\begin{array}{c}\text { Sample } \\
\text { Base } \\
\text { Length } \\
\text { (mm) }\end{array}$ & $\begin{array}{l}\text { Starting } \\
\text { Temp }\end{array}$ & $\begin{array}{l}\text { End } \\
\text { Temp }\end{array}$ \\
\hline $\begin{array}{l}\text { Netzsch } \\
\text { Sapphire }\end{array}$ & $\begin{array}{c}\text { Sapphire Vert } 1 \\
\text { Corr }\end{array}$ & Correction & Sapphire & Sapphire & 20.001 & $25^{\circ} \mathrm{C}$ & $1100^{\circ} \mathrm{C}$ \\
\hline $\begin{array}{l}\text { Netzsch } \\
\text { Sapphire }\end{array}$ & Sapphire Vert 1 & $\begin{array}{l}\text { Sample + } \\
\text { Correction }\end{array}$ & Sapphire & Sapphire & 20.001 & $25^{\circ} \mathrm{C}$ & $1100^{\circ} \mathrm{C}$ \\
\hline $\begin{array}{l}\text { Netzsch } \\
\text { Sapphire }\end{array}$ & $\begin{array}{c}\text { Sapphire Vert } 2 \\
\text { Corr }\end{array}$ & Correction & Sapphire & Sapphire & 20.001 & $25^{\circ} \mathrm{C}$ & $1100^{\circ} \mathrm{C}$ \\
\hline $\begin{array}{l}\text { Netzsch } \\
\text { Sapphire }\end{array}$ & Sapphire Vert 2 & $\begin{array}{l}\text { Sample + } \\
\text { Correction }\end{array}$ & Sapphire & Sapphire & 20.001 & $25^{\circ} \mathrm{C}$ & $1100^{\circ} \mathrm{C}$ \\
\hline SA-V1 & SA-V1 700C Corr & Correction & Sapphire & Sapphire & 20.001 & $25^{\circ} \mathrm{C}$ & $700^{\circ} \mathrm{C}$ \\
\hline SA-V1 & SA-V1 700C & $\begin{array}{l}\text { Sample + } \\
\text { Correction }\end{array}$ & Sapphire & $\begin{array}{l}\text { Low Alloy } \\
\text { Steel }\end{array}$ & 20.006 & $25^{\circ} \mathrm{C}$ & $700^{\circ} \mathrm{C}$ \\
\hline SA-V1 & $\begin{array}{c}\text { SA-V1 } 1200 C \\
\text { Corr }\end{array}$ & Correction & Sapphire & Sapphire & 20.001 & $25^{\circ} \mathrm{C}$ & $1200^{\circ} \mathrm{C}$ \\
\hline SA-V1 & SA-V1 1200C & $\begin{array}{l}\text { Sample + } \\
\text { Correction }\end{array}$ & Sapphire & $\begin{array}{l}\text { Low Alloy } \\
\text { Steel }\end{array}$ & 20.006 & $25^{\circ} \mathrm{C}$ & $1200^{\circ} \mathrm{C}$ \\
\hline SA-V2 & SA-V2 700C Corr & Correction & Sapphire & Sapphire & 20.001 & $25^{\circ} \mathrm{C}$ & $700^{\circ} \mathrm{C}$ \\
\hline SA-V2 & SA-V2 700C & $\begin{array}{l}\text { Sample + } \\
\text { Correction }\end{array}$ & Sapphire & $\begin{array}{l}\text { Low Alloy } \\
\text { Steel }\end{array}$ & 20.005 & $25^{\circ} \mathrm{C}$ & $700^{\circ} \mathrm{C}$ \\
\hline SA-V2 & $\begin{array}{c}\text { SA-V2 } 1200 C \\
\text { Corr }\end{array}$ & Correction & Sapphire & Sapphire & 20.001 & $25^{\circ} \mathrm{C}$ & $1200^{\circ} \mathrm{C}$ \\
\hline
\end{tabular}


Table 5. Tests performed in experimental (vertical) configuration.

\begin{tabular}{|c|c|c|c|c|c|c|c|}
\hline Sample & Designator & Test & $\begin{array}{c}\text { Calibration } \\
\text { Standard }\end{array}$ & $\begin{array}{c}\text { Test } \\
\text { Material }\end{array}$ & $\begin{array}{c}\text { Sample } \\
\text { Base } \\
\text { Length } \\
\text { (mm) }\end{array}$ & $\begin{array}{c}\text { Starting } \\
\text { Temp }\end{array}$ & $\begin{array}{c}\text { End } \\
\text { Temp }\end{array}$ \\
\hline SA-V2 & SA-V2 1200C & $\begin{array}{l}\text { Sample + } \\
\text { Correction }\end{array}$ & Sapphire & $\begin{array}{l}\text { Low Alloy } \\
\text { Steel }\end{array}$ & 20.005 & $25^{\circ} \mathrm{C}$ & $1200^{\circ} \mathrm{C}$ \\
\hline SS-V1 & SS-V1 700C Corr & Correction & Sapphire & Sapphire & 20.001 & $25^{\circ} \mathrm{C}$ & $700^{\circ} \mathrm{C}$ \\
\hline SS-V1 & SS-V1 700C & $\begin{array}{l}\text { Sample + } \\
\text { Correction }\end{array}$ & Sapphire & Stainless Steel & 19.900 & $25^{\circ} \mathrm{C}$ & $700^{\circ} \mathrm{C}$ \\
\hline SS-V1 & $\begin{array}{c}\text { SS-V1 } 1200 C \\
\text { Corr }\end{array}$ & Correction & Sapphire & Sapphire & 20.001 & $25^{\circ} \mathrm{C}$ & $1200^{\circ} \mathrm{C}$ \\
\hline SS-V1 & SS-V1 1200C & $\begin{array}{l}\text { Sample + } \\
\text { Correction }\end{array}$ & Sapphire & Stainless Steel & 19.900 & $25^{\circ} \mathrm{C}$ & $1200^{\circ} \mathrm{C}$ \\
\hline SS-V2 & SS-V2 700C Corr & Correction & Sapphire & Sapphire & 20.001 & $25^{\circ} \mathrm{C}$ & $700^{\circ} \mathrm{C}$ \\
\hline SS-V2 & SS-V2 700C & $\begin{array}{l}\text { Sample + } \\
\text { Correction }\end{array}$ & Sapphire & Stainless Steel & 19.990 & $25^{\circ} \mathrm{C}$ & $700^{\circ} \mathrm{C}$ \\
\hline SS-V2 & $\begin{array}{c}\text { SS-V2 } 1200 C \\
\text { Corr }\end{array}$ & Correction & Sapphire & Sapphire & 20.001 & $25^{\circ} \mathrm{C}$ & $1200^{\circ} \mathrm{C}$ \\
\hline SS-V2 & SS-V2 1200C & $\begin{array}{l}\text { Sample + } \\
\text { Correction }\end{array}$ & Sapphire & Stainless Steel & 19.985 & $25^{\circ} \mathrm{C}$ & $1200^{\circ} \mathrm{C}$ \\
\hline
\end{tabular}

The vertical configuration was first tested by using a sapphire standard provided by Netzsch. This sample is ideal as it yielded the most consistent results for horizontal testing. Figure 42 shows the results of two correction runs done with the vertical setup compared to corrections run using the horizontal configuration. It is clear that there are differences between the curves. First, the two vertical corrections are offset from the horizontal corrections. This is caused by the extra length of the dilatometer components. The correction run measures the total elongation of the standard, the sample holder, and the pushrod. The sample holder and pushrod elongate in opposite directions due to the locations at which they are fixed. It is the difference in elongation of these components for which the system must correct. With the components elongated this difference is greater. Second, there are differences between the two vertical corrections. One correction shows a periodic rise and fall in the signal. This effect was traced to the air conditioning system in the lab. When the system activated cool air would contact the exposed sample holder causing some contraction. This has the same effect on the signal as extra elongation of the pushrod. The second vertical correction curve does not show this effect, as the vent near the dilatometer was sealed. This resulted in a much smoother curve. 


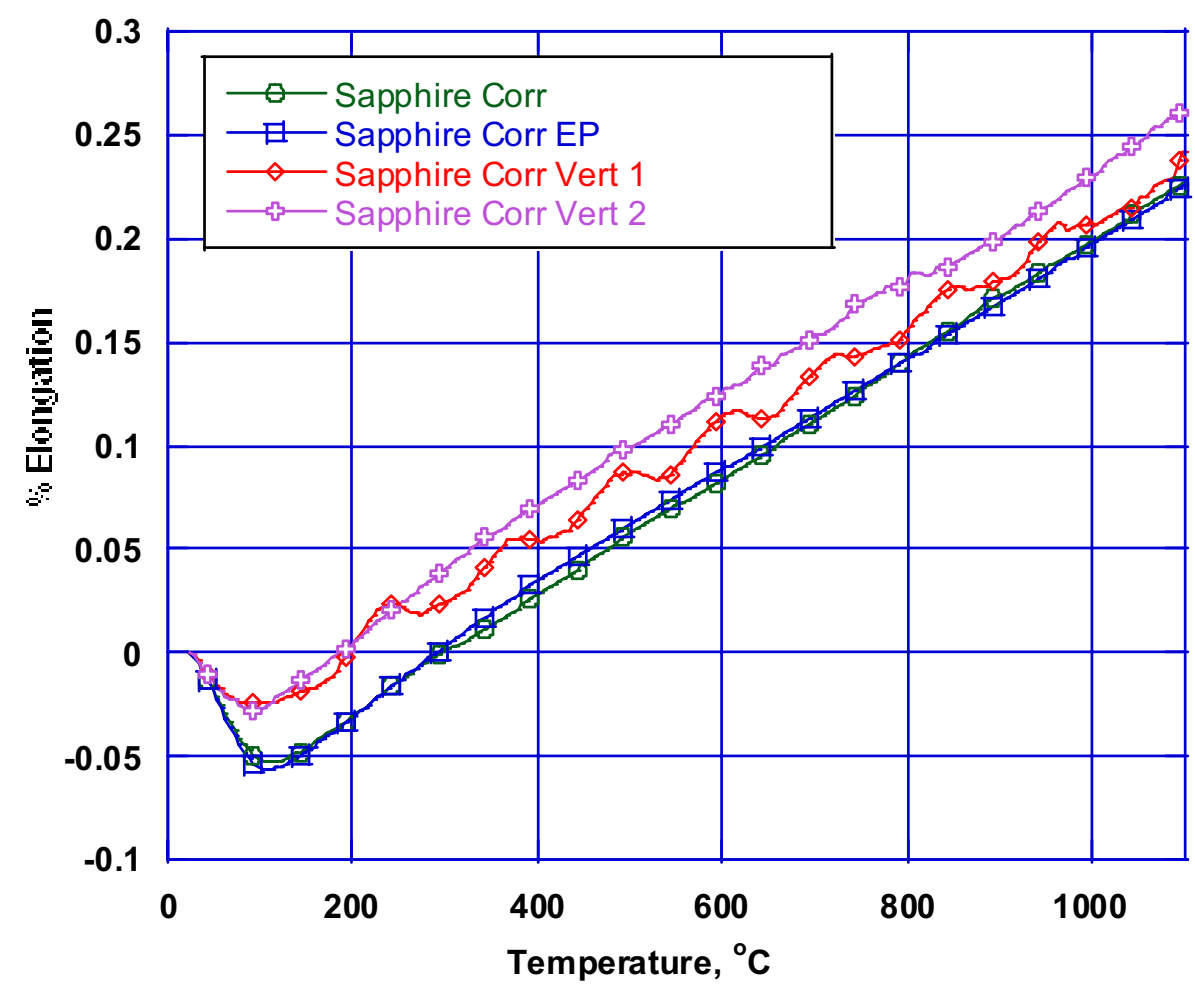

Figure 42. Comparison of correction data for horizontal and vertical configurations.

Figure 43 shows a comparison of corrected expansion data for the sapphire standard in both horizontal and vertical configurations. Some difference may be observed, but both vertical test runs are very close to the data from the horizontal tests (Note: both Sapphire Corr Vert 1 and Sapphire Vert 1 were run with the air conditioner intermittently active). 


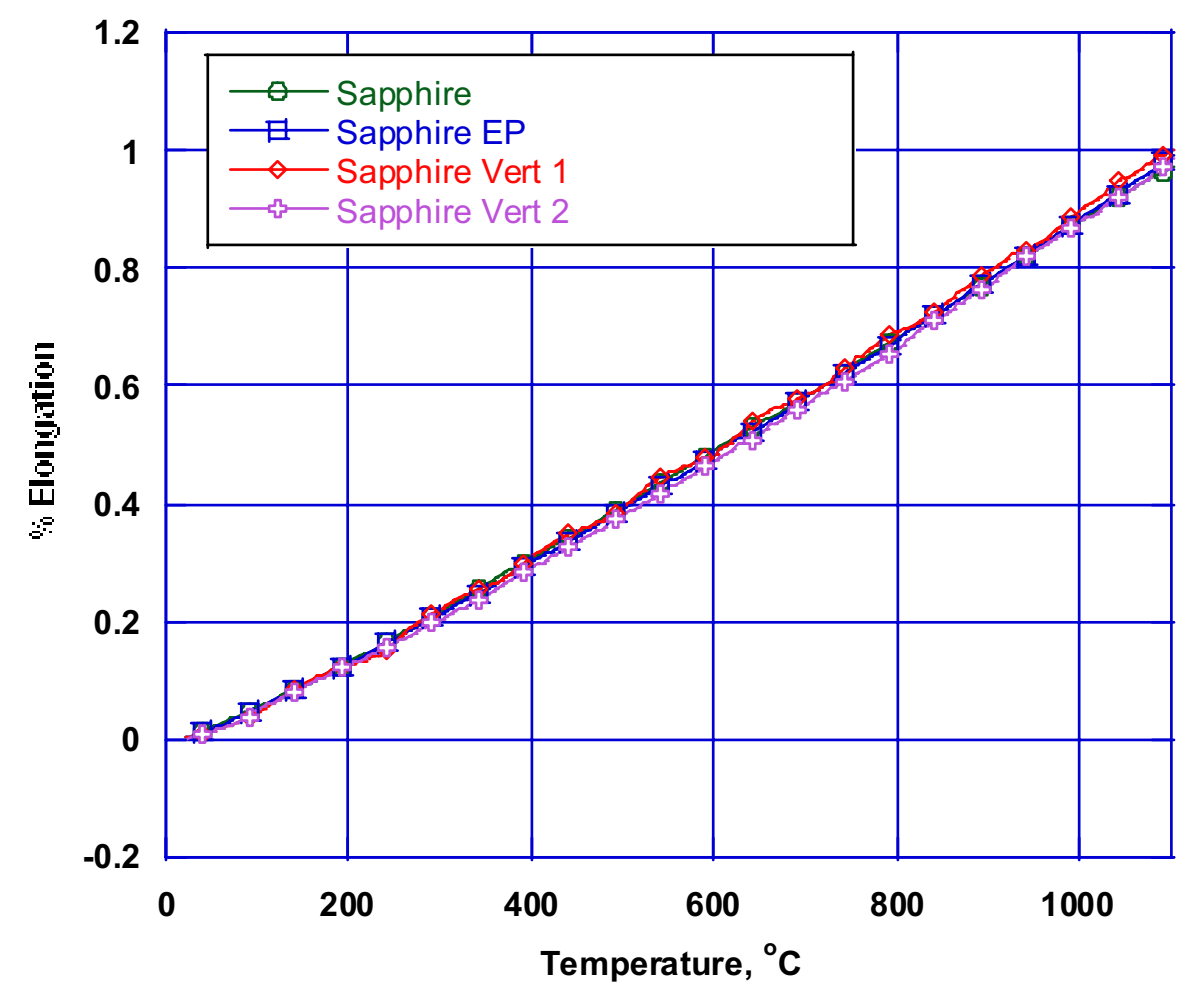

Figure 43. Comparison of corrected expansion data for horizontal and vertical configurations

\subsection{Low Alloy Steel (SA533B1) Vertical Test}

Figure 44 shows test results for a sample of low alloy steel, designated SA-V1. This sample was tested in two cycles, one up to $700{ }^{\circ} \mathrm{C}$ and one up to $1200{ }^{\circ} \mathrm{C}$. Before each test cycle, the dilatometer was calibrated using the Netzsch sapphire standard (the previously used alumina standard was too long for the vertical configuration). The data closely match for the overlapping range and are very close to the data acquired using the horizontal configuration. Figure 45 shows data acquired for a second low alloy steel sample, SA-V2. This data also matches closely the data acquired from the horizontal configuration. Data from both low alloy steel samples tested in the vertical configuration are shown in Figure 46, along with the average of the data acquired for the low alloy steel samples tested in the horizontal configuration. In the temperature range of interest $\left(300{ }^{\circ} \mathrm{C}\right.$ to $\left.1200{ }^{\circ} \mathrm{C}\right)$, the vertical configuration results differ from the average of the reference configuration results by a maximum of $2.0 \%$. Oxidation of the low alloy steel samples tested in the vertical configuration was comparable to oxidation of the samples tested in the horizontal configuration. 


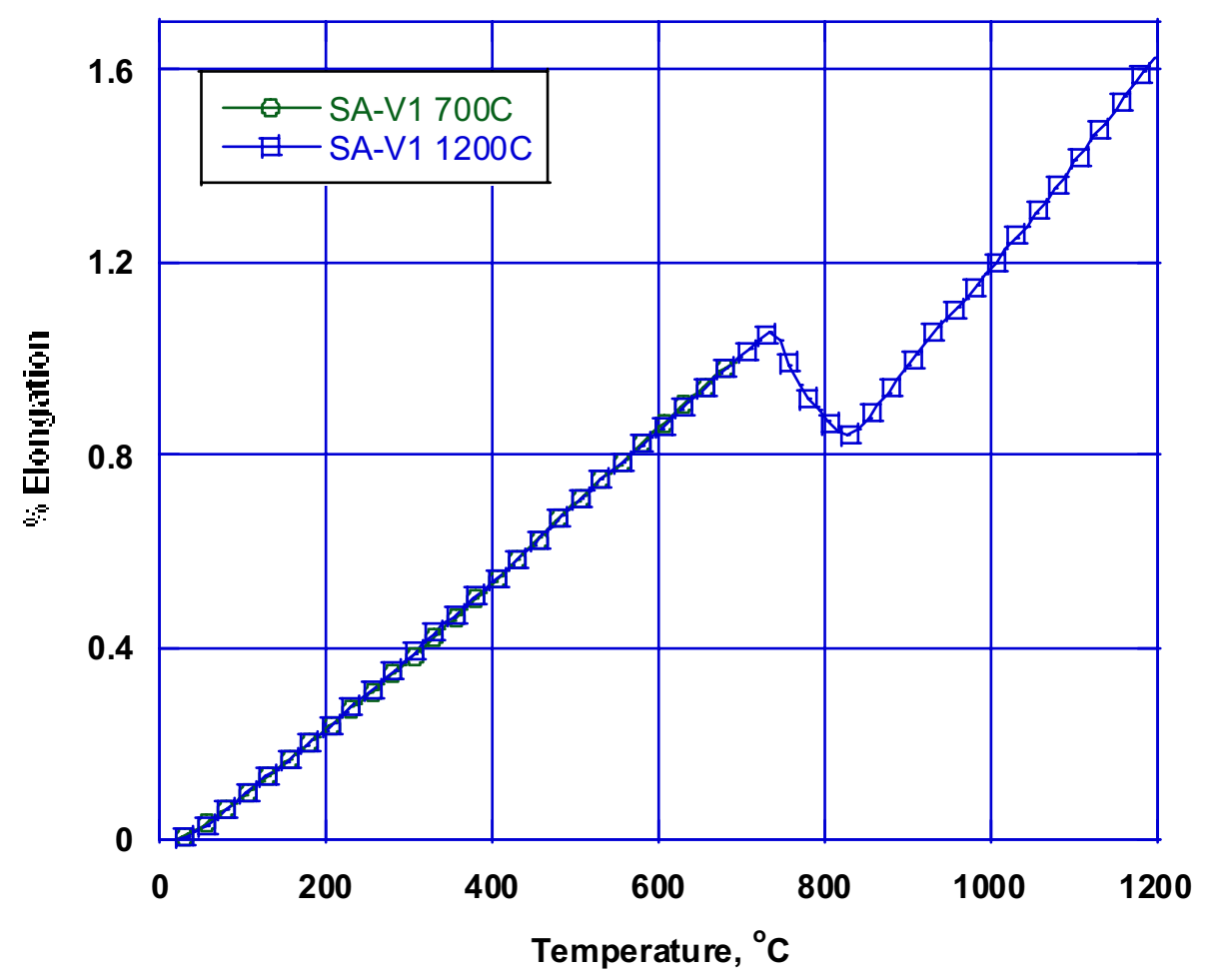

Figure 44. Data acquired for low alloy steel sample SA-V1 using vertical configuration.

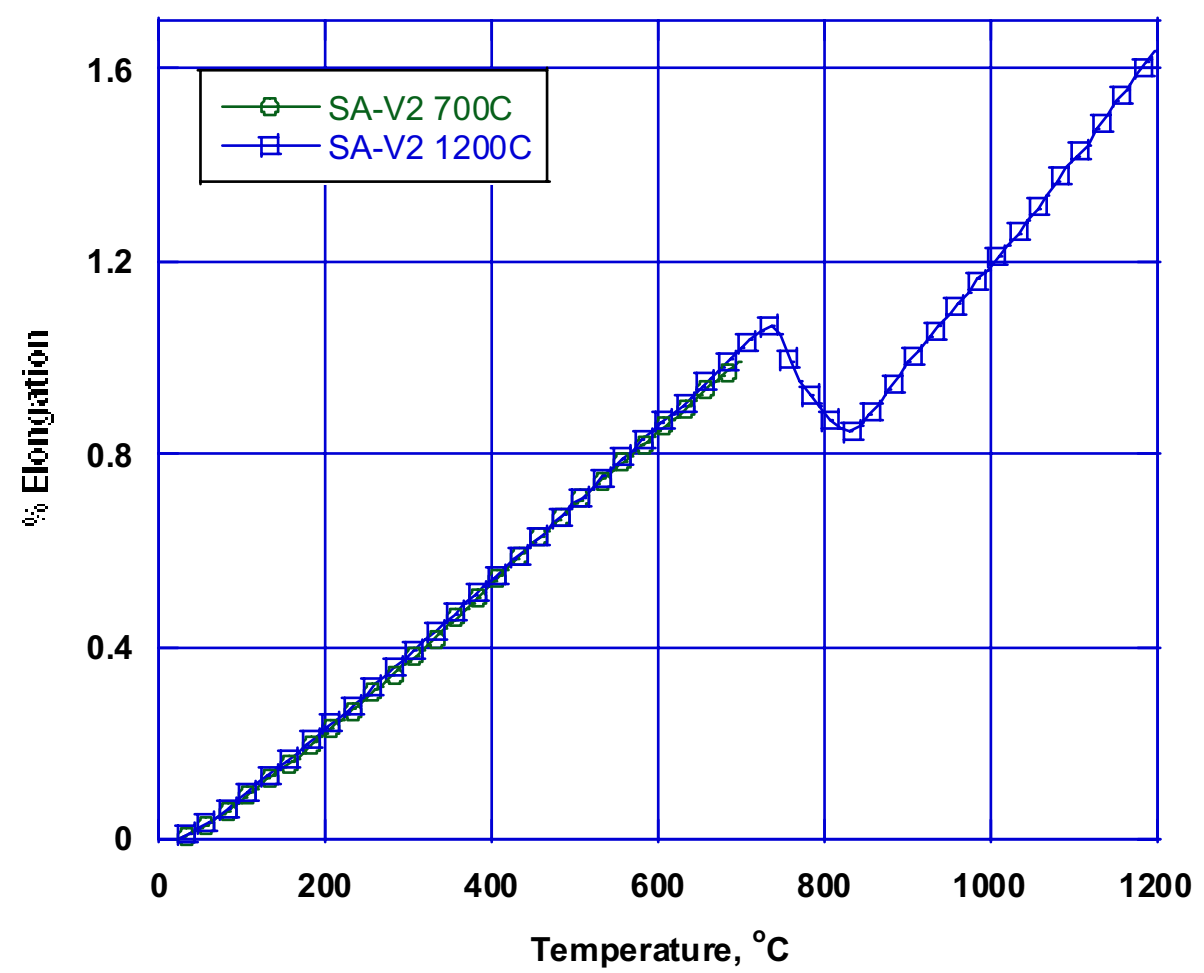

Figure 45. Data acquired for low alloy steel sample SA-V2 using vertical configuration. 


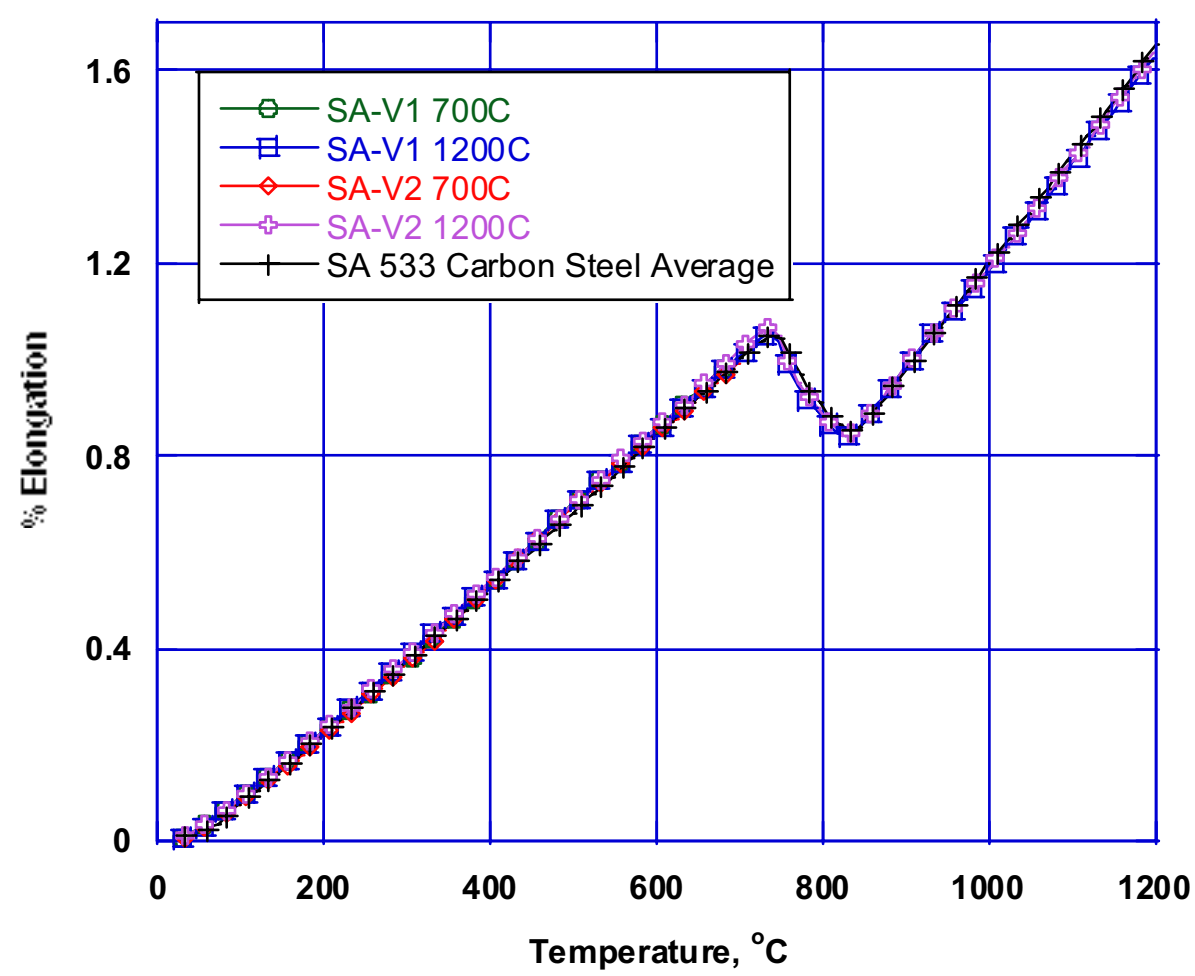

Figure 46. Comparison of vertical low alloy steel data with data obtained using horizontal configuration.

\subsection{Stainless Steel (SS 304) Vertical Test}

Figure 47 shows test results for a sample of stainless steel, designated SS-V1. This sample was tested in two cycles, one up to $700{ }^{\circ} \mathrm{C}$ and one up to $1200^{\circ} \mathrm{C}$. Before each test cycle, the dilatometer was calibrated using the Netzsch sapphire standard. The data closely match for the overlapping range and are very close to the data acquired using the horizontal configuration. Figure 48 shows data acquired for a second stainless steel sample, SS-V2. This data also matches closely the data acquired from the horizontal configuration. Data from both stainless steel samples tested in the vertical configuration are shown in Figure 49 along with the average of the data acquired for the stainless steel samples tested in the horizontal configuration. In the temperature range of interest $\left(300{ }^{\circ} \mathrm{C}\right.$ to $\left.1200{ }^{\circ} \mathrm{C}\right)$, the vertical configuration results differ from the average of the reference configuration results by a maximum of $6.2 \%$. Oxidation of the stainless steel samples tested in the vertical configuration was comparable to oxidation of the samples tested in the horizontal configuration. 


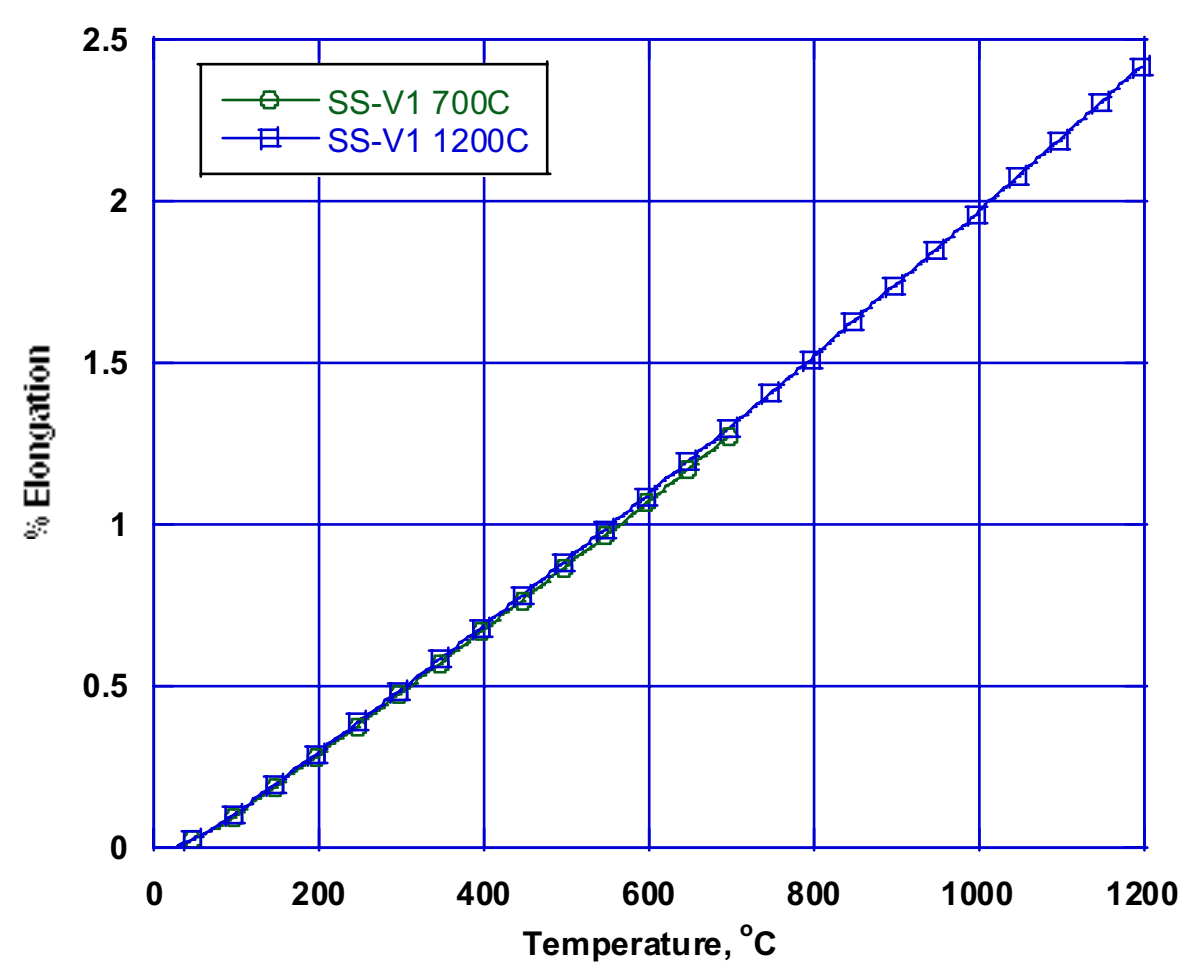

Figure 47. Data acquired for stainless steel sample SS-V1 using vertical configuration.

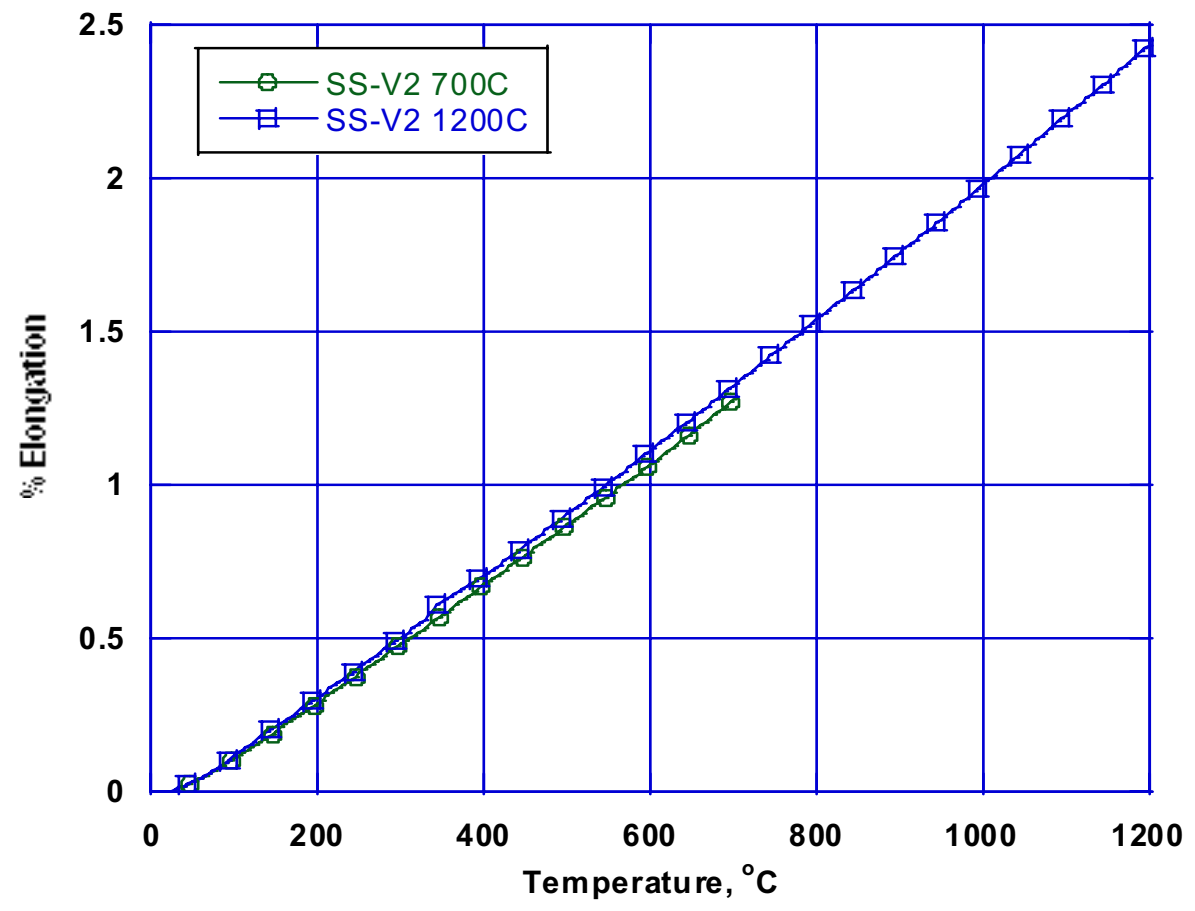

Figure 48. Data acquired for stainless steel sample SS-V2 using vertical configuration. 


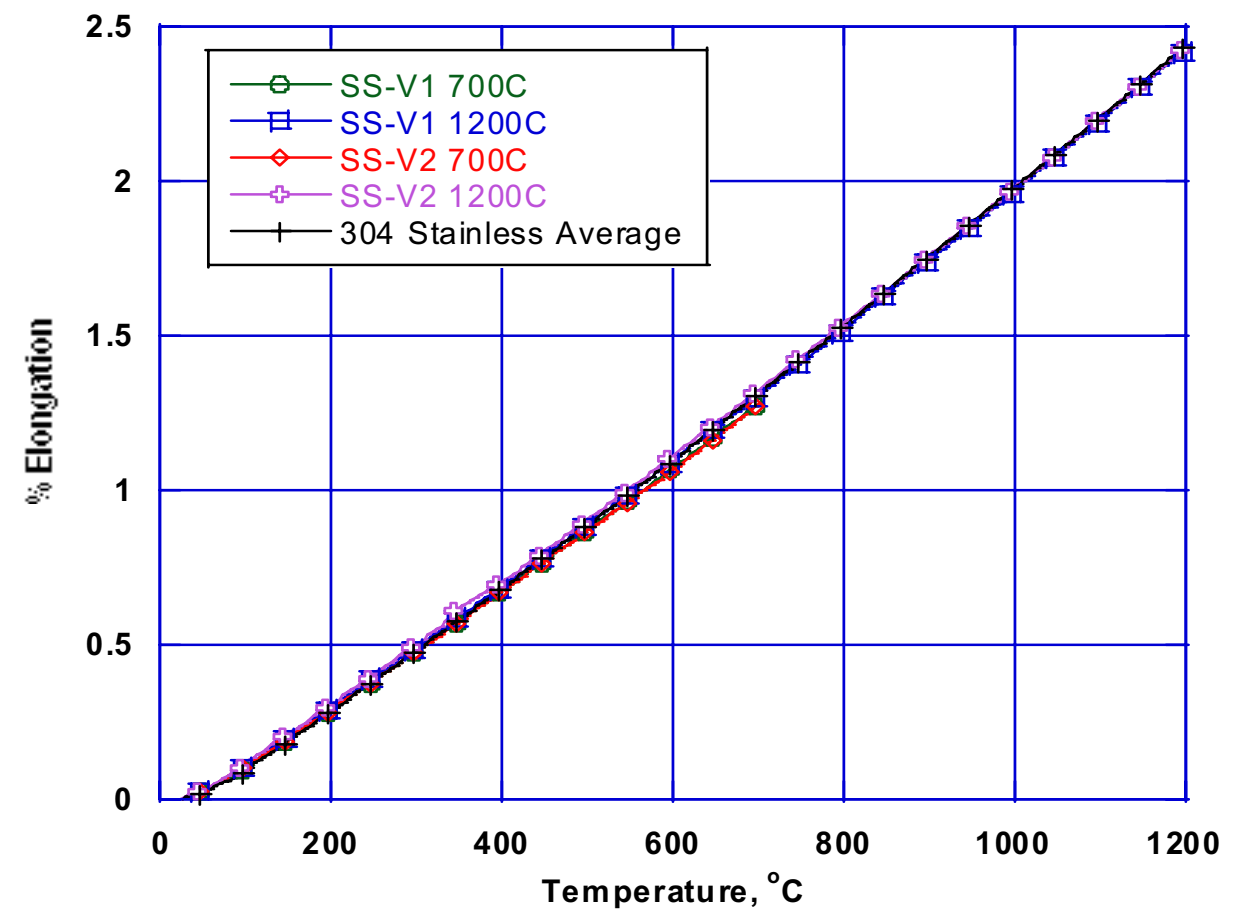

Figure 49. Comparison of vertical stainless steel data with data obtained using horizontal configuration.

\subsection{Vertical Testing Summary}

Pushrod dilatometry techniques were applied to compare thermal property data obtained for steels used in LWR vessels using a horizontal dilatometer configuration to those obtained using a vertical configuration. Average expansion data for various temperatures are shown in Table 6.

Table 6. Comparison of expansion data for horizontal and vertical configurations.

\begin{tabular}{|c|c|c|c|c|}
\hline & \multicolumn{4}{|c|}{$\%$ Elongation } \\
\hline $\begin{array}{c}\text { Temperature } \\
\left(\mathbf{(}^{\mathbf{C}}\right)\end{array}$ & $\begin{array}{c}\text { SA 533 } \\
\text { (Horizontal } \\
\text { Average) }\end{array}$ & $\begin{array}{c}\text { SA 533 } \\
\text { (Vertical } \\
\text { Average) }\end{array}$ & $\begin{array}{c}\text { SS 304 } \\
\text { (Horizontal } \\
\text { Average) }\end{array}$ & $\begin{array}{c}\text { SS 304 } \\
\text { (Vertical } \\
\text { Average) }\end{array}$ \\
\hline 25 & 0.003 & 0.001 & 0.003 & 0.003 \\
\hline 400 & 0.526 & 0.527 & 0.684 & 0.689 \\
\hline 600 & 0.841 & 0.847 & 1.098 & 1.090 \\
\hline 800 & 0.901 & 0.884 & 1.533 & 1.539 \\
\hline 1000 & 1.202 & 1.177 & 1.981 & 1.980 \\
\hline 1200 & 1.652 & 1.627 & 2.442 & 2.435 \\
\hline
\end{tabular}


Expansion values recorded for each technique appear very close. Percent differences between data recorded during horizontal and vertical tests are shown in Table 7. With the

Table 7. Percent differences between horizontal and vertical test data.

\begin{tabular}{|c|c|c|}
\hline Temperature, ${ }^{\mathbf{0}} \mathbf{C}$ & $\begin{array}{c}\text { \% Difference } \\
\text { Between } \\
\text { Horizontal and } \\
\text { Vertical } \\
\text { Data for SA 533 }\end{array}$ & $\begin{array}{c}\text { \% Difference } \\
\text { Between } \\
\text { Horizontal and } \\
\text { Vertical } \\
\text { Data for SS 304 }\end{array}$ \\
\hline 25 & $-71.30 \%$ & $-2.88 \%$ \\
\hline 400 & $0.22 \%$ & $-0.57 \%$ \\
\hline 600 & $0.63 \%$ & $0.83 \%$ \\
\hline 800 & $-1.79 \%$ & $-0.31 \%$ \\
\hline 1000 & $-2.02 \%$ & $0.13 \%$ \\
\hline 1200 & $-1.49 \%$ & $0.29 \%$ \\
\hline
\end{tabular}

exception of the $25^{\circ} \mathrm{C}$ difference between SA 533 samples, due to very small expansion value at this temperature relative to noise levels, the differences are very small.

\section{Conclusions}

This report documents INL efforts to explore the viability of using pushrod dilatometer techniques for in-pile instrumentation to measure deformation. The first objective was to gain familiarity with the use and accuracy of the Netzsch 402 dilatometer system. This was accomplished by running several tests using standard calibration samples and comparing the results to available data. The acquired data matched the available data with a high degree of accuracy. Second were efforts to use this system to obtain high temperature data for steels, specifically SA533 Grade B, Class 1 (SA533B1) Low Alloy Steel and Stainless Steel 304 (SS304), found in Light Water Reactor (LWR) vessels. This objective was accomplished, and the resultant data were found to be somewhat different than that found in the literature, particularly where such data were extrapolated. Finally, results are reported from INL efforts to explore the viability of using a pushrod dilatometer for in-pile deformation measurements. Specifically, data were compared that were obtained using a short pushrod in a horizontal geometry to data obtained using a longer pushrod in a vertical geometry. These data agree with a high degree of accuracy. This indicates that lengthening the pushrod and changing its orientation has a negligible effect on the data acquired using the system.

Further validation of the use of pushrod dilatometers for monitoring in-pile deformations may need to include testing of longer pushrods. The effects of vibration on the system should also 
be further explored because it is likely that reactor coolant flow will introduce signal noise that was not seen in the laboratory. Even so, some vibration effect was seen, causing the need for multiple test runs. Changes in air temperature during the course of individual tests in the lab were observed to have a greater effect on results than vibration, but vibration is a concern for in-pile use. 


\section{References}

1. J. L. Rempe, D. L. Knudson, K. G. Condie, and S. C. Wilkins, "Thermocouples for High-Temperature In-Pile Testing,” Nuclear Technology, 156, No. 3, December 2006, pp 320-331.

2. J.L. Rempe, K. G. Condie, and D. L. Knudson, Thermal Properties for Candidate SCWR Materials, INL/EXT-05-01030, December 2005.

3. Netzch DIL 402 ES Instrument Manual.

4. Y. S. Touloukian, et al., Thermal Expansion Nonmetallic Solids, Thermophysical Properties of Matter, Vol. 13, IFI/Plenum, New York, New York, 1977.

5. Idaho National Engineering and Environmental Laboratory, SCDAP/RELAP5-3D ${ }^{\odot}$ Code Manuals, INEEL/EXT-02-00589, Idaho National Engineering and Environmental Laboratory, May 2002 .

6. Sandia National Laboratory, MELCOR Computer Code, Version 1.8.6, www.melcor.sandia.gov, accessed December 8, 2006.

7. Fauske Associates, Incorporated, Modular Accident Analysis Program, Version 4, www.maap.com, accessed December 8, 2006.

8. J. L. Rempe and D. L. Knudson, "High Temperature Thermal Properties for Metals used in LWR Vessels," Journal of Nuclear Materials, accepted March 22, 2007.

9. J. C. Spanner et al., Nuclear Systems Material Handbook, TID-26666, April 1976.

10. G. E. Korth, Metallographic and Hardness Examinations of TMI-2 Lower Pressure Vessel Head Samples, NUREG/CR-6194, March 1994. 
